NATIONAL LABORATORY

\title{
The Impact of Interface Bonding Efficiency on High-Burnup Spent Nuclear Fuel Vibration Integrity during Normal Transportation
}

\section{August 2013}

Prepared by

Jy-An John Wang

Hao Jiang

Hong Wang

Program Manager

Bruce Bevard

Rob Howard

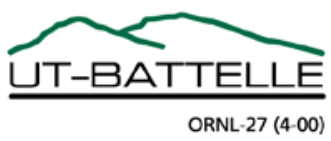




\title{
DOCUMENT AVAILABILITY
}

Reports produced after January 1, 1996, are generally available free via the U.S. Department of Energy (DOE) Information Bridge.

Web site http://www.osti.gov/bridge

Reports produced before January 1, 1996, may be purchased by members of the public from the following source.

\author{
National Technical Information Service \\ 5285 Port Royal Road \\ Springfield, VA 22161 \\ Telephone 703-605-6000 (1-800-553-6847) \\ TDD 703-487-4639 \\ Fax 703-605-6900 \\ E-mail info@ntis.gov \\ Web site http://www.ntis.gov/support/ordernowabout.htm
}

Reports are available to DOE employees, DOE contractors, Energy Technology Data Exchange (ETDE) representatives, and International Nuclear Information System (INIS) representatives from the following source.

Office of Scientific and Technical Information

P.O. Box 62

Oak Ridge, TN 37831

Telephone 865-576-8401

Fax 865-576-5728

E-mail reports@osti.gov

Web site http://www.osti.gov/contact.html

This report was prepared as an account of work sponsored by an agency of the United States Government. Neither the United States Government nor any agency thereof, nor any of their employees, makes any warranty, express or implied, or assumes any legal liability or responsibility for the accuracy, completeness, or usefulness of any information, apparatus, product, or process disclosed, or represents that its use would not infringe privately owned rights. Reference herein to any specific commercial product, process, or service by trade name, trademark, manufacturer, or otherwise, does not necessarily constitute or imply its endorsement, recommendation, or favoring by the United States Government or any agency thereof. The views and opinions of authors expressed herein do not necessarily state or reflect those of the United States Government or any agency thereof. 


\title{
THE IMPACT OF INTERFACE BONDING EFFICIENCY ON HIGH- BURNUP SPENT NUCLEAR FUEL VIBRATION INTEGRITY DURING NORMAL TRANSPORTATION
}

Jy-An John Wang, Hao Jiang, and Hong Wang

Program Manager

Bruce Bevard and Rob Howard

Date Published: August 2013

\author{
Prepared by \\ OAK RIDGE NATIONAL LABORATORY \\ Oak Ridge, Tennessee 37831-6283 \\ managed by \\ UT-BATTELLE, LLC \\ for the \\ U.S. DEPARTMENT OF ENERGY \\ under contract DE-AC05-00OR22725
}





\section{CONTENTS}

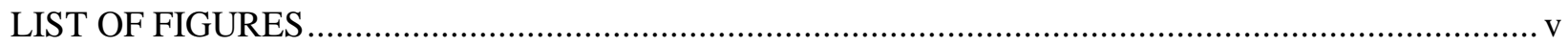

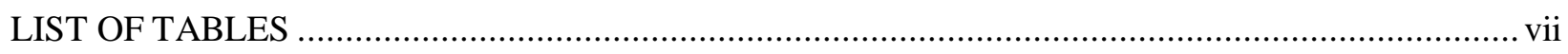

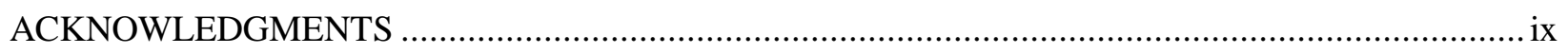

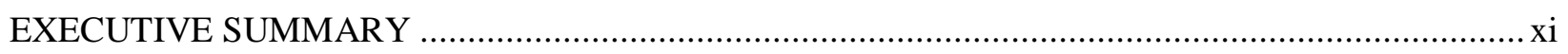

1. INTRODUCTION AND BACKGROUND ..................................................................

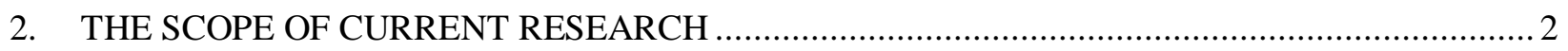

3. INTERFACE BONDING EFFICIENCY ANAL YSIS OF SURROGATE RODS..........................

3.1 GOOD INTERFACE BONDING AND NO SURROGATE ROD SYSTEM

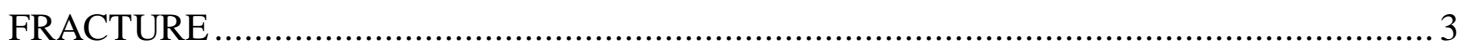

3.2 THE EFFECT OF PELLET-CLAD INTERFACE BONDING EFFICIENCY ................... 13

3.3 DE-BONDED PELLET-CLAD AND PELLET-PELLET INTERFACES........................ 24

3.4 DE-BONDED PELLET-CLAD INTERFACE AND PELLET-PELLET INTERFACE ....... 29

3.5 VARIATIONS IN PELLETS LOCATIONS WITHIN GAGE SECTION........................ 34

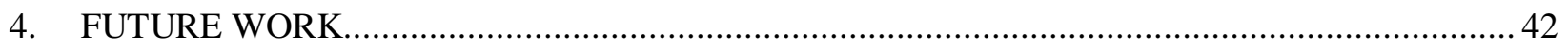

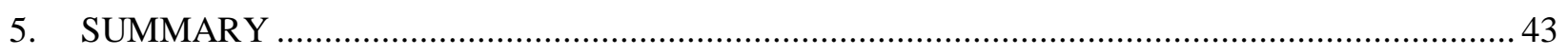

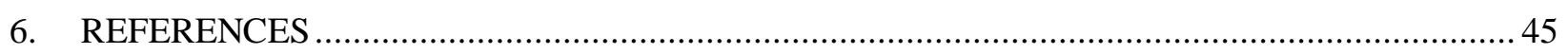





\section{LIST OF FIGURES}

Page

Fig. 1. Geometry of horizontal U-frame bending fatigue testing system with co-planar configuration

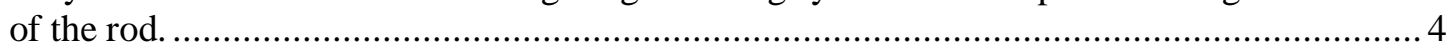

Fig. 2. Geometry of Clad-Epoxy-Pellet section model with a single rod. ........................................... 5

Fig. 3. Resultant normal stress distribution and curvature of Clad-Epoxy-Pellet section model with a

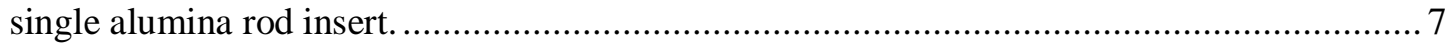

Fig. 4. Geometry of Clad-Epoxy-Pellet section model with four pellets.............................................. 7

Fig. 5. Zoom-in area of Fig. 4 for the case of no gaps at bonded pellet-pellet interfaces.......................... 8

Fig. 6. Resultant normal stress distribution and curvature of Clad-Epoxy-Pellet section model with four pellets with no gaps at pellet-pellet interfaces. ........................................................... 9

Fig. 7. Zoom-in area of Fig. 4 for the case where epoxy filled in the gaps at bonded pellet-pellet interfaces.

Fig. 8. Resultant normal stress distribution and curvature of Clad-Epoxy-Pellet section model with four pellets and epoxy filled in the gaps at pellet-pellet interfaces.

Fig. 9. Symmetrical reversed output force obtained for composite rod (stainless steel tube + alumina rod) using a U-frame bending fatigue testing system with a displacement input: $0.1 \mathrm{~Hz}$,

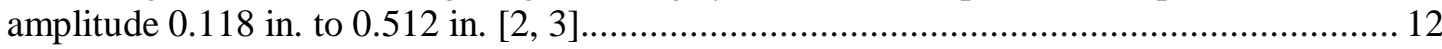

Fig. 10. ORNL SSAP05 specimen test data, flexural rigidity vs. curvature [3] ................................. 13

Fig. 11. Transportation-induced reversal bending stress fields in a SNF system................................... 14

Fig. 12. Zoom-in area of Fig. 4 for the case where epoxy filled in the gaps at de-bonded pellet-pellet

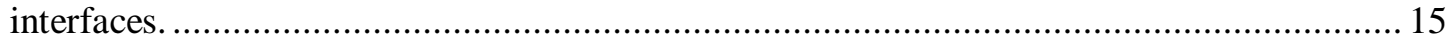

Fig. 13. Resultant stress distribution and curvature of Clad-Epoxy-Pellet section model with four pellets with epoxy filling in the gaps at de-bonded pellet-pellet interfaces. .......................... 17

Fig. 14. Zoom-in area of Fig. 4 for the case where there were empty gaps at de-bonded pellet-pellet

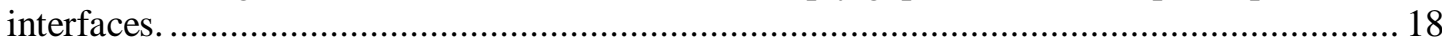

Fig. 15. Resultant stress distribution and curvature of Clad-Epoxy-Pellet section model with four pellets with empty gaps at de-bonded pellet-pellet interfaces......................................... 20

Fig. 16. Zoom-in area of Fig. 4 for the case of no gaps at de-bonded pellet-pellet interfaces.................. 21

Fig. 17. Resultant stress distribution and curvature of Clad-Epoxy-Pellet section model with four pellets with no gaps at de-bonded pellet-pellet interfaces.

Fig. 18. Zoom-in area of Fig. 4 for the case of empty gaps at de-bonded pellet-pellet interfaces and an epoxy-filled layer at de-bonded pellet-clad interfaces.

Fig. 19. The resultant stress distribution and curvature of Clad-Epoxy-Pellet section model with four pellets with gaps at de-bonded pellet-pellet interfaces and an epoxy layer at debonded pellet-clad interfaces.

Fig. 20. Zoom-in area of Fig. 4 for the case of no gaps at de-bonded pellet-pellet interfaces and epoxy layer at de-bonded pellet-clad interfaces.

Fig. 21. The resultant stress distribution and curvature of Clad-Epoxy-Pellet section model with four pellets with no gaps at de-bonded pellet-pellet interfaces and with an epoxy layer at de-bonded pellet-clad interfaces.

Fig. 22. Geometry of Clad-Pellet section model with four pellets. .................................................... 30

Fig. 23. Zoom-in area of Fig. 4 for the case of gaps at pellet-clad and pellet-pellet interfaces with no epoxy bonding.

Fig. 24. Resultant stress distribution and curvature of Clad-Pellet section model with four pellets and gaps at pellet-clad and pellet-pellet interfaces without epoxy bonding.......................... 31

Fig. 25. Zoom-in area of Fig. 4 for the case of no gaps at pellet-pellet interfaces and gaps at pelletclad interfaces with no epoxy bonding. 
Fig. 26. Resultant stress distribution and curvature of Clad-Pellet section model with four pellets and gaps at pellet-clad interfaces with no epoxy bonding and no gaps at pellet-pellet interfaces.

Fig. 27. Bending fatigue test results of SSAP02 specimen (with no epoxy bonding) under displacement control: (a) the curvature, (b) the flexural rigidity [4].

Fig. 28. Geometry of Clad-Epoxy-Pellet section model with three pellets.

Fig. 29. Zoom-in area of Fig. 4 for the case of no gaps at de-bonded pellet-pellet interfaces and epoxy bonding at pellet-clad interfaces in the section model with three pellets.

Fig. 30. Resultant stress distribution and curvature of Clad-Pellet section model with three pellets and epoxy bonding at pellet-clad interfaces with no gaps at pellet-pellet interfaces.

Fig. 31. Zoom-in area of Fig. 4 for the case of no gaps at de-bonded pellet-pellet interfaces and epoxy contact at de-bonded pellet-clad interfaces in the section model with three pellets.

Fig. 32. Resultant stress distribution and curvature of Clad-Pellet section model with three pellets, with filled epoxy at de-bonded pellet-clad interfaces and no gaps at de-bonded pelletpellet interfaces.

Fig. 33. Resultant stress distribution and curvature of Clad-Pellet section model with three pellets and epoxy bonding at pellet-clad interfaces with no gaps at pellet-pellet interfaces under displacement control.

Fig. 34. Resultant stress distribution and curvature of Clad-Pellet section model with three pellets, with filled epoxy at de-bonded pellet-clad interfaces and no gaps at de-bonded pelletpellet interfaces under displacement control. 


\section{LIST OF TABLES}

Page

Table 1. Material properties of surrogate rod................................................................................. 3

Table 2. The curvature and flexural rigidity for the perfect interface bonding simulation....................... 12

Table 3. The curvature and flexural rigidity for bonded pellet-clad and de-bonded pellet-pellet case ....... 23

Table 4. The curvature and flexural rigidity for de-bonded pellet-clad and pellet-pellet interfaces .......... 29

Table 5. The curvature and flexural rigidity for pellet-clad and pellet-pellet interfaces with no epoxy

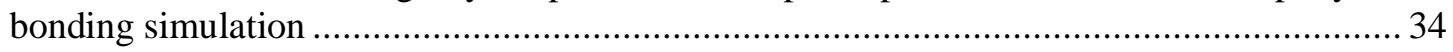

Table 6. The curvature and flexural rigidity for Clad-Epoxy-Pellet section model with three pellet

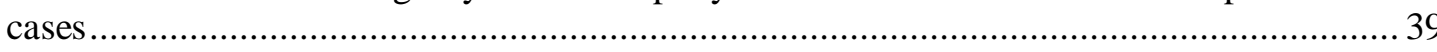

Table 7. The curvature and flexural rigidity for Clad-Epoxy-Pellet section model with three pellets

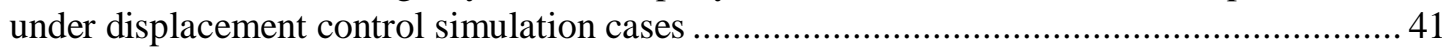

Table 8. The flexural rigidity comparison between the different bonding and de-bonding cases............. 44 



\section{ACKNOWLEDGMENTS}

This research was sponsored by DOE UFDC and was carried out at Oak Ridge National Laboratory under contract DE-AC05-00OR22725with UT-Battelle, LLC.

The authors would like to thank Program Managers Harold Adkins, Bruce Bevard, and Rob Howard for providing guidance and support to this project. 



\section{EXECUTIVE SUMMARY}

Finite element analysis (FEA) was used to investigate the impacts of interfacial bonding efficiency at pellet-pellet and pellet-clad interfaces on spent nuclear fuel (SNF) vibration integrity. The FEA simulation results were validated and benchmarked with ORNL reversal bending fatigue test results on surrogate rods consisting of stainless steel (SS) tubes with alumina-pellet inserts.

A 2-in. gauge section model of a surrogate rod was used in the FEA development using the ABAQUS code. The FEA model consists of SS clad, alumina pellets, and an epoxy compliant layer that functions as a cohesion bonding media. Bending moments $(M)$ are applied to the FEA models to evaluate the system responses of the surrogate rods. From the induced curvature $\kappa$, the flexural rigidity EI can be estimated as

$$
E I=M / \kappa
$$

Based on a series of FEA simulations, the discussions and the conclusions concerning the impact of the interface bonding efficiency on SNF vibration integrity are provided in this report; this includes the moment carrying capacity distribution between pellets and clad and the impact of cohesion bonding on the flexural rigidity of the surrogate rod system. As progressive de-bonding occurs at the pellet-pellet and pellet-clad interfaces, the load ratio of the bending moment carrying capacity gradually shifts from the pellets to the clad; the clad starts to carry a significant portion of the bending moment resistance until reaching the full de-bonding state at the pellet-pellet interface regions. This results in localized plastic deformation of the clad at the pellet-pellet-clad interface region; the associated plastic deformations of SS clad lead to a significant degradation in the stiffness of the surrogate rod. For instance, the flexural rigidity was reduced by $39 \%$ from the perfect bond state to the de-bonded state at the pellet-pellet interfaces.

After further de-bonding at the pellet-clad interfaces, the clad gradually takes over the majority of bending moment resistance. This significant load shift leads to clad yielding throughout the gauge section on the tension side and a further reduction in the flexural rigidity of the surrogate rod system. On the compression side of the surrogate rod, the pellets are in direct contact with each other at the upper or bottom corners of the pellets; this enables the pellets to carry a large portion of the bending moment resistance, especially for the case of "no gaps" at the pellet-pellet interfaces. This in turn significantly reduces the intensity of the compressive stress field experienced by the clad under bending cycle fatigue; that is, the surrogate rod will experience a full tension stress and less intensity in compression stress in the clad during the reversal bending fatigue cycles.

The immediate consequences of interface de-bonding are a load carrying capacity shift from the fuel pellets to the clad and a reduction of the composite rod system flexural rigidity. Therefore, the flexural rigidity of the surrogate rod and the bending moment resistance capacity between the clad and fuel pellets are strongly dependent on the interface bonding efficiency at the pellet-pellet and pellet-clad interfaces. The above noted phenomenon was calibrated and validated by ORNL on reversal bending fatigue testing using a surrogate fuel rod system. 



\section{INTRODUCTION AND BACKGROUND}

This research is being conducted in support the DOE Used Fuel Disposition Campaign under the work scope for Used Nuclear Fuel Loading and Structural Performance under Normal Conditions of Transportation - Modeling, Simulation, and Experimental Integration RD\&D Plan [1]. For high-burnup spent nuclear fuel (SNF), the fuel pellets and clad are normally fused together to form an integrated SNF system. To understand the underlying mechanism of the pellet-pellet and pellet-clad interface dynamics in a transportation environment, it is essential to accurately evaluate the mechanical properties of the integrated SNF system. Prior to conducting physical experimentation on high-burnup SNF, ORNL developed a series of FEA protocols to investigate SNF vibration integrity using a surrogate rod system that resembles a SNF composite rod system.

It is important to understand and to quantify the bonding efficiency at the pellet-pellet and pellet-clad interfaces of the high-burnup SNF system under normal transportation conditions including normal handling drops and transient shocks. ORNL has used FEA methods to develop simulation protocols, in addition to experimental calibration and verification efforts, to establish qualitative as well as quantitative assessments of SNF rod system performance under normal SNF transportation conditions. This project report describes the methodology used to evaluate the effect of pellet-pellet and pellet-clad interactions with consideration of the interfacial bonding efficiency on SNF vibration integrity. This methodology provides a solid road map for further protocol development with respect to effective lifetime prediction of a SNF system under normal transportation vibration. The proposed methodology that couples FEA simulations and experimental exploration efforts is also under development at ORNL. The current methodology is focused on assessing the influence of interfacial bonding at the pellet-pellet and the pellet-clad interfaces on SNF vibration integrity.

The FEA models of a surrogate rod system are formed using alumina pellets and stainless steel tubing, with the appropriate boundary conditions, including the bonded epoxy at the clad/pellet interfaces. The model consists of a surrogate rod with 3D representation of fuel pellets, clad, and possible combinations of the gaps at the pellet-pellet and pellet-clad interfaces. The ABAQUS code was used in the FEA, and the surrogate rod was represented by the beam element with the associated effective stiffness. This approach was used to obtain the effective properties of the beam elements that can be used as input for the further developments of the detailed SNF assembly model. The approach is also designed to estimate the damping properties of the beam elements due to frictional resistance between the clad and embedded pellets. This pellet-clad interaction modeling uses a "contact element” algorithm and can be further implemented into other embedded boundary conditions, such as internal pressure and residual stress, etc.

This study provides detailed explanations on the effects of pellet-pellet and pellet-clad interactions, including pellet fracture and pellet-clad bonding efficiency, on the clad performance reliability under normal transportation considerations. The FEA simulation results were also calibrated and benchmarked with the fatigue aging data $[2,3]$ obtained from ORNL reversal bending fatigue testing. 


\section{THE SCOPE OF CURRENT RESEARCH}

The objective of this research is to investigate the potential impact of interfacial bonding efficiency at pellet-pellet and pellet-clad interfaces on SNF vibration integrity. The FEA simulation results are validated and calibrated using ORNL reversal bending fatigue testing on the surrogate stainless steel (SS) rod with alumina-pellet inserts.

The FEA models, with a 2-in. gauge section that covered the SS clad and alumina pellets and epoxy layers that served as cohesion bonds, were developed using the ABAQUS code. In order to estimate the surrogate rod system responses including the stress profile and the associated curvature, $\kappa$, the bending moments $(M)$ were applied to both ends of the surrogate rod. From the FEA results, the flexural rigidity (EI) of the simulation cases is estimated as $E I=M / \kappa$. Detailed discussions of the simulation cases are divided into the following five sections.

- The section model with good interface bonding and without pellet fracture

- The section model with good bonding at pellet-clad interfaces and de-bonding at pellet-pellet interfaces

- The section model with de-bonding both at pellet-clad and pellet-pellet interfaces

- The section model without epoxy bonding at both pellet-clad and pellet-pellet interfaces

- The section model with pellets arranged at a different position within the gauge section

The simulation results indicate that the system response and the associated flexural rigidity are strongly dependent on the interface bonding efficiency. 


\section{INTERFACE BONDING EFFICIENCY ANALYSIS OF SURROGATE RODS}

The structural analysis and interfacial bonding evaluation of surrogate rods used in the bending fatigue testing system [2-4] were carried out using the ABAQUS Code. The ORNL-developed reversal bending fatigue testing system used surrogate rods to calibrate and improve the test setup in an out-of-cell environment. In order to validate simulation results via out-of-cell surrogate data, the surrogate rod materials used in FEA are the same as those used in the out-of-cell testing. High-density alumina was selected as the pellet material, and stainless steel (SS 304) was used as the clad material. Epoxy was also used as the interface bonding material. The material properties of the surrogate rod are listed in Table 1.

Table 1. Material properties of surrogate rod

\begin{tabular}{ccccc}
\hline Material & $\begin{array}{c}\text { Young's } \\
\text { Modulus (psi) }\end{array}$ & Poisson's Ratio & $\begin{array}{c}\text { Yield Strength } \\
\text { (psi) }\end{array}$ & $\begin{array}{c}\text { Density } \\
\text { (lb/inn }^{\mathbf{3}} \text { ) }\end{array}$ \\
\hline Stainless Steel $^{a}$ & $2.800 \mathrm{E} 7$ & 0.300 & 42061 & 0.2901 \\
$\mathrm{Al}_{2} \mathrm{O}_{3}{ }^{b, c}$ & $5.395 \mathrm{E} 7$ & 0.22 & $3.626 \mathrm{E} 5$ & 0.1416 \\
$\mathrm{Epoxy}^{d, e}$ & $5.076 \mathrm{E} 5$ & 0.37 & 10007.6 & 0.0452 \\
\hline
\end{tabular}

${ }^{a}$ Product Data Bulletin, 304/304L stainless steel, AK Steel Corporation. <http://www.aksteel. com>

${ }^{b}$ Ceramic Properties Standard, CoorsTek, Inc. <http://www.coorstek.com>

${ }^{c}$ The mean flexural strength of the $\mathrm{Al}_{2} \mathrm{O}_{3}$ is around $48 \mathrm{ksi}$ from the vendor McMaster-Carr.

${ }^{d}$ More about Glass, Ceramics, Carbon; More About Stainless Steel Alloys, Mechanical and Physical Properties, http://www.mcmaster.com

${ }^{e}$ http://www.engineeringtoolbox.com/engineering-materials-propertiesd_1225.html

\subsection{GOOD INTERFACE BONDING AND NO SURROGATE ROD SYSTEM FRACTURE}

Figure 1 shows the geometry of a U-frame bending fatigue testing system with a co-planar configuration for the surrogate rod. The 2-in. gauge section is highlighted in black. A finite element model was established to represent the 2-in. gauge section of the test specimen, referred to as the Clad-Epoxy-Pellet section model. Figure 2 shows the cross section and longitudinal cut views of the 2-in. surrogate rod. The inside and outside diameters of the clad (ID and OD) are 0.382 and $0.436 \mathrm{in}$., respectively. The alumina pellet OD is $0.372 \mathrm{in.}$ The epoxy has a thickness of $0.005 \mathrm{in}$. In the first model, the alumina pellet was modeled with a 2-in.-long alumina rod to simulate "a good interface bonding” at the pellet-pellet interface and with no fracture of the rod system. Bending moments were applied on the both ends of the surrogate rod rotating along the $x$ axis, as shown in Fig. 2(b). According to the out-of-cell surrogate data, the bending moments ranged from $20 \mathrm{~N} * \mathrm{~m}$ to $30 \mathrm{~N} * \mathrm{~m}$; the bending moment $M_{\mathrm{x}}$ was selected as $25 \mathrm{~N} * \mathrm{~m}$. Both loading surfaces of the surrogate rod were constrained with rotation along $y$ and $z$ axes and translation along the $x$ direction. In the following finite element models, the global mesh is $0.02 \mathrm{in}$. Some local meshes are as small as 0.0025 in. 


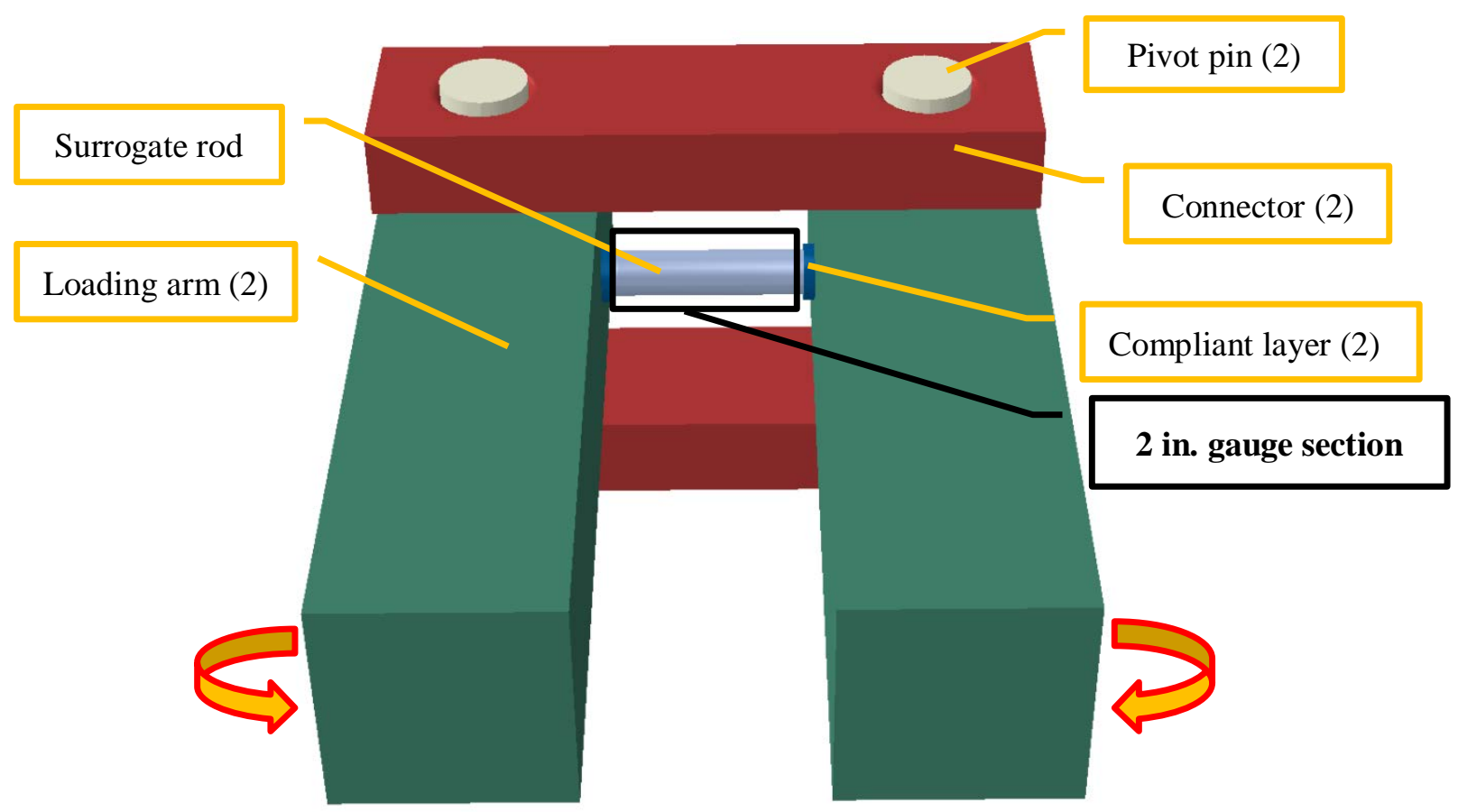

Fig. 1. Geometry of horizontal U-frame bending fatigue testing system with co-planar configuration of the rod.

The quasi-static procedure is used in FEA from the ABAQUS code. At the alumina rod-clad interface, thin epoxy layer elements are tied to both surfaces to simulate good cohesive bonds. The resultant stress distribution and curvature are shown in Fig. 3. The resultant curvature is $0.123 \mathrm{~m}^{-1}$, too small to be noticeable, as illustrated in Fig. 3(a). In order to see the bending effect, the curvature is deliberately enlarged 100 times in Fig. 3(b). From the resultant stress distribution shown in Fig. 3, the maximum stress occurs at the outer surface of the alumina rod, and the resultant forces also indicate that the alumina rod carries a larger portion of the moment resistance than the clad. The stress in the clad is under a yield point of $42 \mathrm{ksi}$.

The second model is the Clad-Epoxy-Pellet section model with four pellets shown in Fig. 4, which is similar to the Clad-Epoxy-Pellet section model with the single rod configuration. The materials and diameters of all components are the same as those used in the first model. The surrogate rod is 6 in. long and consists of 10 pellet inserts. Thus, each pellet is $\sim 0.6 \mathrm{in}$. long regardless of the machining. Within the 2-in. gauge section, two pellets in the middle section have a the length of $0.6 \mathrm{in}$. and the two ends pellets have a length of $0.4 \mathrm{in}$. The boundary conditions of the surrogate rod are clamped at both ends to simulate the rigid body motion associated with the loading arms of the reversal bending tester. Bending moments at both ends are set as $25 \mathrm{~N}^{*} \mathrm{~m}$. This boundary condition is the same as that of the first model with a single rod insert. 


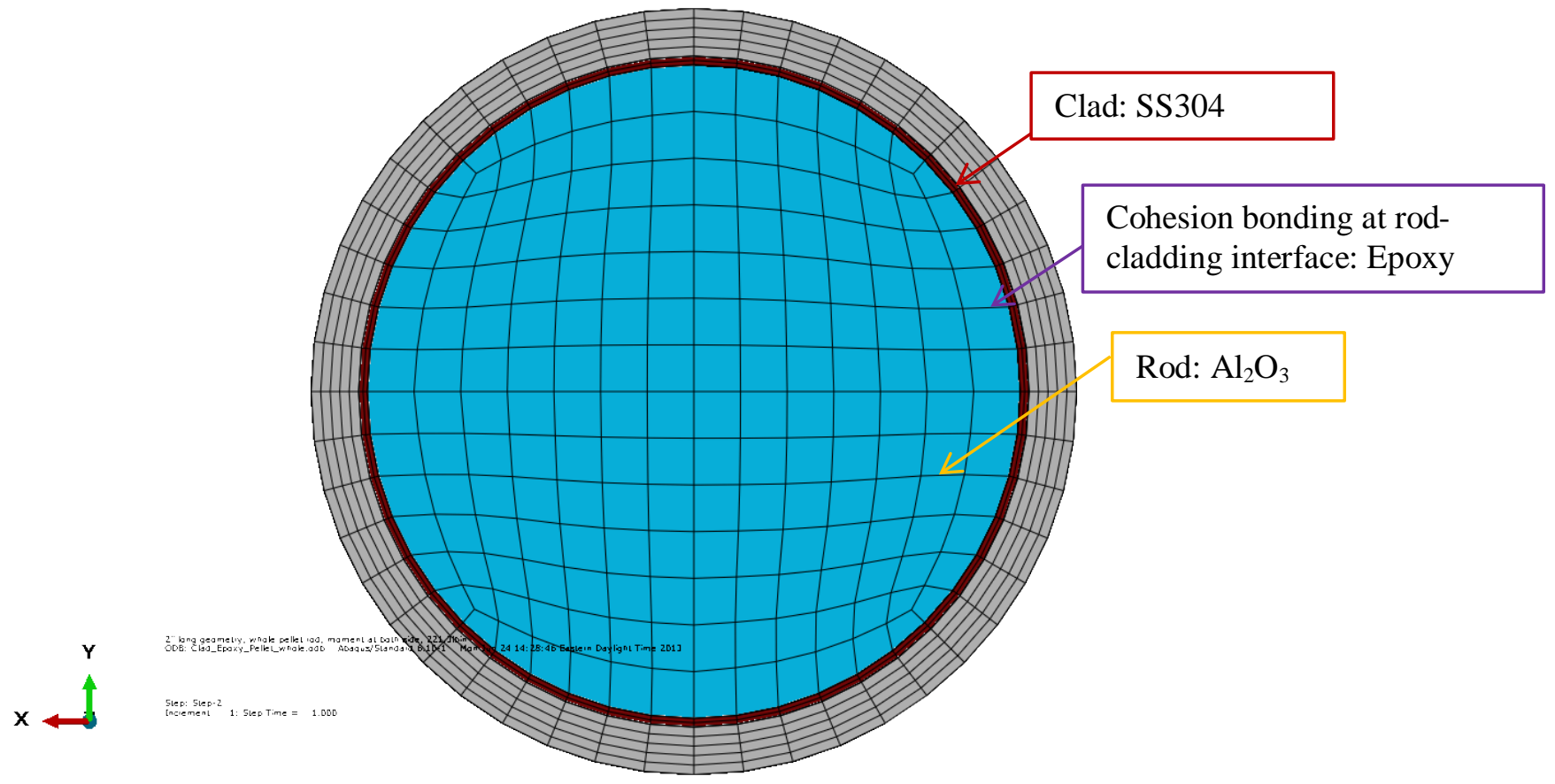

(a) Cross-sectional view

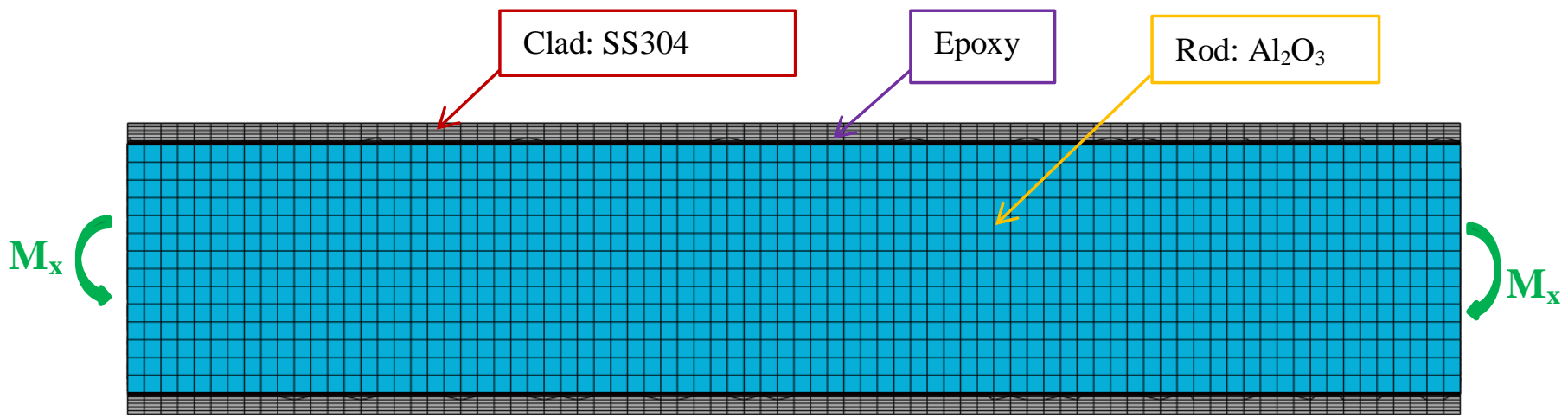

(b) Longitudinal cut view

Fig. 2. Geometry of Clad-Epoxy-Pellet section model with a single rod. 

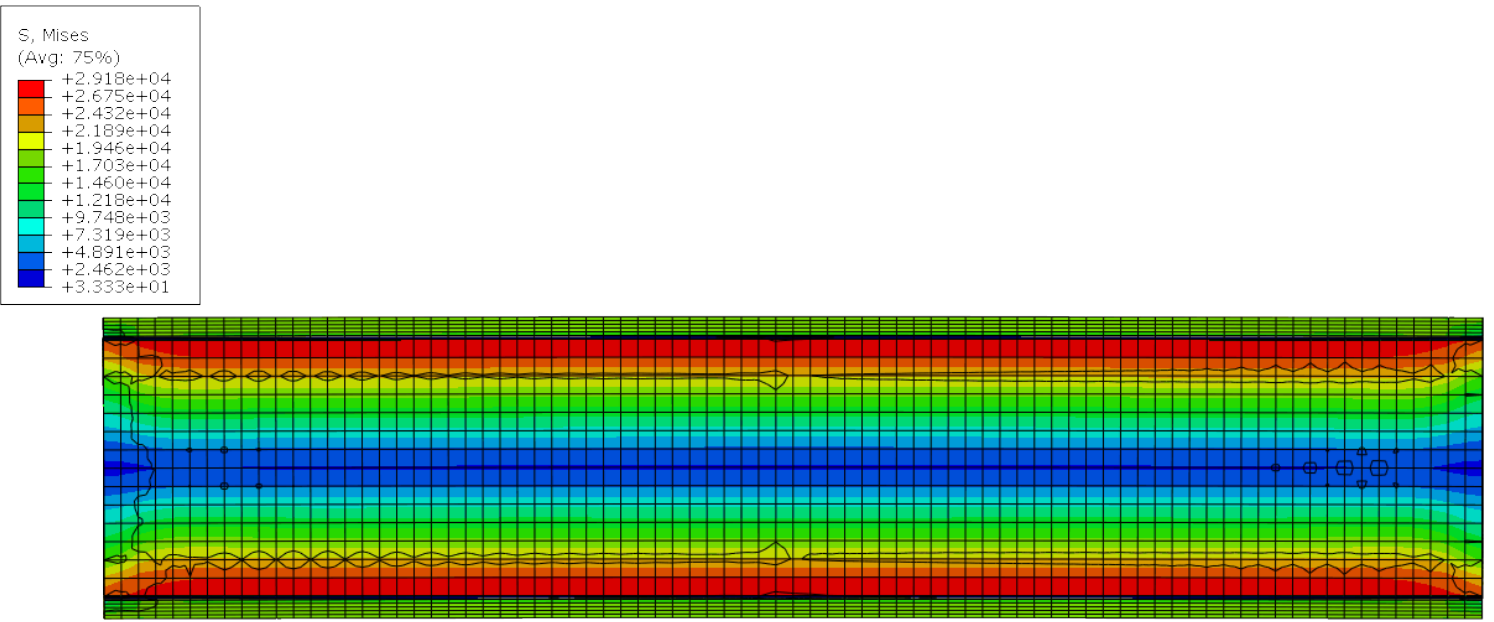

$Z \underset{Y}{Y}$

(a) Resultant curvature

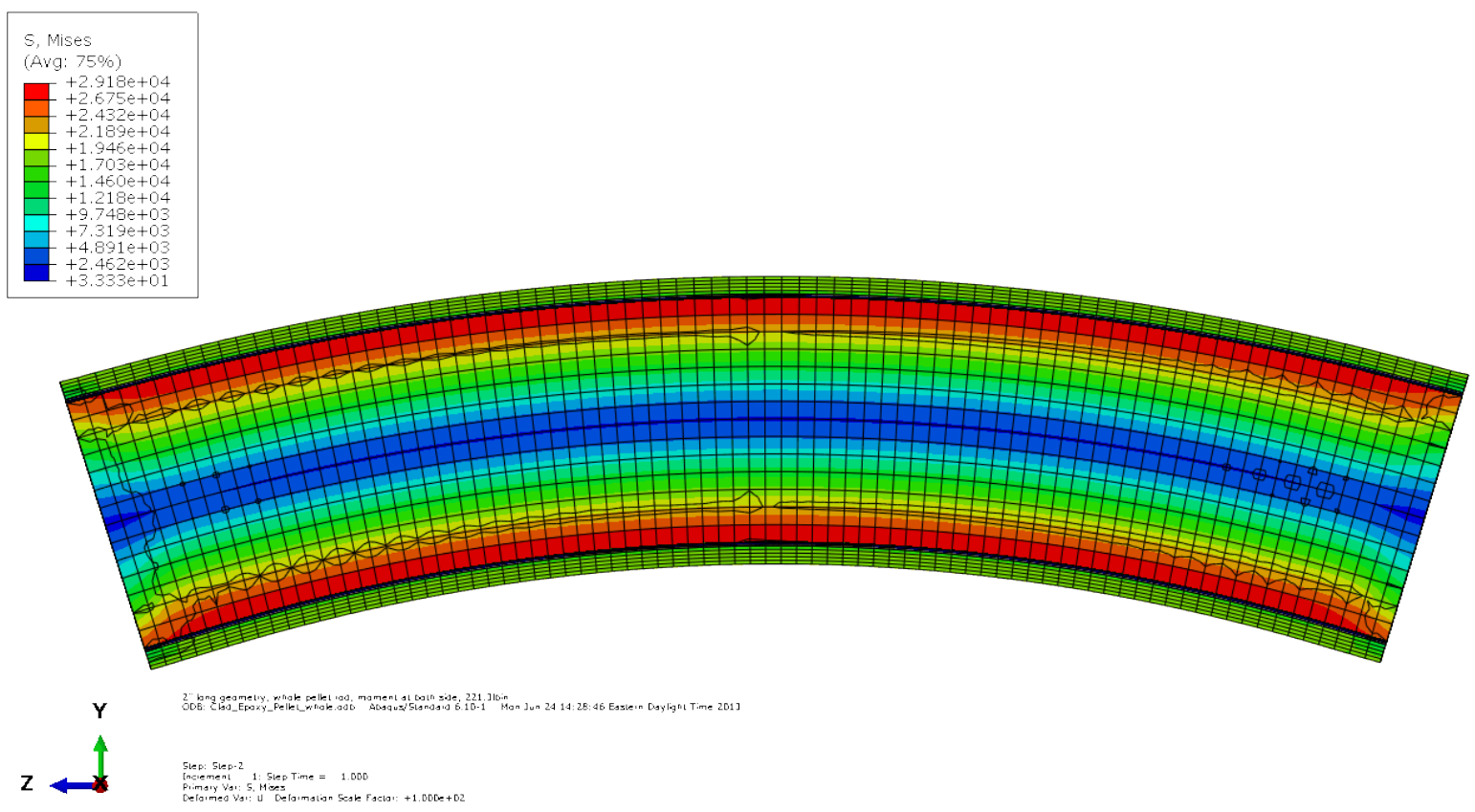

(b) Enlarged curvature by 100 times 


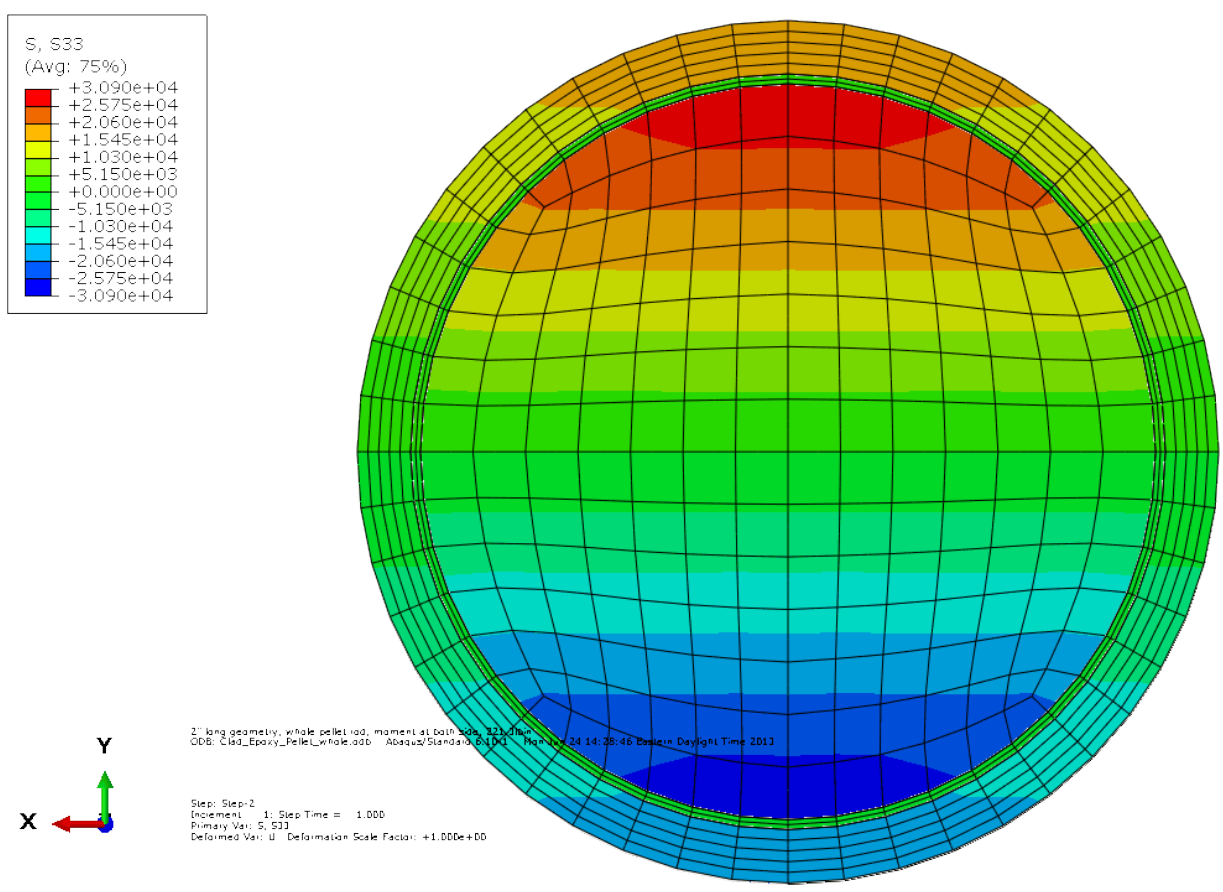

(C) Cross-sectional view of resultant normal stress $\sigma \mathrm{zz}$

Fig. 3. Resultant normal stress distribution and curvature of Clad-Epoxy-Pellet section model with a single alumina rod insert.

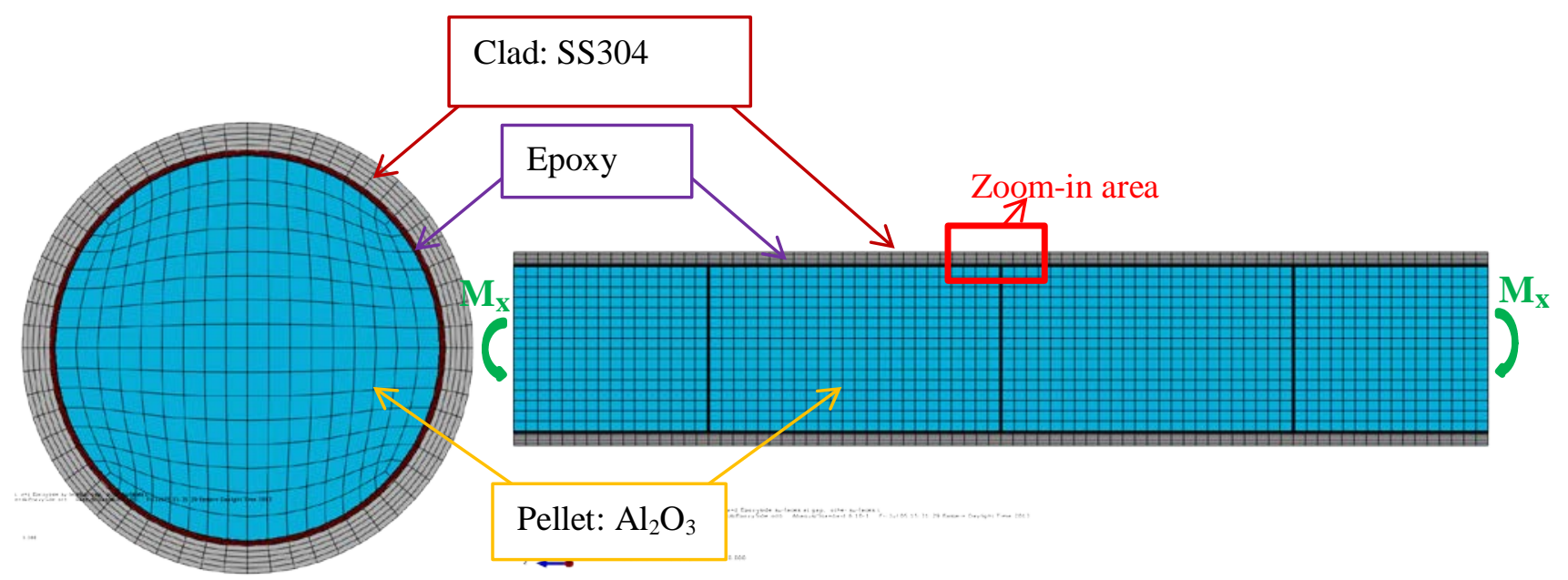

(a) Cross-sectional view

(b) Longitudinal cut view

Fig. 4. Geometry of Clad-Epoxy-Pellet section model with four pellets.

In order to simulate the interface of a perfect bond without alumina pellets or clad fracture in the CladEpoxy-Pellet section model with four pellets, two different cases were investigated and discussed below. The first case result is shown in Fig. 5, where a thin epoxy layer is tied to the surfaces of the pellet-clad interfaces to simulate good cohesive bonding; at the pellet-pellet interfaces, the pellets are tied together without gaps. 


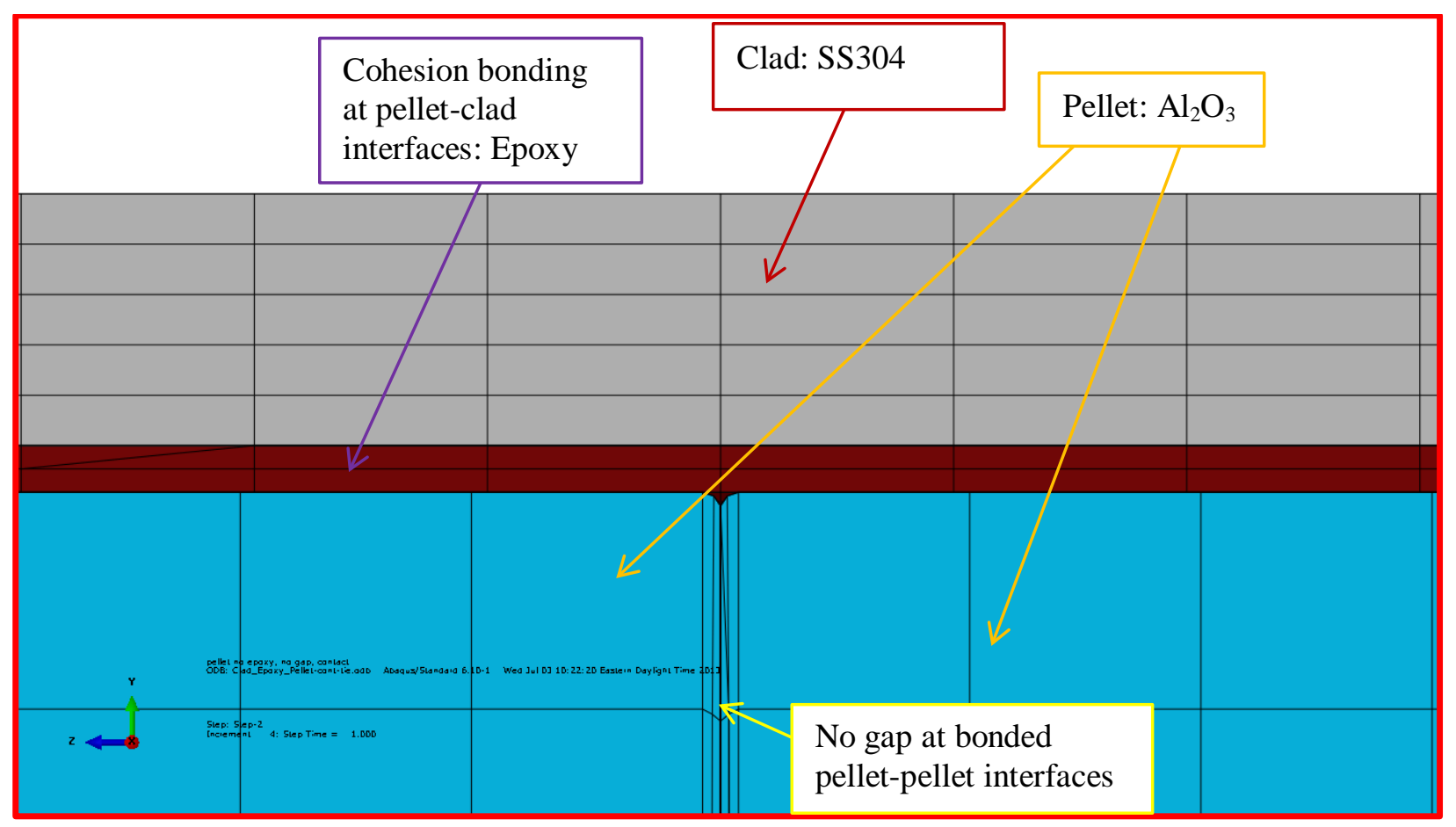

Fig. 5. Zoom-in area of Fig. 4 for the case of no gaps at bonded pellet-pellet interfaces.

The stress distribution and curvature shown in Fig. 6 reveal results that are similar to those of the CladEpoxy-Pellet section model with a single rod. The resultant curvature is $0.140 \mathrm{~m}^{-1}$. Maximum stress occurs at the outer surfaces of the pellets. Tied pellets carry most of the bending moment. The clad did not yield under a $25 \mathrm{~N}^{*} \mathrm{~m}$ bending moment, nor did the alumina pellet, which has a much higher yield strength than the SS clad. This indicates that the surrogate rod of a perfect bonding condition will remain within the linear elastic range under the target loading. 

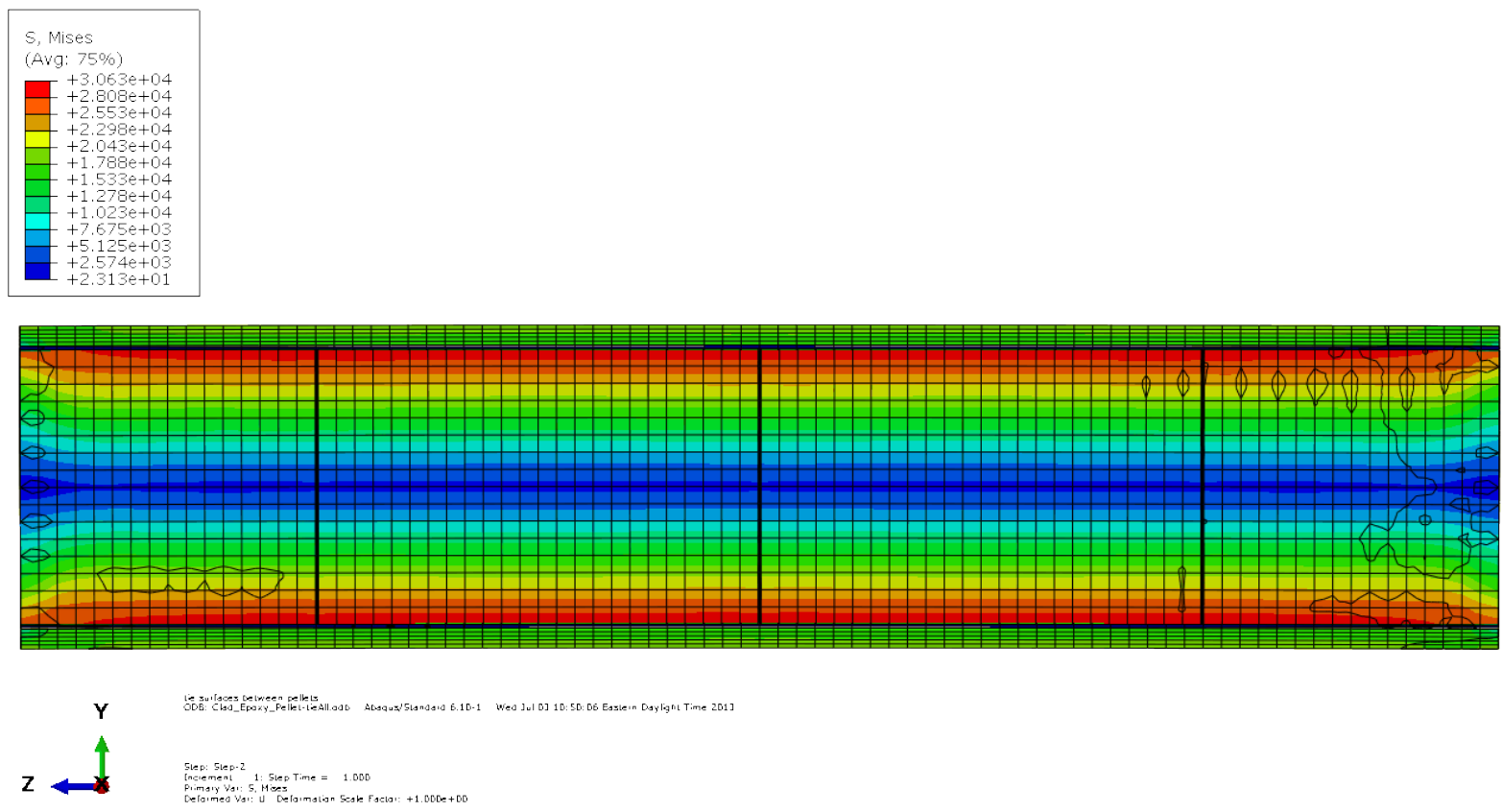

(a) Longitudinal cut view of resultant curvature and von Mises stress
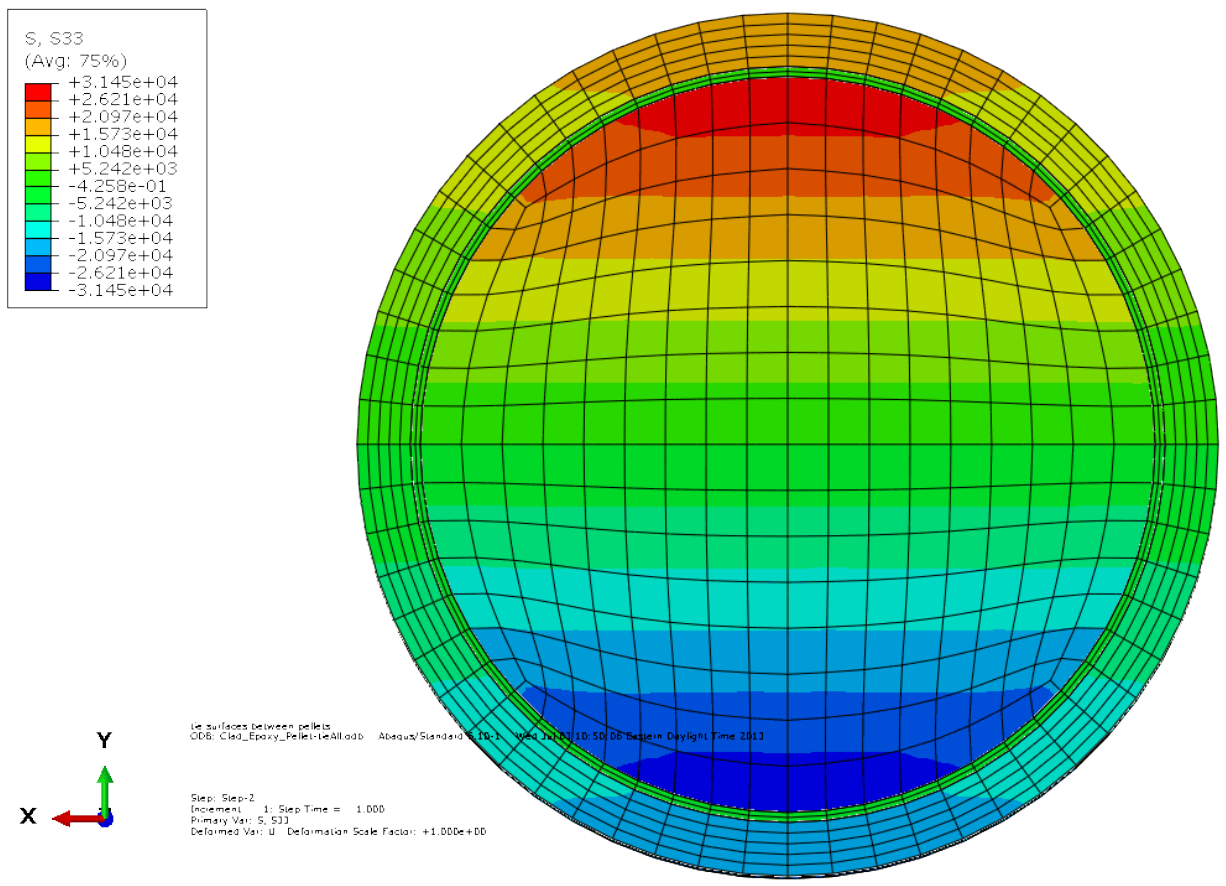

(b) Cross-sectional view of resultant $\sigma \mathrm{zz}$ at a pellet-pellet interface

Fig. 6. Resultant normal stress distribution and curvature of Clad-Epoxy-Pellet section model with four pellets with no gaps at pellet-pellet interfaces. 
In the Clad-Epoxy-Pellet section model with four pellets, the configuration of the second case is shown in Fig. 7. Thin epoxy layers are tied to the surfaces at the pellet-clad interfaces and at the pellet-pellet interfaces to simulate cohesive bonding. There are three 0.0014-in. gaps at the pellet-pellet interfaces filled with epoxy in this model. Loading and boundary conditions are the same as those in the previous cases.

Figure 8 illustrates the results of normal stress distribution and curvature of the second case, with epoxy in the gap at pellet-pellet interfaces. The stress distribution is very similar to that of the previous two models. This occurs because of the perfect bonding assigned at the interfaces and because the pellets are carrying most of the bending moment resistance. The maximum stresses of the clad and pellets are all under yielding strength; thus, the surrogate rod under the target load is still in the linear elastic region. The curvature for this case is $0.157 \mathrm{~m}^{-1}$.

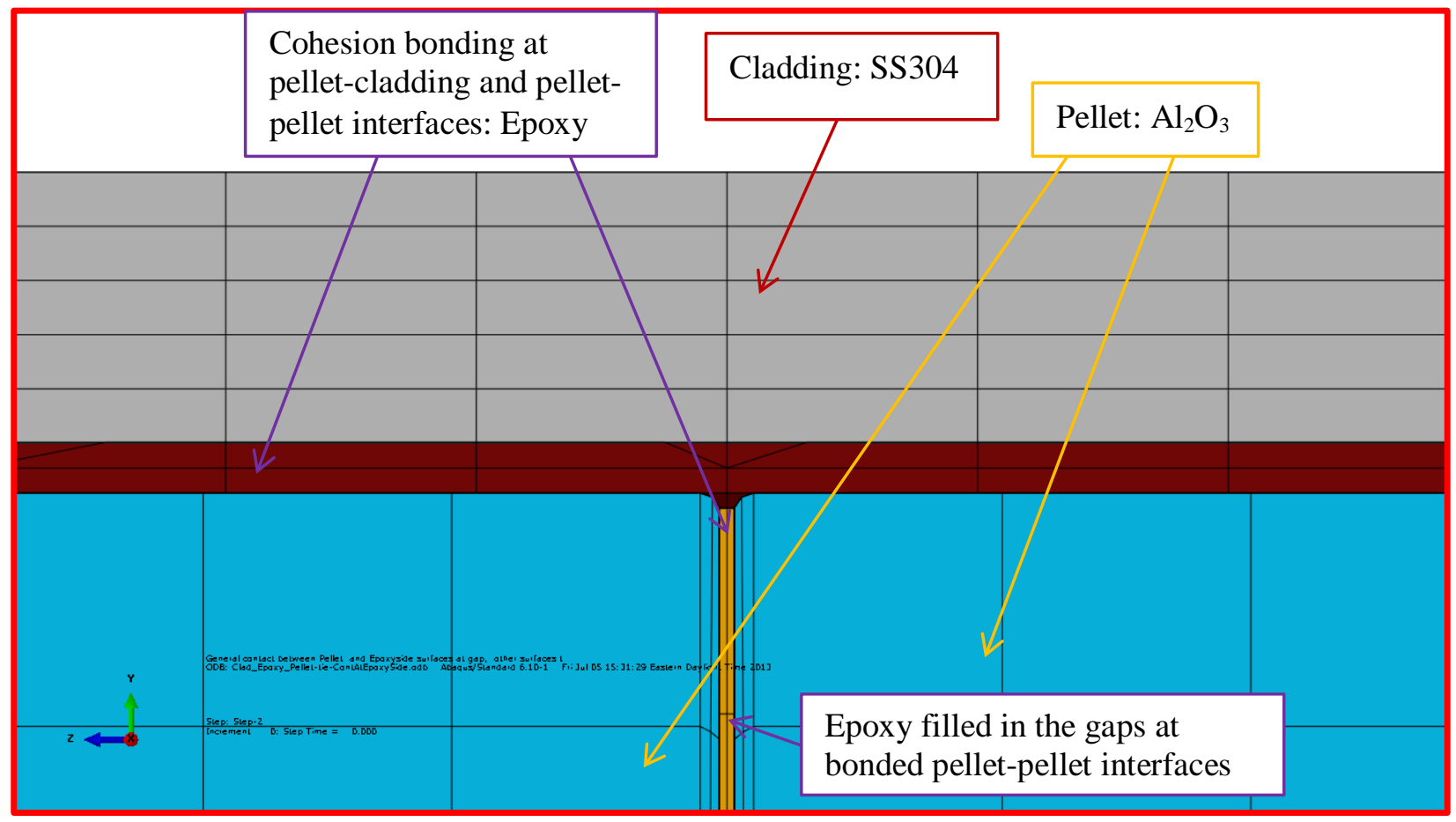

Fig. 7. Zoom-in area of Fig. 4 for the case where epoxy filled in the gaps at bonded pellet-pellet interfaces. 

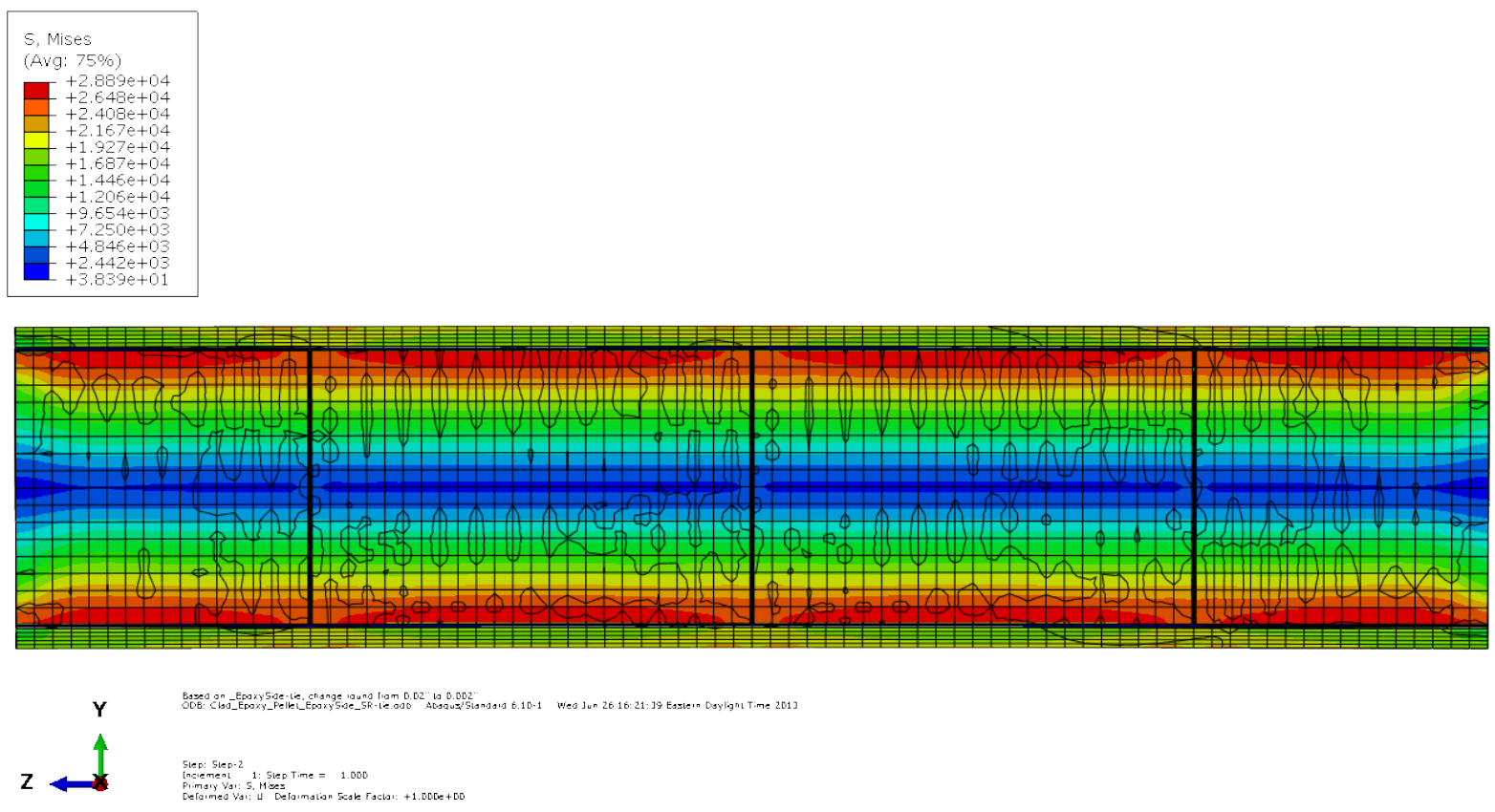

(a) Longitudinal cut view of resultant curvature and von Mises stress
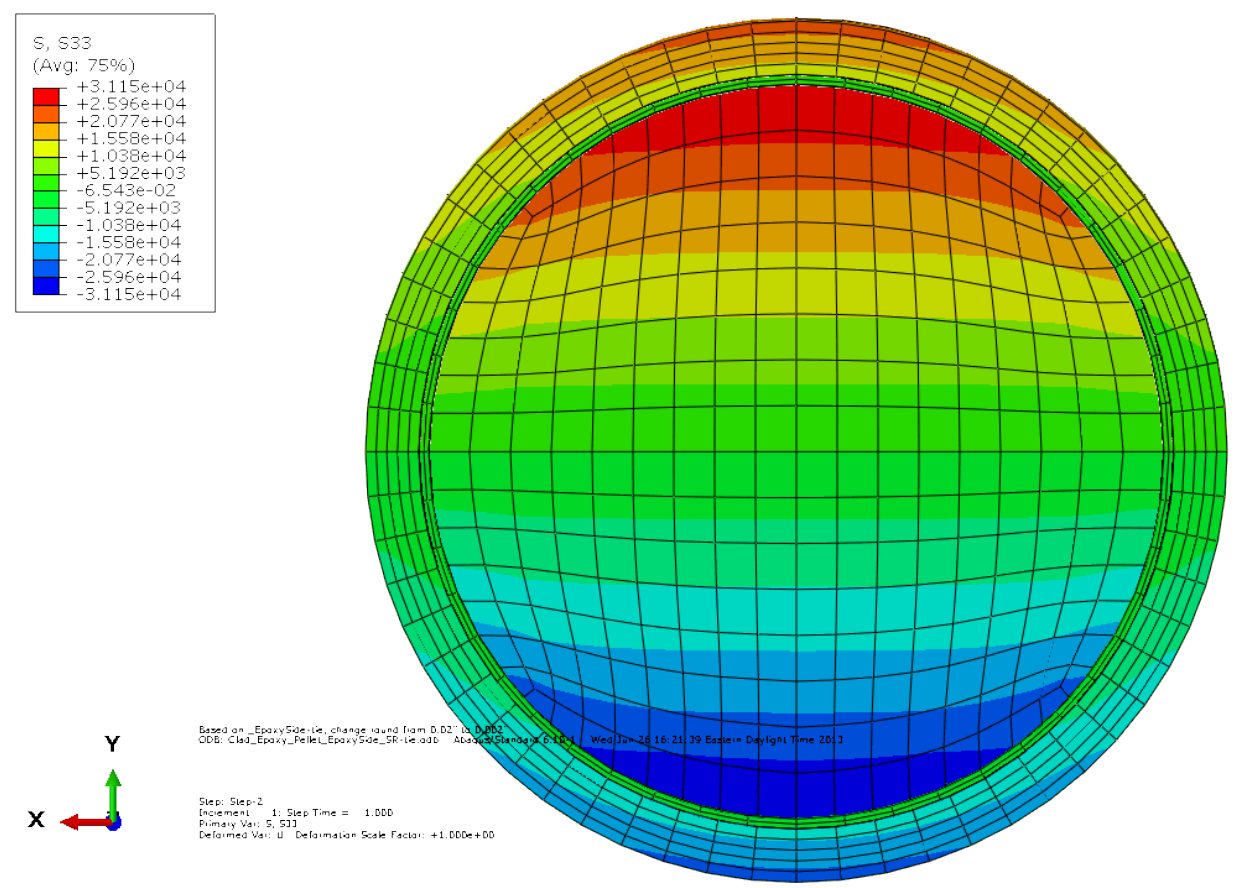

(b) Cross-sectional view of resultant $\sigma \mathrm{zz}$ at a pellet-pellet interface

Fig. 8. Resultant normal stress distribution and curvature of Clad-Epoxy-Pellet section model with four pellets and epoxy filled in the gaps at pellet-pellet interfaces.

Symmetrical reversed output force was obtained for composite rod (SS tube + alumina rod) using a U-frame bending fatigue testing system, as shown in Fig. 9. Displacement control was used for bending tests with amplitudes of 0.118 to $0.512 \mathrm{in}$. (3 to $13 \mathrm{~mm}$ ) with a frequency of $0.1 \mathrm{~Hz}$, and the deflection was measured at the mid-point of the rod. The composite rod bending test results indicate that before the inserted alumina rod fracture, the composite rod responded linearly and most of the bending load carrying 
capacity resided on the alumina rod due to a Young's modulus twice that of the SS clad. Upon the alumina insert fracture, sudden load transfer occurred and the SS tube started to carry the majority of the bending moment, which resulted in plastic deformation of SS clad, as will be demonstrated in the following simulation cases.

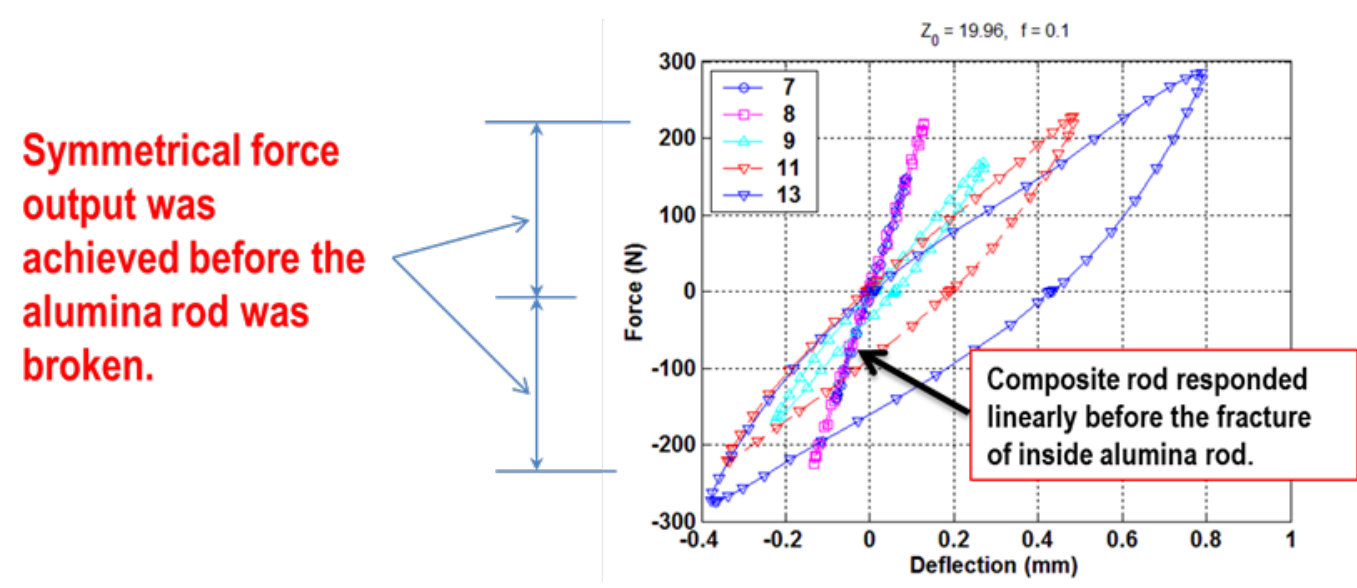

Fig. 9. Symmetrical reversed output force obtained for composite rod (stainless steel tube + alumina rod) using a U-frame bending fatigue testing system with a displacement input: $0.1 \mathrm{~Hz}$, amplitude 0.118 in. to 0.512 in. [2, 3].

In this section, three simulation cases for the surrogate rod, with good interface bonding and without inserted rod fracture, were studied. In order to simulate a good cohesive bonding in FEA, the pellet-clad interfaces are tied with a thin epoxy layer, while the pellet-pellet interfaces are either removed as a single rod or tied together without gaps, or tied with epoxy filling in the gaps.

The curvature and flexure rigidity for those cases are summarized in Table 2. In those cases, a load control procedure was used, the bending moment $M$ was applied to both ends of the surrogate rod, and the bending curvature $\kappa$ was estimated from the FEA result within the gage section. Furthermore, the flexural rigidity $E I$ (the product of Young's modulus $E$ and moment of inertia $I$ ) of a surrogate rod can be estimated using the applied moment $M$ and the resultant curvature $\kappa$ as described in Eq. 1.

$$
E I=M / \kappa
$$

Table 2. The curvature and flexural rigidity for the perfect interface bonding simulation

\begin{tabular}{|c|c|c|c|}
\hline & $\begin{array}{c}\text { Curvature, } \kappa \\
(1 / \mathrm{m})\end{array}$ & $\begin{array}{l}\text { Bending moment, } M \\
\left(\mathrm{~N}^{*} \mathrm{~m}\right)\end{array}$ & $\begin{array}{c}\text { Flexural rigidity, } E I \\
\left(\mathrm{~N}^{*} \mathrm{~m}^{2}\right)\end{array}$ \\
\hline Clad-Epoxy-Rod-Tie & 0.123 & 25 & 203 \\
\hline $\begin{array}{l}\text { Clad-Epoxy-Pellet4-Tie-Pellet- } \\
\text { Tie-noGap }\end{array}$ & 0.140 & 25 & 178 \\
\hline $\begin{array}{l}\text { Clad-Epoxy-Pellet4-Tie-Pellet- } \\
\text { Epoxy-Tie-atGap }\end{array}$ & 0.163 & 25 & 153 \\
\hline
\end{tabular}

Table 2 shows that the flexure rigidity variations are due to interface bonding and the interface geometry. Pellet-pellet interfaces tied together with no gaps result in a $12 \%$ curvature increase compared to that of the single rod case. Pellet-pellet interfaces tied to epoxy filling in gaps further increase the curvature up to 24.5\% compared to those of the single rod case. The condition of ORNL surrogate rod testing specimens most closely resembles the third case, that is, the Clad-Epoxy-Pellet section model with four pellets with 
epoxy filling in the gaps at pellet-pellet interfaces. In surrogate rod SSAP05, alumina pellets were bonded to the SS tube and to each other using epoxy. The SSAP05 specimen was tested under a 25N*m bending moment. High flexural rigidity was observed, as shown in Fig. 10. The initial (first cycle) test data, which has the highest flexural rigidity, indicates that the pellet-clad and pellet-pellet interface bonds should remain intact. The flexural rigidity of first test data is very close to the FEA estimation of $153 \mathrm{~N}^{*} \mathrm{~m}^{2}$.

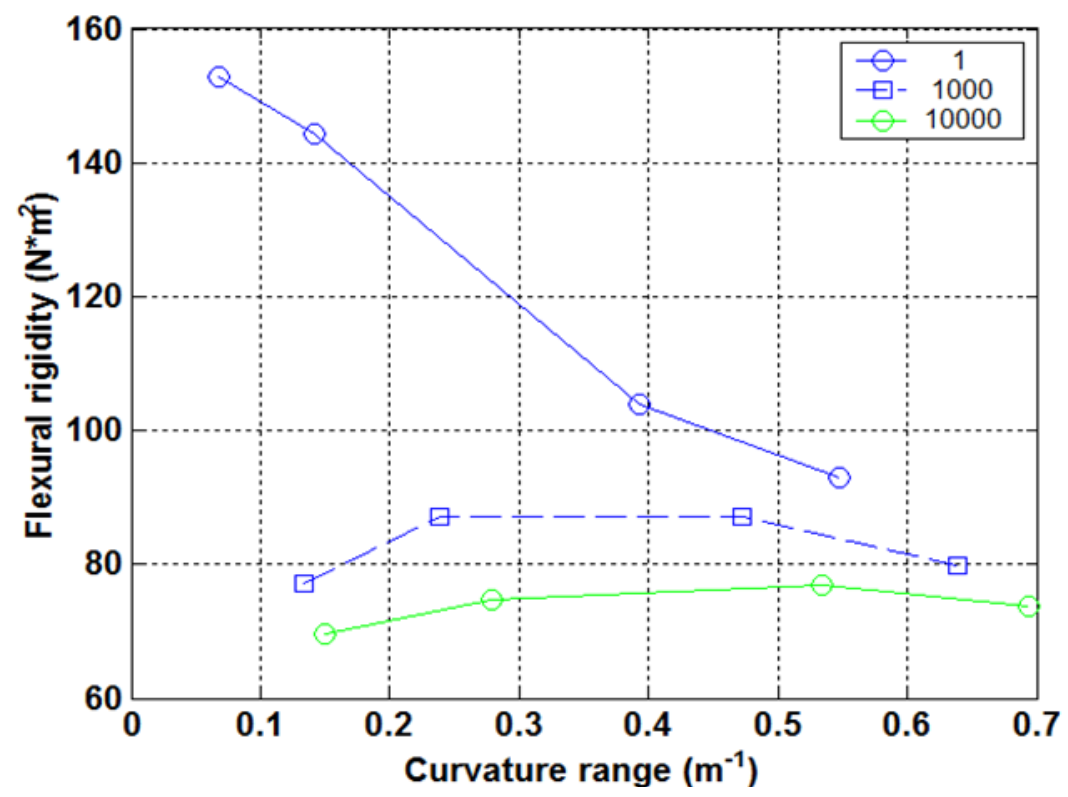

Fig. 10. ORNL SSAP05 specimen test data, flexural rigidity vs. curvature [3].

With good interface bonding and without alumina rod fracture, the alumina rod can carry most of the bending moment under normal transportation vibration due the Young's modulus of alumina rod being twice that of the clad, in addition to having a much higher compressive yield stress, as shown in Table 1 . ORNL surrogate data verifies that the inserted pellets can carry more moment resistance than the clad due to their higher stiffness if pellet-clad and pellet-pellet interface bonds remain intact. Due to the high yield strength of the alumina pellets, the surrogate rod responds to the bending moment within the linear elastic range. The high flexural rigidity estimated from FEA is in a good agreement with that estimated from bending fatigue testing data. Furthermore, under cyclic loading it is expected that the interface bond will progressively degrade, as demonstrated in Fig. 10, with decreasing flexural rigidity under increased loading cycles.

\subsection{THE EFFECT OF PELLET-CLAD INTERFACE BONDING EFFICIENCY}

Before being transported, the SNF system exhibits an inherent stress fields, such as axial tensile stress and tangential tensile stress due to pellet-clad mechanical interaction, or due to oxide volume expansion, as well as radial compressive stress due to hydride compaction and tangential shear stress due to hydride volume expansion. Vibration during transportation will induce reversal bending in a SNF assembly. Repeated expansion and contraction in both the axial and tangential directions of the SNF rod due to reversal bending flexural deformation, combined with stress concentration, can degrade the interface bonding at fuel pellet-clad interfaces and pellet-pellet interfaces, as shown in Fig. 11. While the shear stress is small relative to the normal stress due to bending, it does not mean that it can be neglected. In particular, in a composite rod or SNF rods, excessive shear due to material mismatch can be a cause for interface bonding failure. 


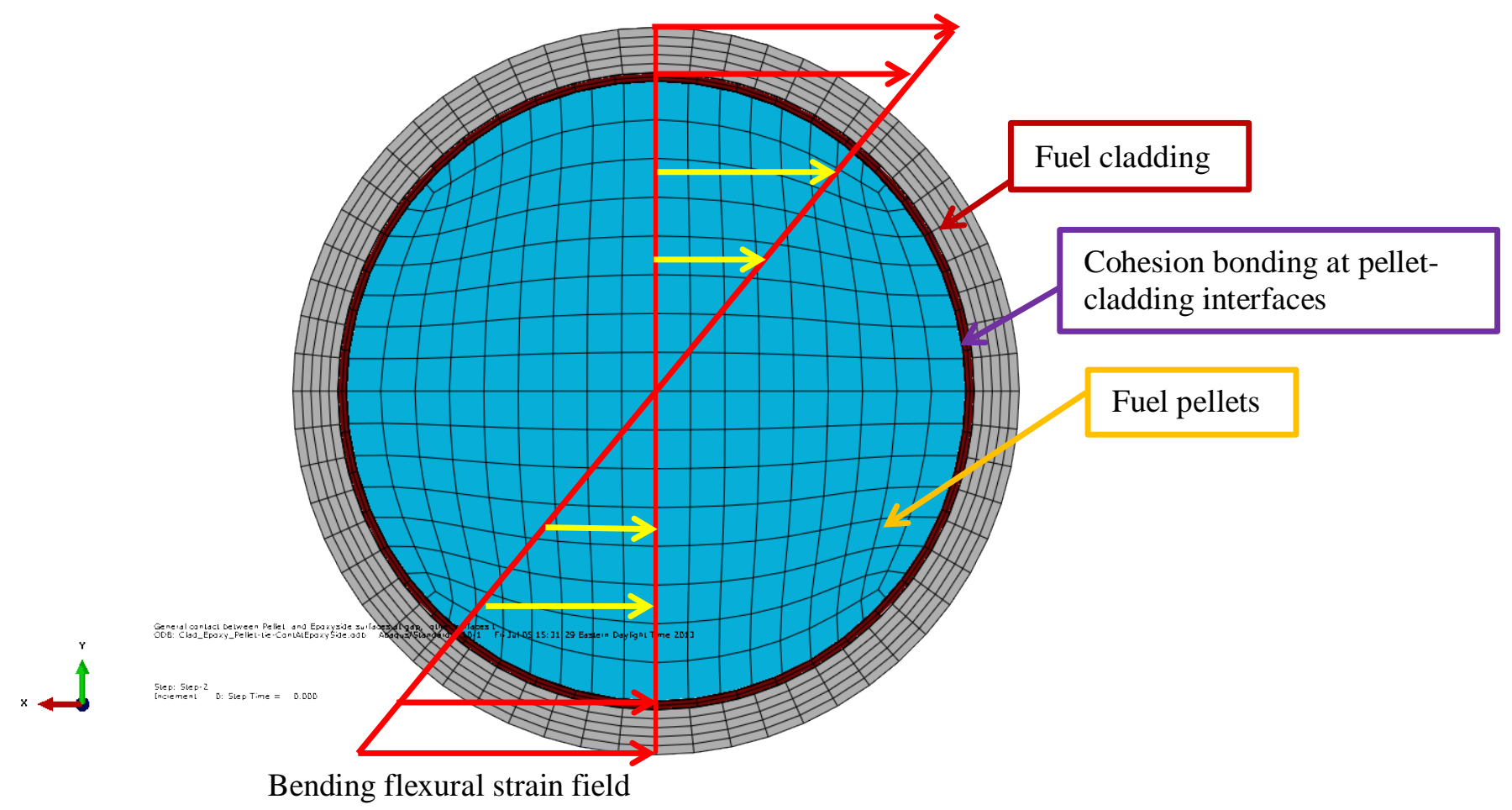

(a)

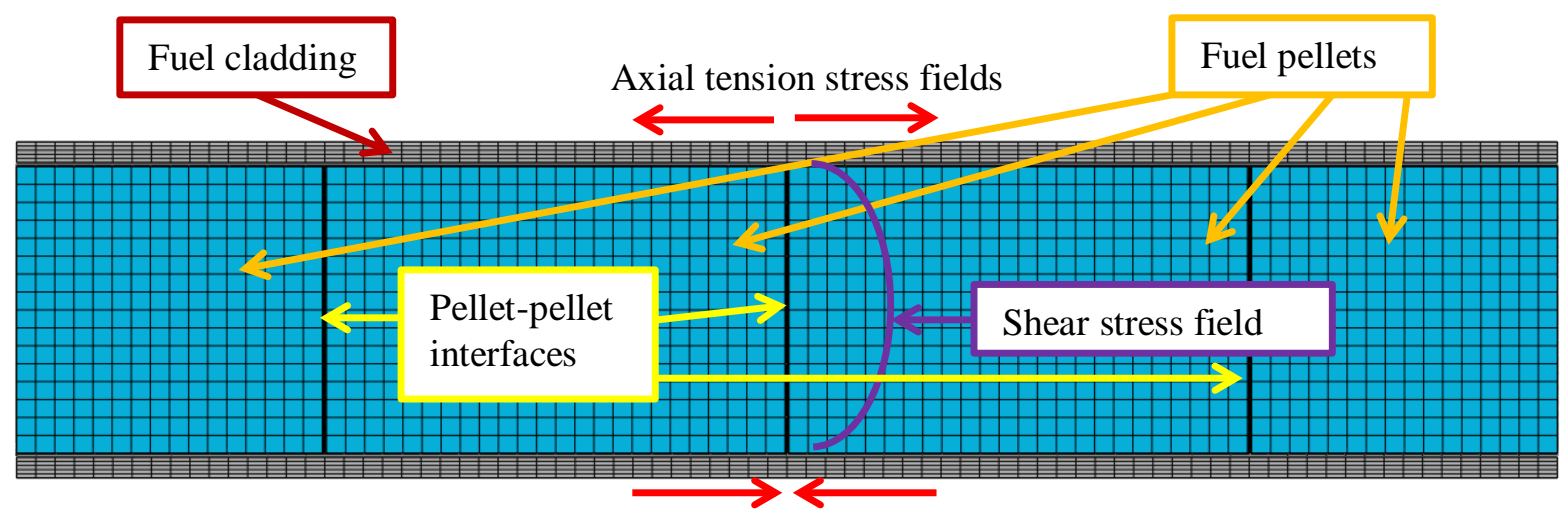

Axial compression stress fields

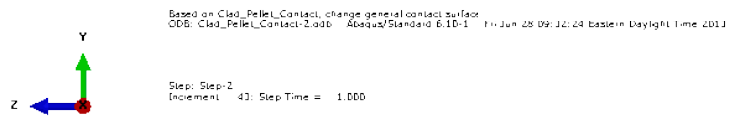

(b)

Fig. 11. Transportation-induced reversal bending stress fields in a SNF system.

At pellet-pellet interfaces, interface bonding failure is mostly caused by normal stress due to reversal bending flexural deformation, combined with relatively smaller shear stress, as shown in Fig. 11; at pellet-clad interfaces, localized high shear stress will also arise to compensate for the material mismatch under flexural deformation. As mentioned above, the shear stress is small relative to the normal stress; thus, it is likely that the interfacial bonding failure at pellet-pellet interfaces will occur before the de- 
bonding at pellet-clad interfaces. Observation of the ORNL reversal bending fatigue of the surrogate SS rod with alumina pellets verified this hypothesis. In this section, the Clad-Epoxy-Pellet section model with four pellets was used to investigate the surrogate rod bending response with perfect bonding at pellet-clad interfaces and a de-bonded state at pellet-pellet interfaces. The material properties, geometry, and loading and boundary conditions are the same as those used in the previous FEA simulation.

To simulate a good cohesion bond condition at pellet-clad interfaces, a thin epoxy layer was tied to the surfaces at pellet-clad interfaces. In this section, the first case study was designated to simulate the response with de-bonded pellet-pellet interface status. A thin epoxy layer filled in the gaps at pellet-pellet interfaces but with no cohesion bonds to the adjacent surfaces, as shown in Fig. 12.

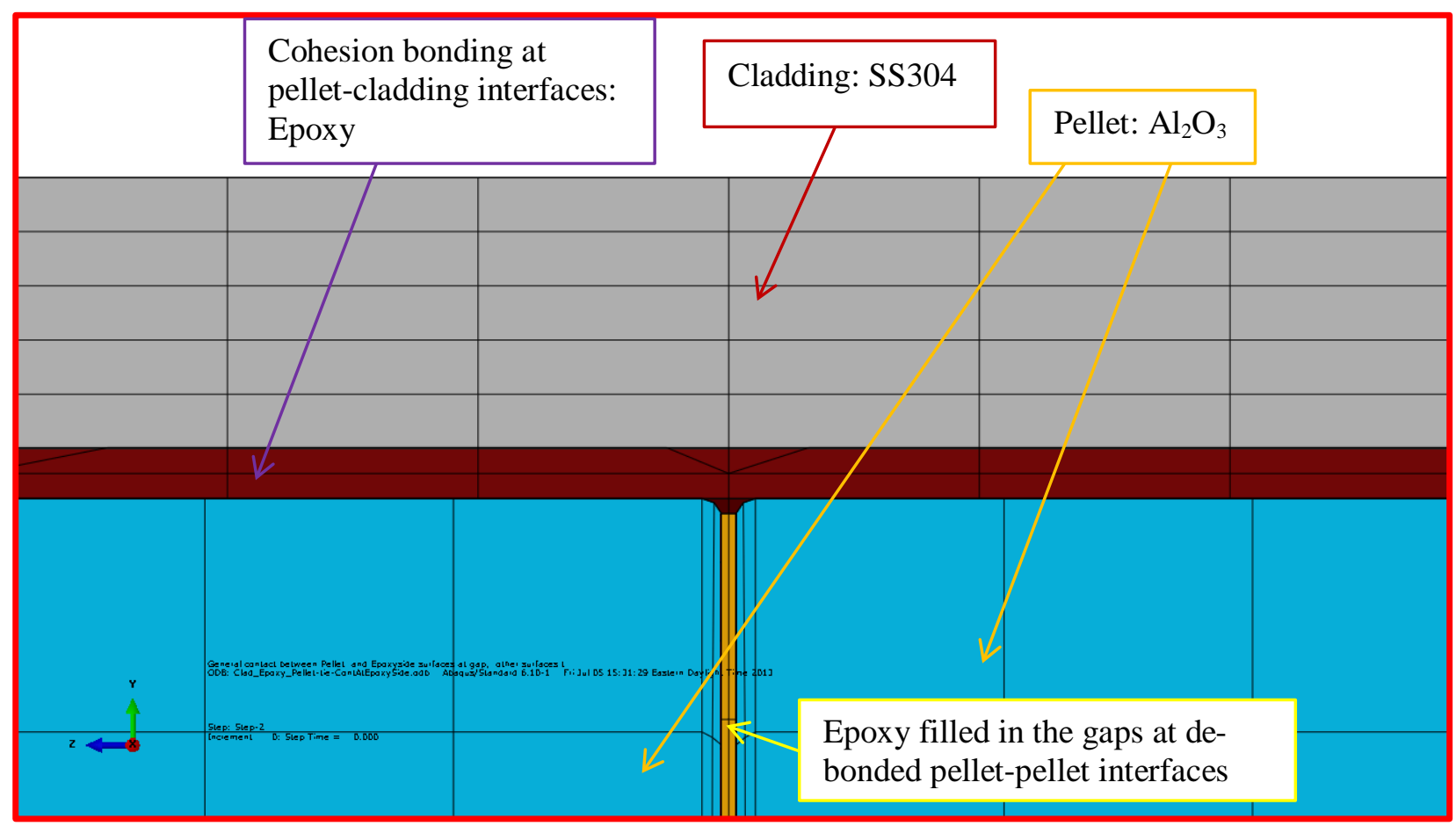

Fig. 12. Zoom-in area of Fig. 4 for the case where epoxy filled in the gaps at de-bonded pellet-pellet interfaces.

The stress and curvature responding to the bending moment are illustrated in Fig. 13. Compared to the results shown in Fig. 8, there are significant differences in the stress distribution between the pellet-pellet interface bond case and the pellet-pellet interface de-bonded case, where perfect bonding remains for both pellet-clad interface cases. For instance, for the pellet-pellet interface of the de-bonded case, the maximum tensile stress, which reaches a clad yield strength of $42 \mathrm{ksi}$, occurs at the clad and is located at the top portion of pellet-pellet interface regions. The curvature profile enlarged 10 times is shown in Fig. 13(b), where the pellets at the top corner (tension side) appear to be separated, and the pellets at the bottom interface (compression side) are in direct contact. Near the compression side pellet-pellet interface, the cross-sectional view of the resultant $\sigma_{\mathrm{zz}}$ shows that the maximum compressive stress fields resided in both pellets and clad regions with the same magnitude. 

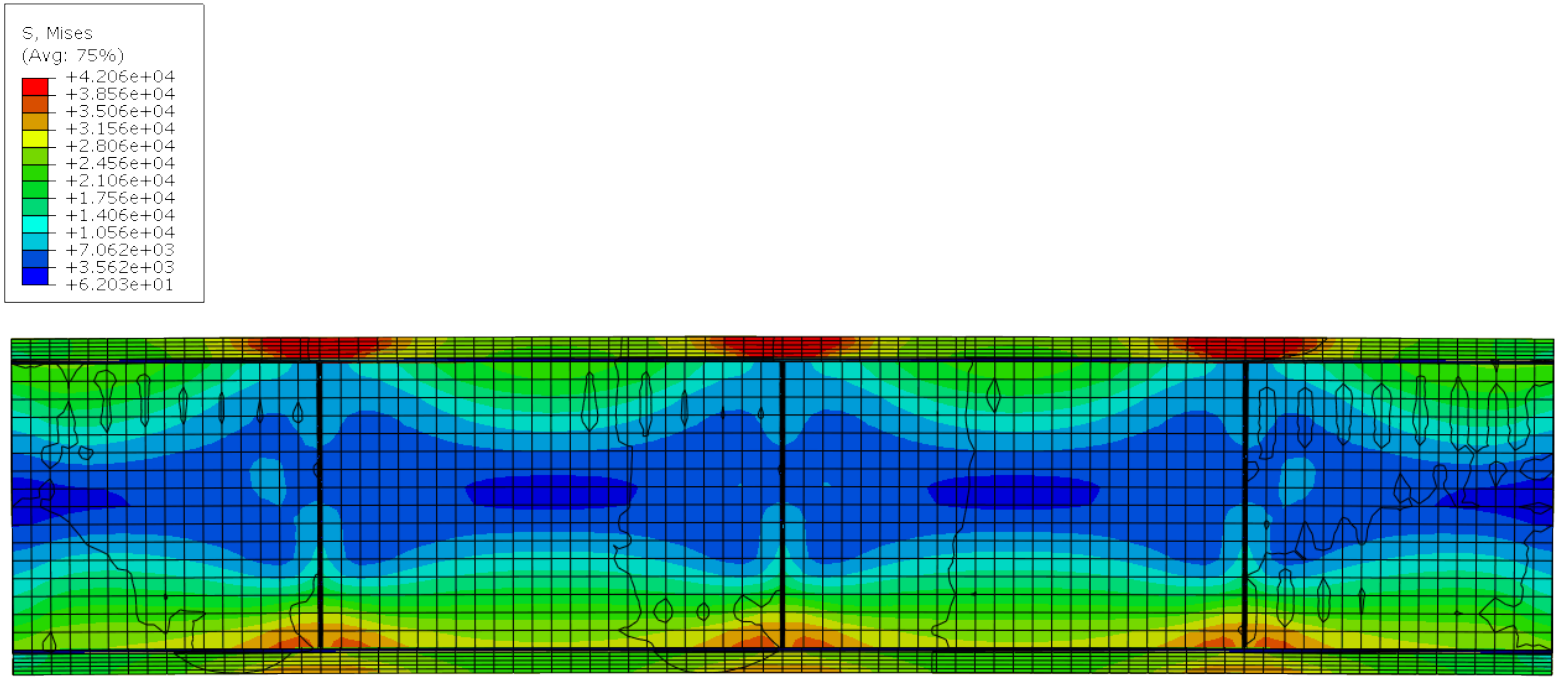

$Z \longrightarrow$

(a) Longitudinal cut view of resultant curvature and von Mises stress

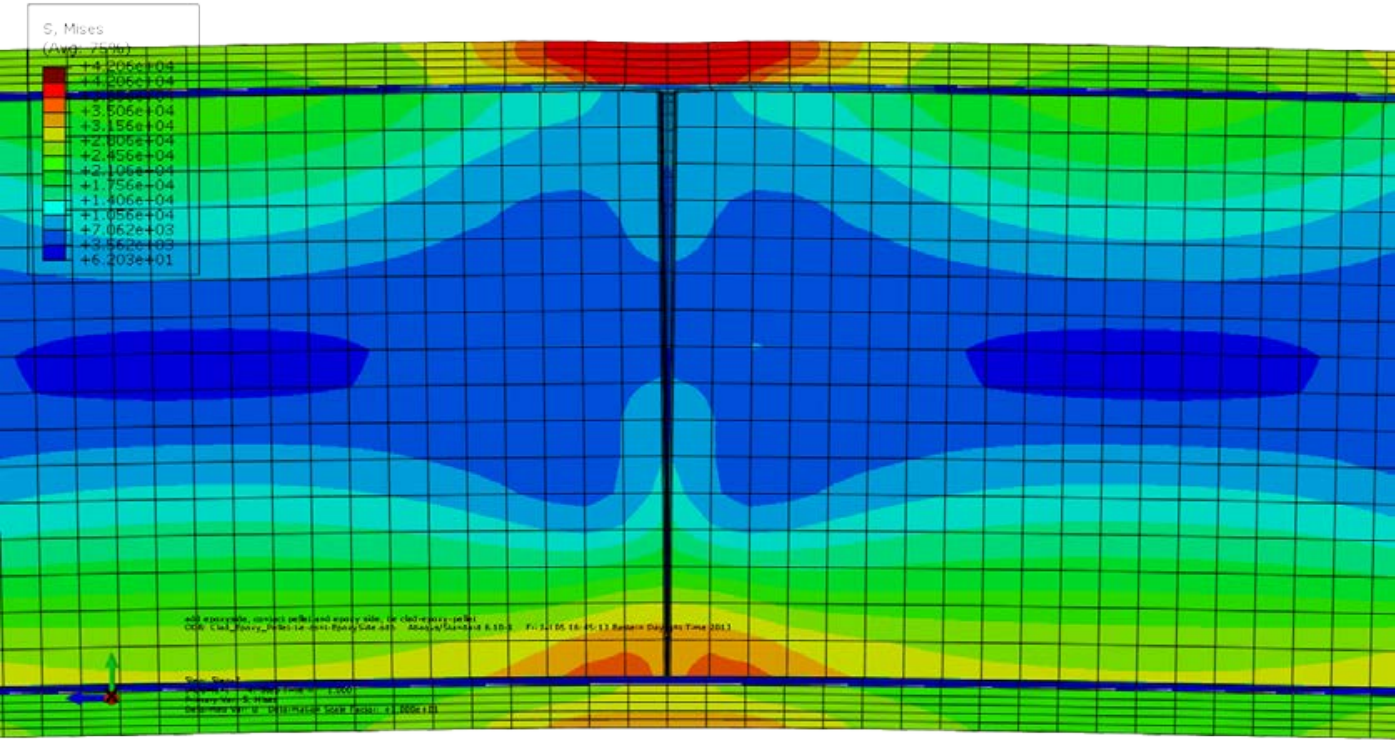

(b) Longitudinal cut view of curvature enlarged 10 times 


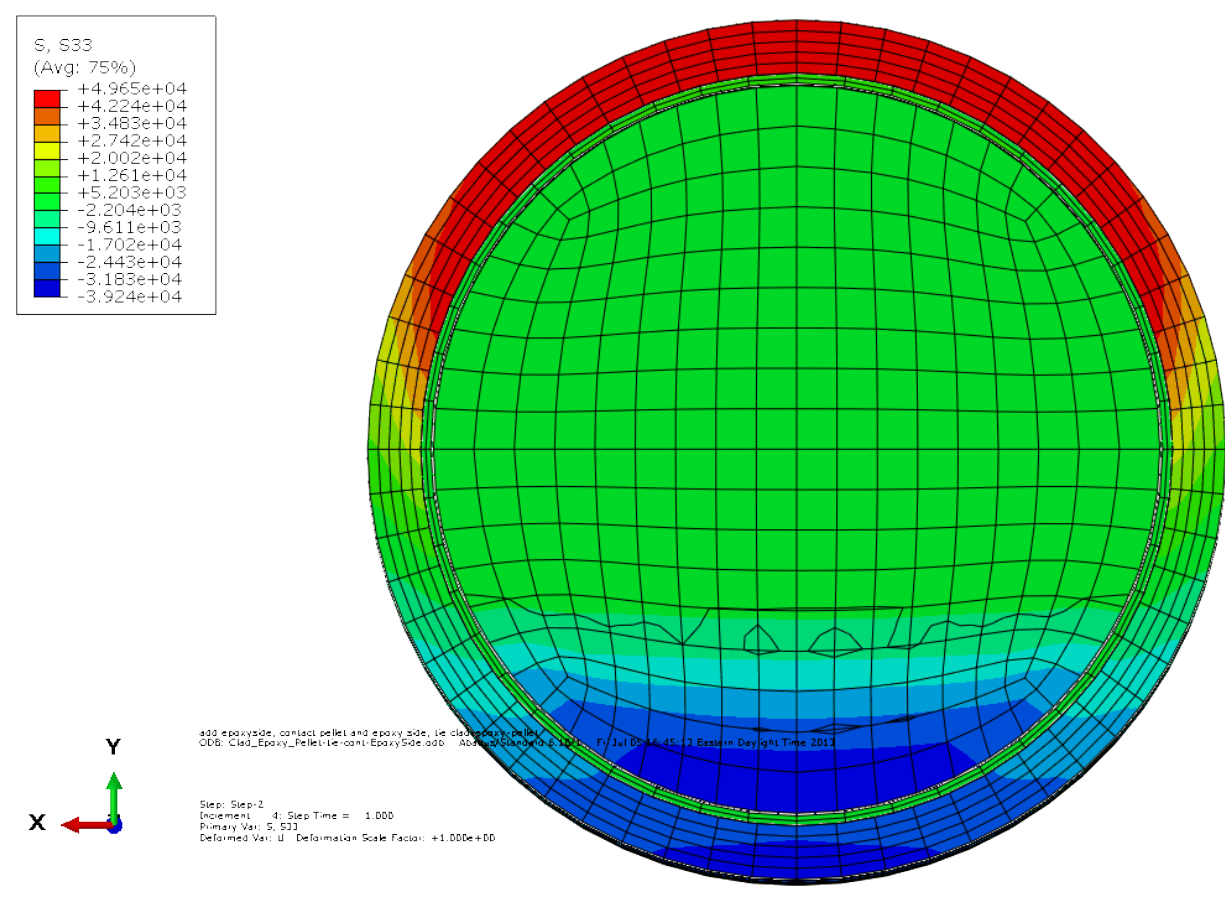

(c) Cross-sectional view of resultant normal stress $\sigma \mathrm{zz}$ at a pellet-pellet interface

Fig. 13. Resultant stress distribution and curvature of Clad-Epoxy-Pellet section model with four pellets with epoxy filling in the gaps at de-bonded pellet-pellet interfaces.

At the de-bonded pellet-pellet interfaces, the pellets can only transfer load via hard contact, so the load carrying capacity shifts significantly from pellets to the clad. The SS tube starts to carry the majority of bending moment at the tension-side pellet-pellet interface region, which results in a significant localized plastic deformation at the SS clad. At the bottom compression-side pellet-pellet interface regions, the pellet-pellet contact/compression interaction can also carry significant bending moment resistance, thus mitigating the stress intensity for the clad at interface regions. Therefore, the compression-side clad will experience a marginal compression stress with less yielding potential at those regions at the target loading shown in Fig. 13(c). Over most of the gauge section, the pellets still provide sufficient internal support to the clad due to good cohesion bonding at the pellet-clad interfaces and will carry most of the bending load; therefore, there is no yielding at most regions of the SS clad.

Figure 8, the results of the perfect bond case, shows that the pellets carry significant bending moment resistance; the maximum stress resides at the pellets, and there is no yielding at either the pellets or the clad. It is also interesting to note that the von Mises stress distribution in the de-bonded pellets case appears to be in a dog-bone shape due to contact pressure at pellet-pellet interfaces. This also differs when compared to the results of the bonded pellet-pellet interface case. The third discrepancy lies in the induced curvature. In the de-bonded case, the resultant curvature is $0.266 \mathrm{~m}^{-1}$, which is almost twice that of the perfect bonding case shown in Fig. 8.

The second case study of simulating pellet-pellet interfacial de-bonding was defined as no epoxy or gaps at pellet-pellet interfaces, while a thin epoxy layer still existed at pellet-clad interfaces and was tied to the adjacent surfaces to provide perfect cohesion bonding, as shown in Fig. 14.

Figure 15 illustrates the simulation results of the second case of the pellet-pellet interface de-bonding condition, which shows a stress profile similar to that of Fig. 13, and the maximum stress occurs at the clad region. However, the SS tube yields at both the top and bottom portions of the pellet-pellet interface 
regions due to significant load shifting to the clad, whereas at the majority of the SS tube with a perfect pellet-clad bond, the tube did not yield. Figure 15(b) also shows at a lateral contraction and lateral expansion at the tension and compression sides of clad, respectively. Furthermore, a localized clad buckle was also observed and is likely due to the lack of internal support at pellet-pellet-clad interface gap region. The clad deforms continuously until the gaps are diminished by the direct contact of pellet-pellet surfaces. There are no stress concentrations observed at pellet-pellet contact corners. Resultant $\sigma_{\mathrm{zz}}$ clearly indicates that the clad takes over more bending moment resistance than that of the pellets at the debonded pellet-pellet interfaces. Pellets have the same dog-bone shape stress distribution as those of the previous case. The induced curvature of this pellet-pellet interface de-bonding with gaps case is $0.669 \mathrm{~m}^{-1}$, much bigger than that of previous cases.

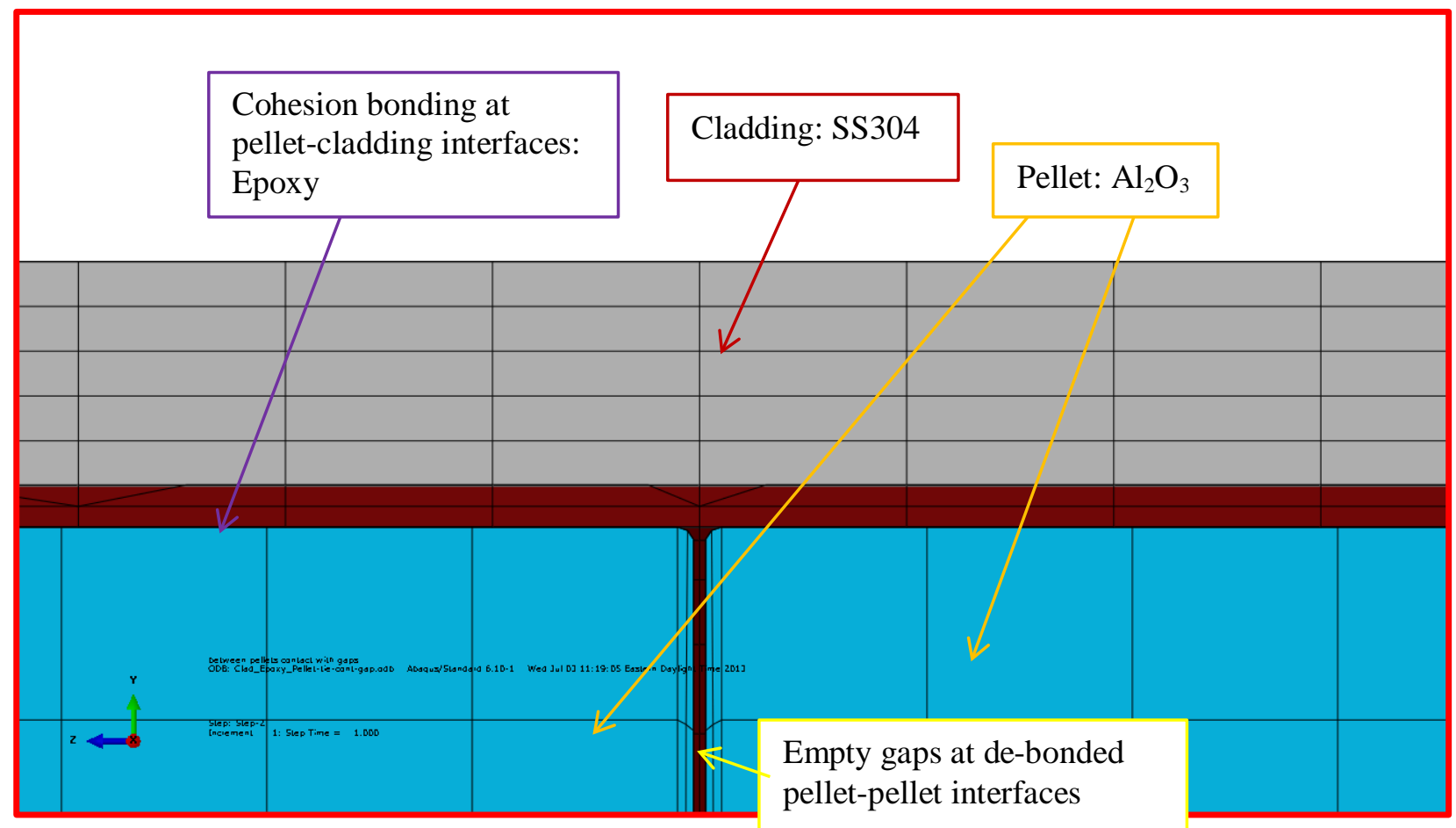

Fig. 14. Zoom-in area of Fig. 4 for the case where there were empty gaps at de-bonded pellet-pellet interfaces. 

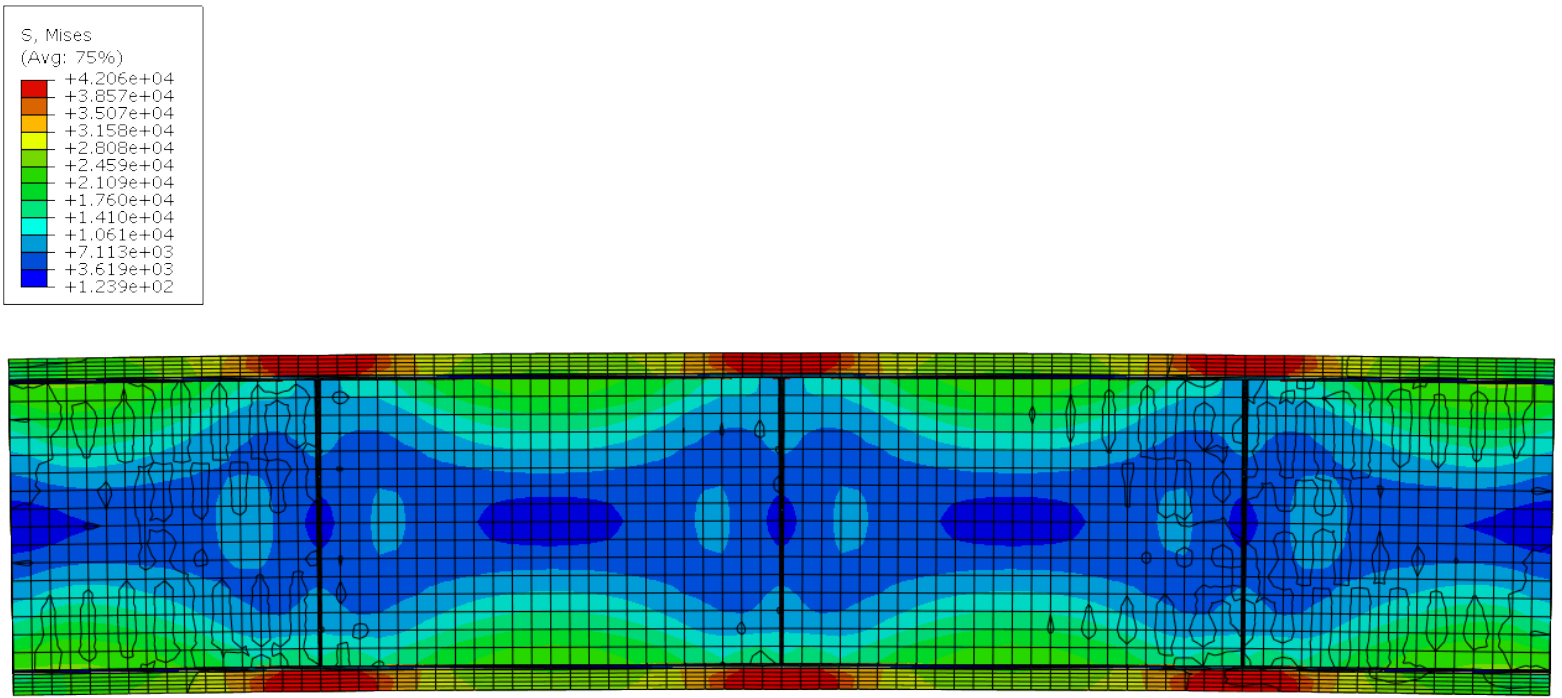

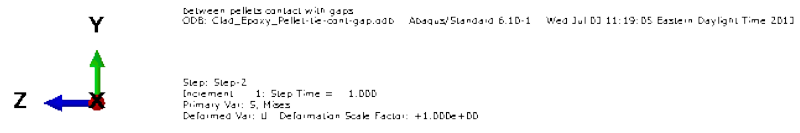

(a) Longitudinal cut view of resultant curvature and von Mises stress

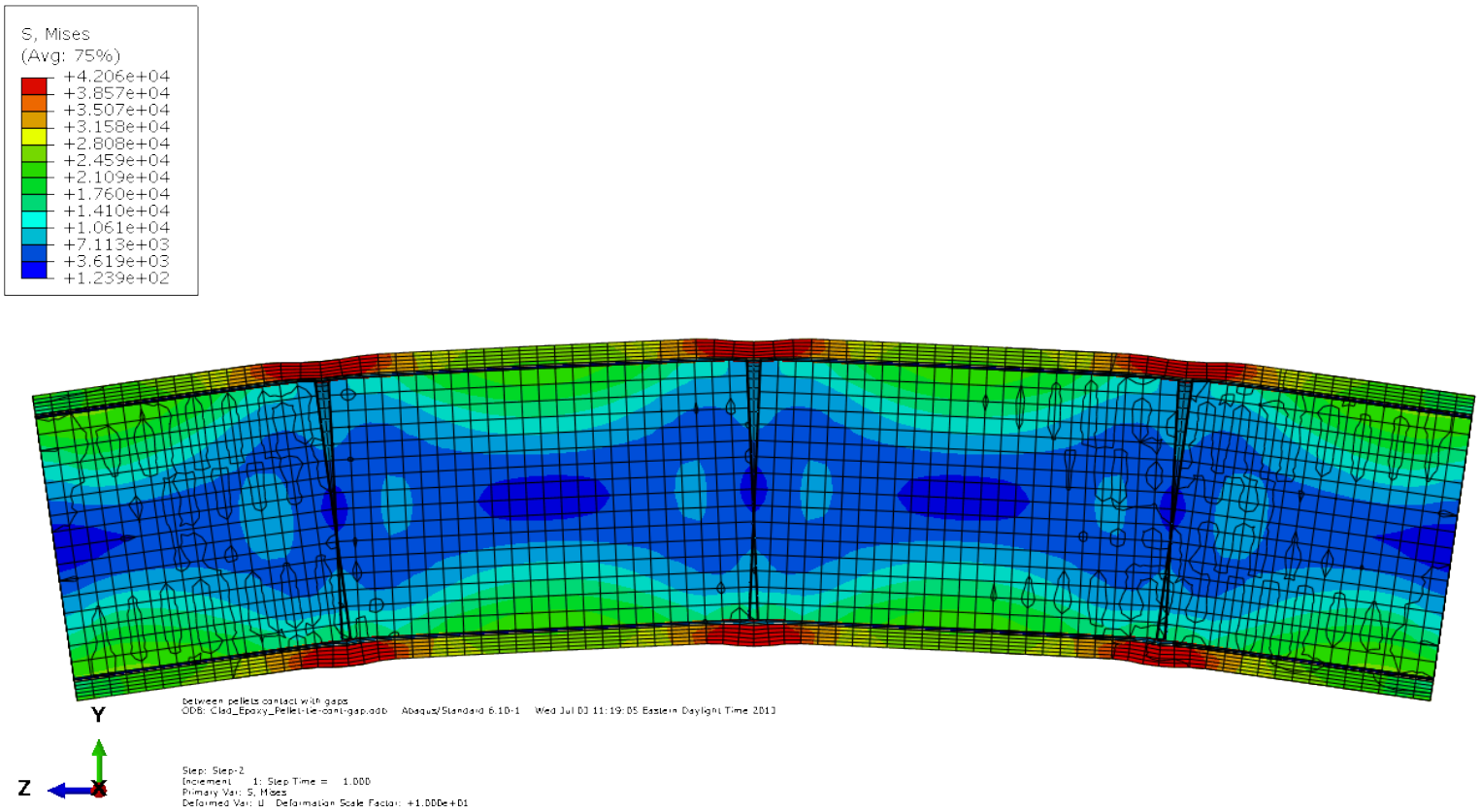

(b) Longitudinal cut view of enlarged curvature by 10 times 

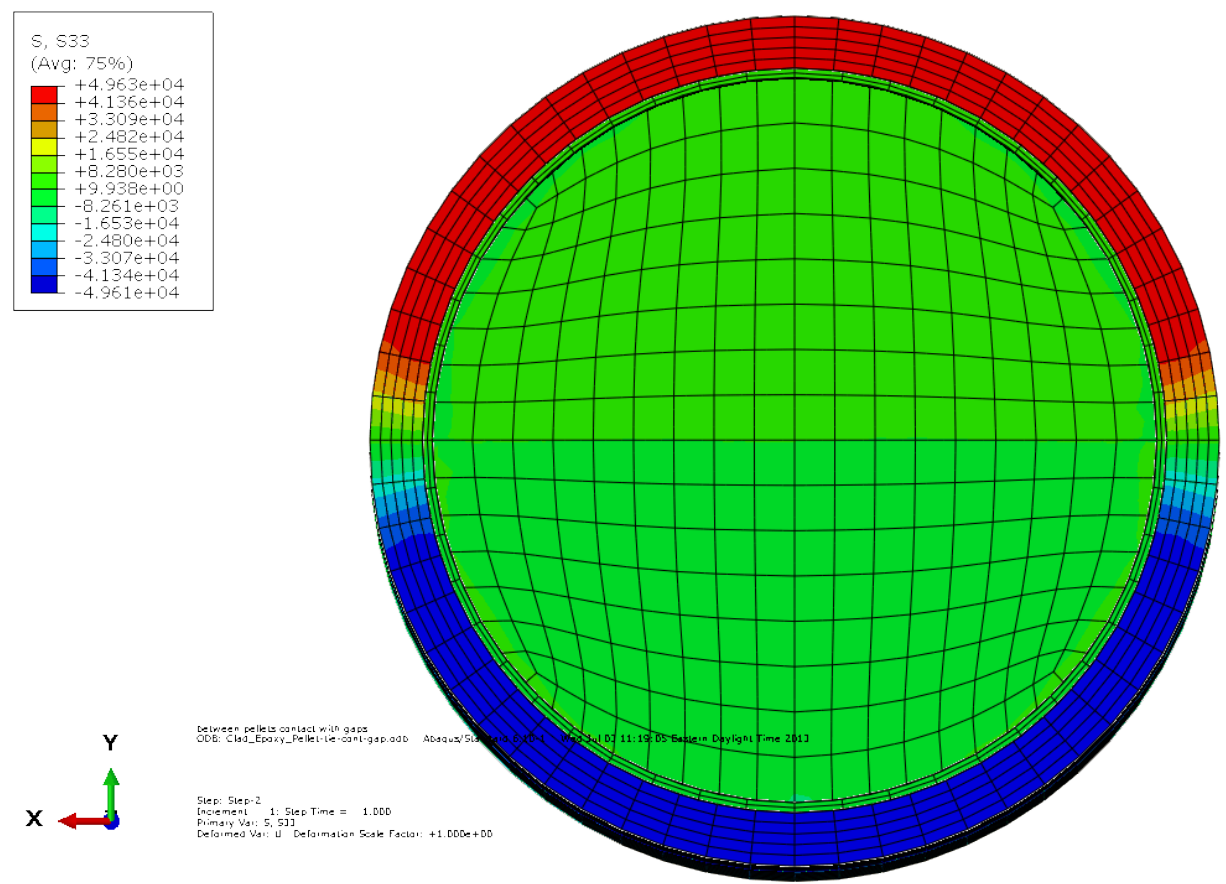

(c) Cross-sectional view of resultant $\sigma \mathrm{zz}$ at a pellet-pellet interface

Fig. 15. Resultant stress distribution and curvature of Clad-Epoxy-Pellet section model with four pellets with empty gaps at de-bonded pellet-pellet interfaces.

The third case of simulating a "de-bonded pellet-pellet interface" and a "bonded pellet-clad interface" is illustrated in Fig. 16. No gaps exist at pellet-pellet interfaces before applying bending load. As in previous cases, a thin epoxy layer is applied and tied to surfaces at pellet-clad interfaces to simulate good cohesion bonding. 


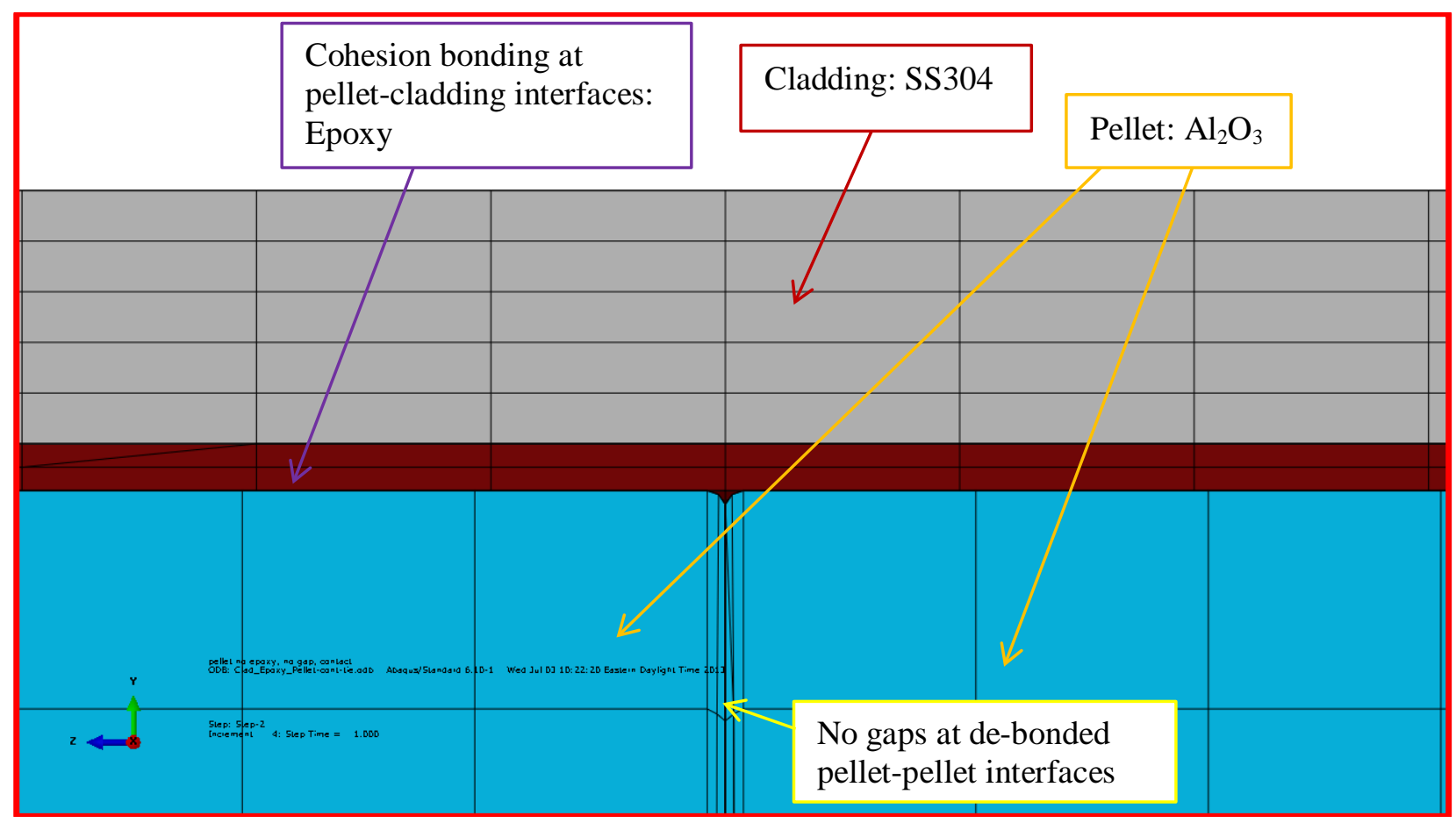

Fig. 16. Zoom-in area of Fig. 4 for the case of no gaps at de-bonded pellet-pellet interfaces.

As illustrated in Fig. 17, the stress distribution of this case appears to be similar to that of the de-bonded pellet-pellet interface case with epoxy filling in the gaps (Fig. 15). The SS clad reaches yield at the top pellet-pellet interface regions; however, at the compression-side interface, the maximum stress occurs at the pellets instead of clad, as shown in Fig. 15. Due to its high yield strength, the pellet is under the linear elastic range at the maximum stress level. From the curvature profile, there is no clad buckling observed at bottom (compression) region. This is because of the absence of gaps at pellet-pellet-clad interface region; thus, the contained pellets provide good internal support to the clad tubing structure. Furthermore, pellets seem to carry a significant portion of bending moment resistance via pellet-pellet interaction (pinching at pellet corners), which significantly mitigates the stress level of the clad at the bottom (compression) region. The pellet stress profiles also show a dog-bone shape due to contact pressure at the pellet-pellet interfaces. The resultant $\sigma_{\mathrm{zz}}$ profile with no gaps at the pellet-pellet interface indicates that these pellets can carry more bending moment resistance than pellets with gaps, as shown in Fig. 15. 

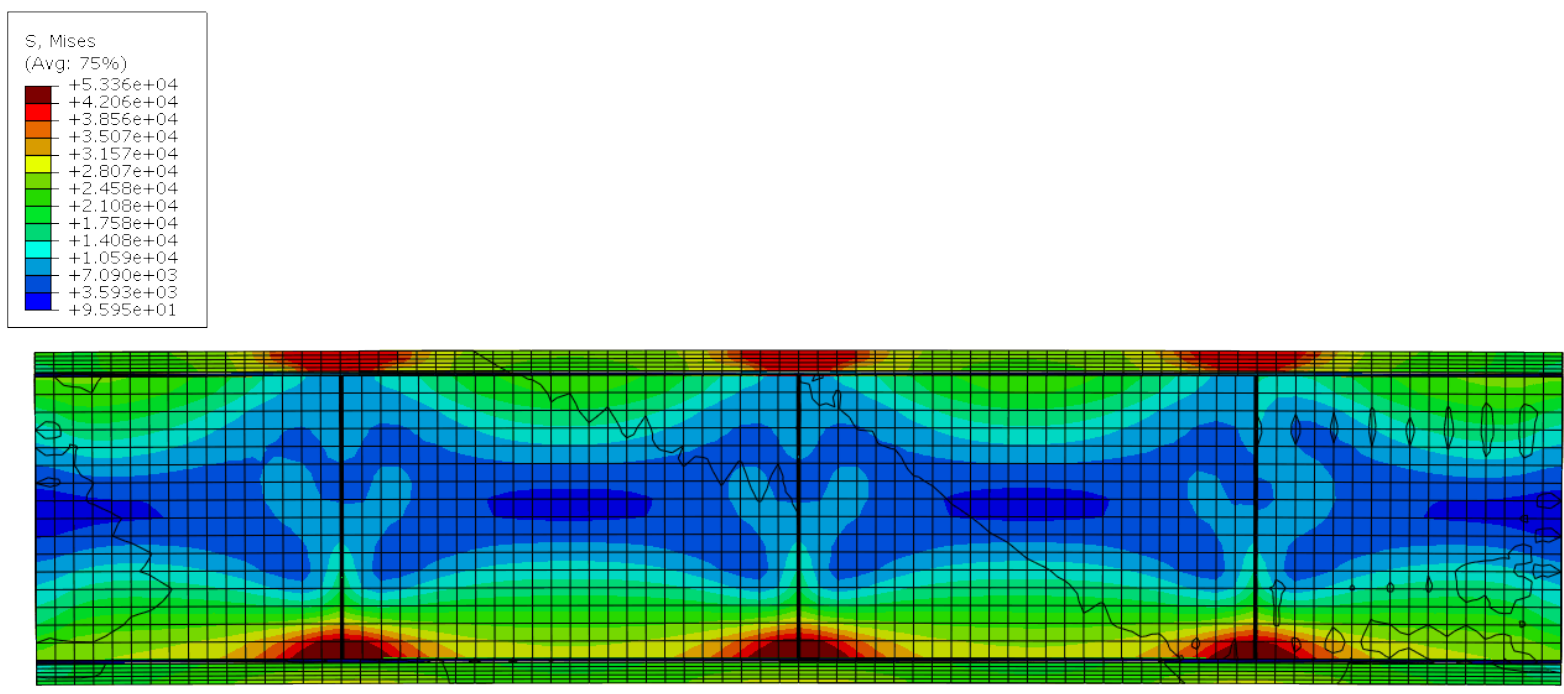

$\mathbf{Y}$
$Z$

(a) Longitudinal cut view of resultant curvature and von Mises stress
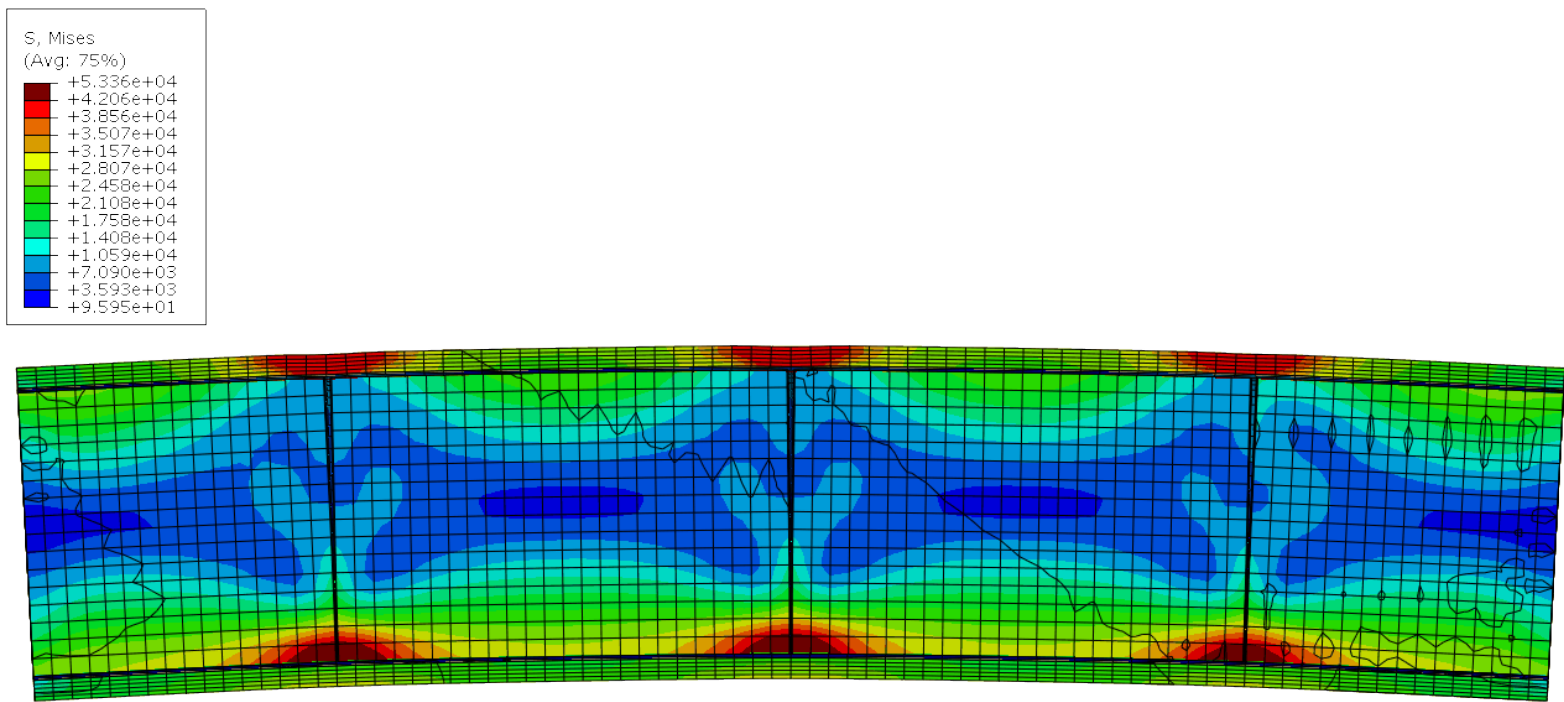

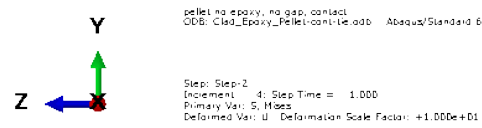

(b) Longitudinal cut view of enlarged curvature by 10 times 


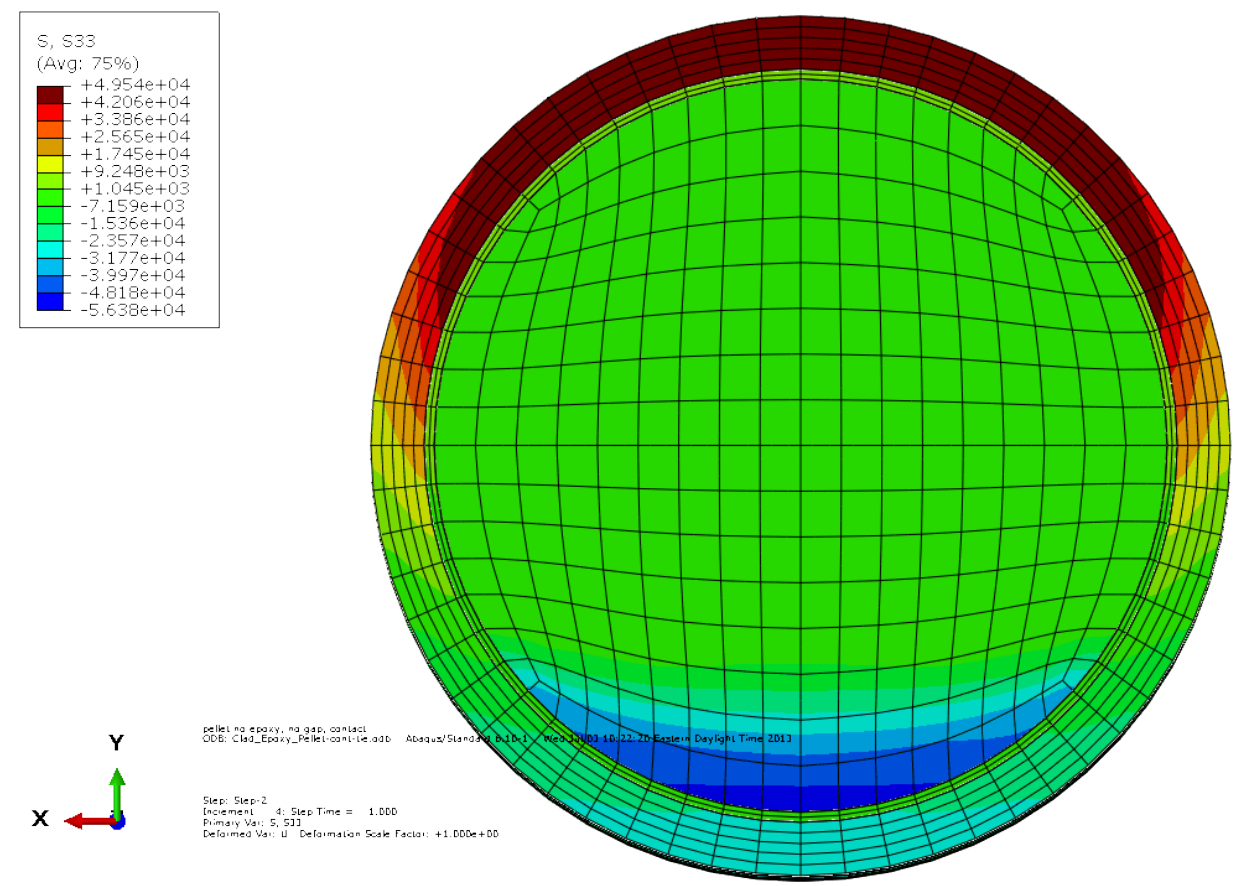

(c) Cross-sectional view of resultant $\sigma \mathrm{zz}$ at a pellet-pellet interface

Fig. 17. Resultant stress distribution and curvature of Clad-Epoxy-Pellet section model with four pellets with no gaps at de-bonded pellet-pellet interfaces.

Table 3 summarizes the estimated curvature and the flexural rigidity based on three FEA simulation cases discussed in this section. The same bending moment is used in all FEA simulations. The curvature and the flexural rigidity listed in Table 2 indicate that for the perfect interface bonding simulation, the immediate consequence of de-bonded pellet-pellet interface is a significant increase in curvature, and this results in a significant reduction in the estimated flexural rigidity. This phenomenon is primary due to the load carrying capacity shifting from the pellets to the clad.

Table 3. The curvature and flexural rigidity for bonded pellet-clad and de-bonded pellet-pellet case

\begin{tabular}{|c|c|c|c|}
\hline & $\begin{array}{c}\text { Curvature } \kappa \\
(1 / \mathrm{m})\end{array}$ & $\begin{array}{l}\text { Bending moment } M \\
\left(N^{*} \mathbf{m}\right)\end{array}$ & $\begin{array}{c}\text { Flexural rigidity EI } \\
\left(\mathrm{N}^{*} \mathrm{~m}^{2}\right)\end{array}$ \\
\hline $\begin{array}{l}\text { Clad-Epoxy-Pellet4-Tie-Pellet- } \\
\text { Epoxy-Contact-atGap }\end{array}$ & 0.266 & 25 & 94 \\
\hline $\begin{array}{l}\text { Clad-Epox-Pellet4-Tie-Pellet- } \\
\text { Contact-Gap }\end{array}$ & 0.669 & 25 & 37 \\
\hline $\begin{array}{l}\text { Clad-Epoxy-Pellet4-Tie-Pellet- } \\
\text { Contact-noGap }\end{array}$ & 0.241 & 25 & 104 \\
\hline
\end{tabular}

The induced curvature of $0.261 \mathrm{~m}^{-1}$ for the de-bonded pellet-pellet interfaces with epoxy filling in the gaps case is 1.6 times the curvature of $0.163 \mathrm{~m}^{-1}$ for perfect bonding with epoxy filling in the gaps case. The estimated flexural rigidity of $94 \mathrm{~N}^{*} \mathrm{~m}^{2}$ for the de-bonded pellet-pellet interface case is about $39 \%$ less than $153 \mathrm{~N}^{*} \mathrm{~m}^{2}$ for the perfect bonding interface case. 
Table 3 shows that the gaps at pellet-pellet interfaces play a critical role in estimating the flexural rigidity of the surrogate rod. The induced curvature of $0.669 \mathrm{~m}^{-1}$ for the de-bonded pellet-pellet interfaces with empty (no epoxy filled) gaps is 2.5 times that of the de-bonded pellet-pellet interfaces with epoxy filling the gaps, and this results in a $61 \%$ reduction in flexural rigidity from $94 \mathrm{~N}^{*} \mathrm{~m}^{2}$ for the epoxy-filled gaps case to $37 \mathrm{~N}^{*} \mathrm{~m}^{2}$ for the empty gaps case. When the gaps are eliminated, the highest flexural rigidity value is $104 \mathrm{~N}^{*} \mathrm{~m}^{2}$. The above indicates that the gap-induced large plastic deformations of SS clad at the pelletpellet interface region can lead to significant reduction in the bending stiffness, that is, the flexural rigidity (EI) of the surrogate rod system. If there are no gaps at the pellet-pellet interfaces, the pellets can carry a significant portion of bending moment resistance via direct pellet-pellet contact (interaction) to mitigate the potential yield of the clad.

\subsection{DE-BONDED PELLET-CLAD AND PELLET-PELLET INTERFACES}

Under a flexural deformation, high shear stress will arise at pellet-clad interfaces to compensate for the material mismatch, in addition to the flexural shear stress in the SNF system. Thus, under reversal bending load during normal transportation, both cyclic normal stress and shear stress can further degrade the interface bonding at fuel pellet-clad interfaces. In this section, de-bonded pellet-clad interfaces and debonded pellet-pellet interfaces cases are investigated using the Clad-Epoxy-Pellet section model with four pellets. The surrogate rod consists of SS clad and alumina pellet inserts and is used to study the system response to bending moment with de-bonded interfaces. Loading and boundary conditions are the same as those of the previous cases, and the assigned bending moment is $25 \mathrm{~N}^{*} \mathrm{~m}$.

The first simulation case of interfacial de-bonding for both at pellet-clad and pellet-pellet interfaces is illustrated in Fig. 18. There are empty gaps at de-bonded pellet-pellet interfaces and a thin epoxy layer at de-bonded pellet-clad interfaces.

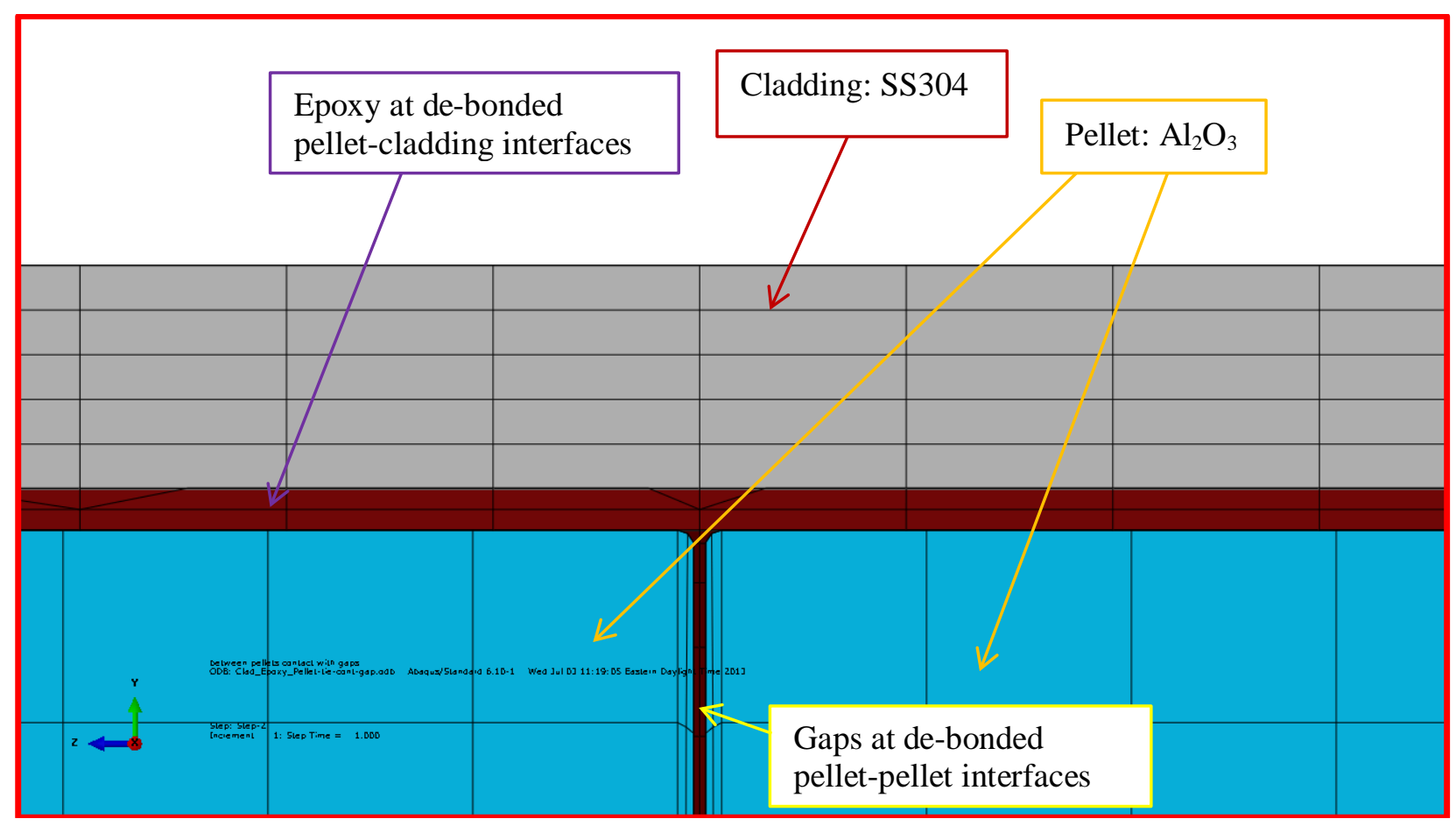

Fig. 18. Zoom-in area of Fig. 4 for the case of empty gaps at de-bonded pellet-pellet interfaces and an epoxy-filled layer at de-bonded pellet-clad interfaces. 
The resultant stress distribution shown in Fig. 19 indicates that the yielded SS clad almost extends throughout the whole gauge section, when the interfacial de-bonding occurs at both pellet-clad and pelletpellet interfaces. This is in great contrast to the results shown in Fig. 15, where the SS tube only locally yields at pellet-pellet interface regions and the maximum stress resides at pellets at the compression side of pellet-pellet interfaces. The pellets were all below yield at the maximum stress level due to high yield strength. The pellet stress contours also show a dog-bone shape due to pellet-pellet contact interaction. The induced curvature of $0.727 \mathrm{~m}^{-1}$ is large enough to be visualized from the longitudinal cut view without increasing scale. It suggests that due to the interface de-bonding both at pellet-clad and pelletpellet interfaces, the contained pellet inserts and the SS clad can only contact (or pin) at the pellet-pelletclad interface region, and the pellets cannot provide direct internal support to the clad. Therefore, the load carrying capacity shifts significantly from pellets to the clad over the entire gauge section; the results also indicate that the SS clad carries the majority of the bending moment resistance. The bending deformation in the de-bonded pellet-clad region will likely result in further pinning action at pellet-clad interfaces, which may also result in an accelerated aging of the clad tubing.
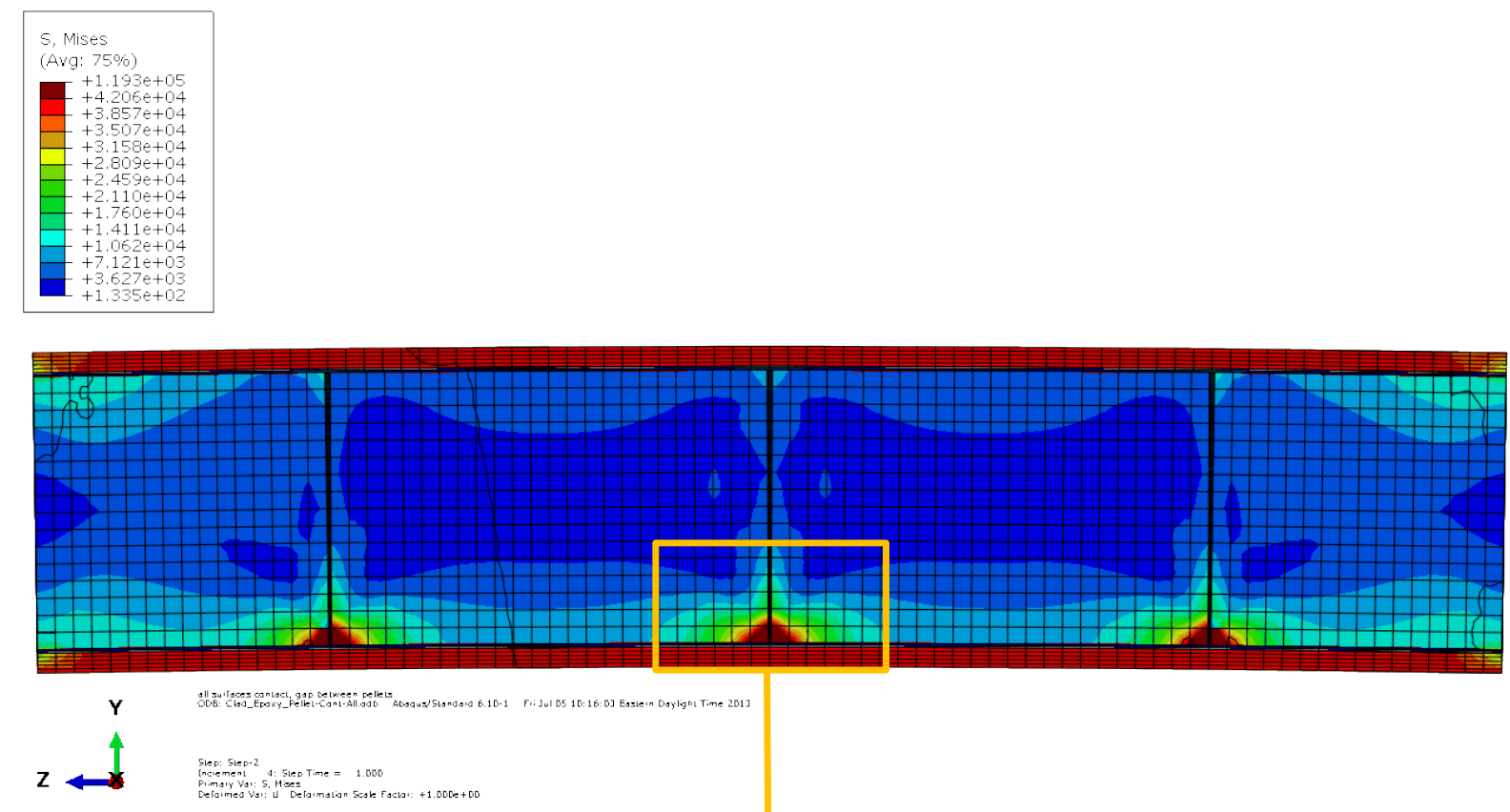

(a) Longitudinal cut view of resultint curvature and von Mises stress 


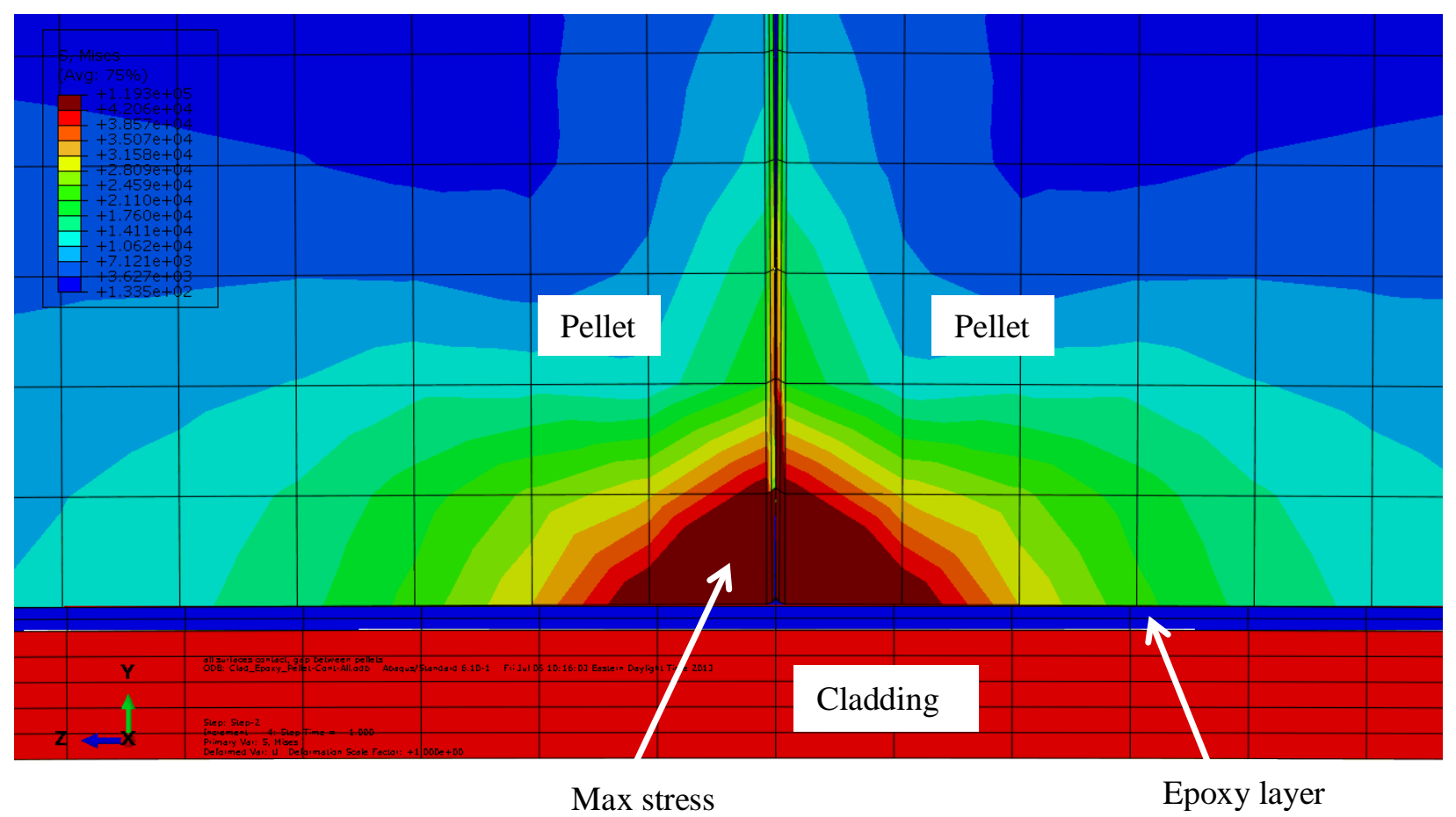

(b) Zoom-in view of stress distribution at pellet-clad pinning region

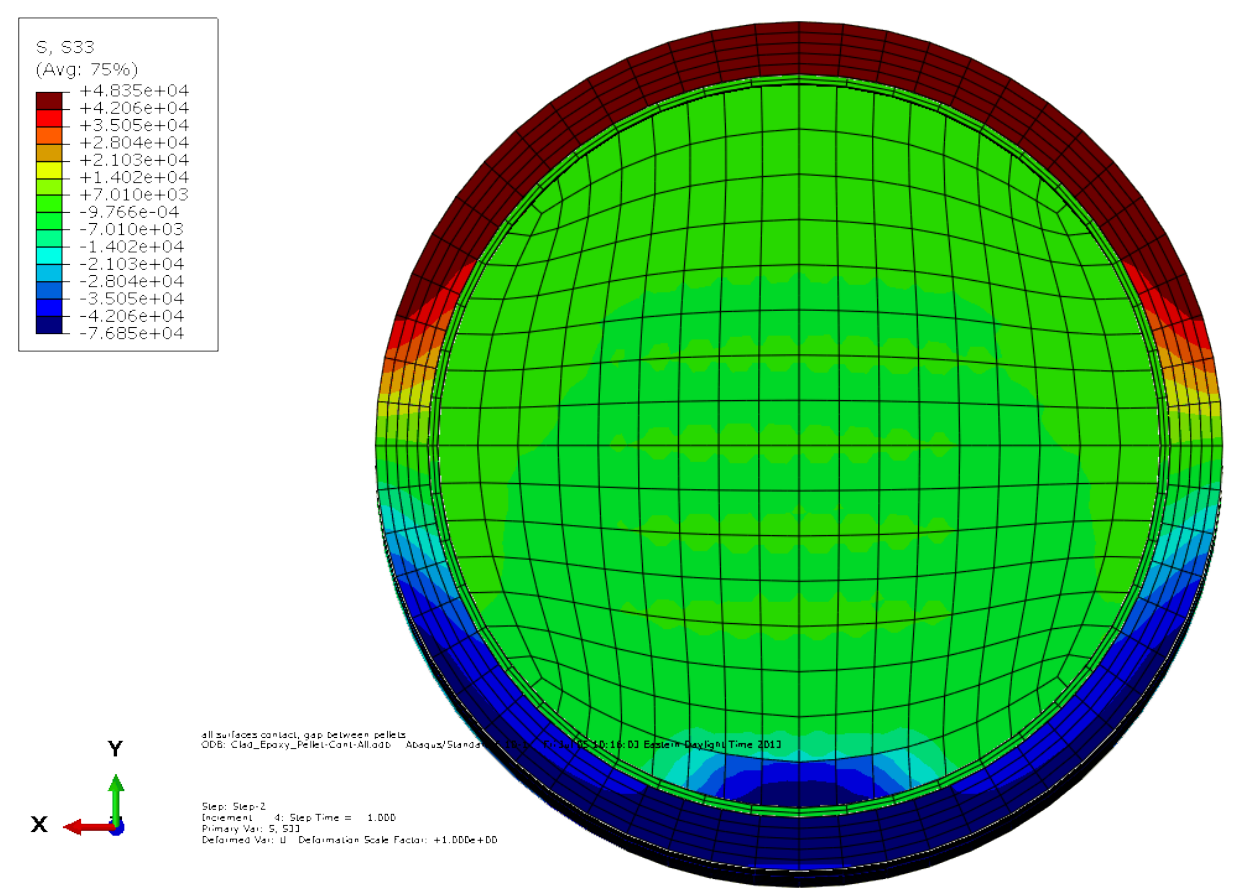

(c) Cross-sectional view of resultant $\sigma z z$ at a pellet-pellet interface

Fig. 19. The resultant stress distribution and curvature of Clad-Epoxy-Pellet section model with four pellets with gaps at de-bonded pellet-pellet interfaces and an epoxy layer at de-bonded pellet-clad interfaces.

The second case in this section is shown in Fig. 20, where a thin epoxy layer is filled at de-bonded pelletclad interfaces and the pellets are all in direct contact to each other with no gaps at the pellet-pellet 
interfaces. The loading and boundary conditions as well as material properties are the same as those of the previous cases.

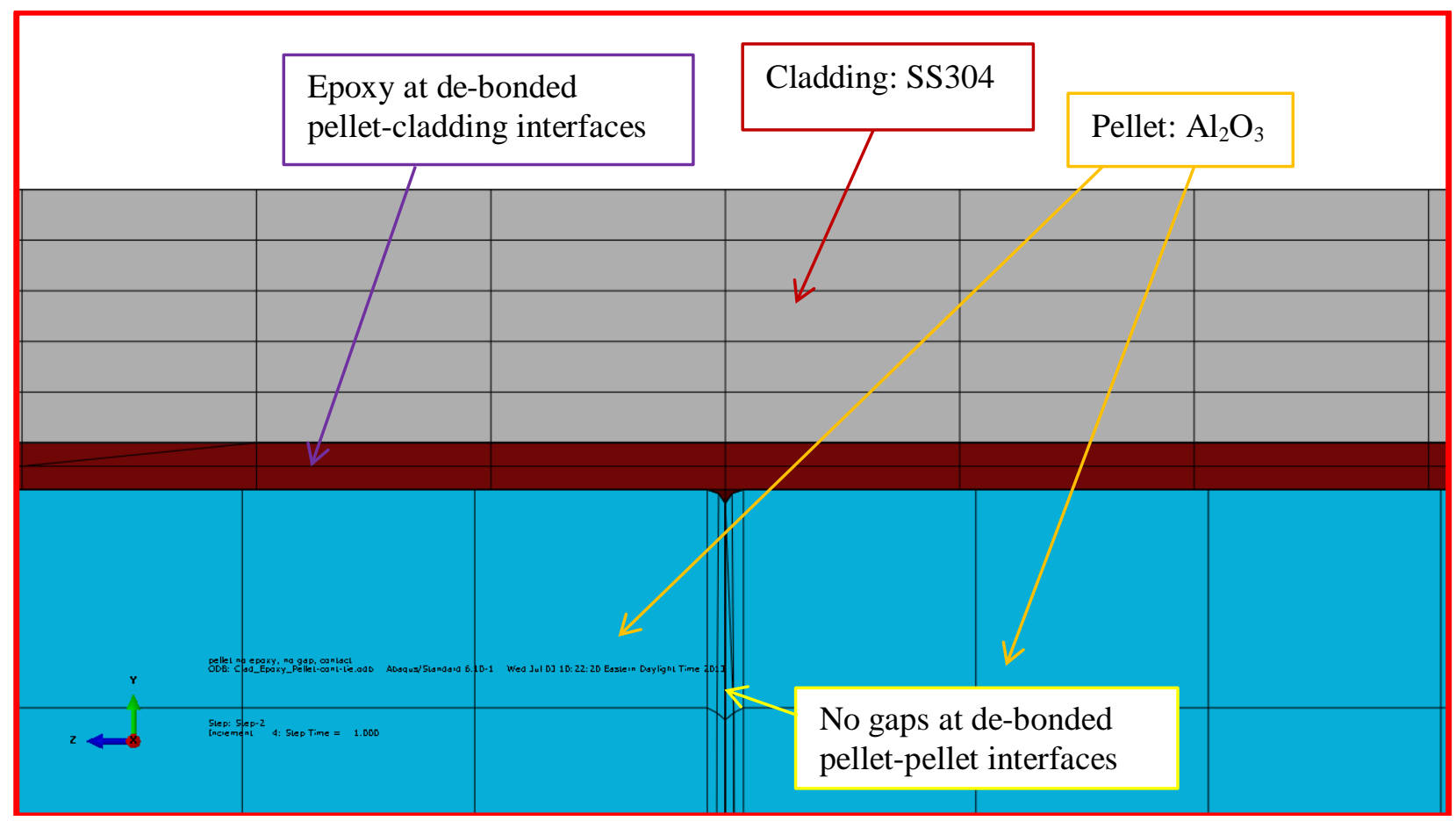

Fig. 20. Zoom-in area of Fig. 4 for the case of no gaps at de-bonded pellet-pellet interfaces and epoxy layer at de-bonded pellet-clad interfaces.

Figure 21 illustrates the surrogate rod responses to the bending moment upon interfacial de-bonding without gaps at the pellet-pellet interfaces. The longitudinal cut view shows that the SS clad yields at the top (tension) region throughout the gauge section but remains elastic at the bottom (compression) region. The maximum stress still occurs at the compression side of pellet region where the pellets are pinning to each other. Figure 21 shows interfacial results similar to those observed in Fig. 17 for the bonded pelletclad interfaces and de-bonded pellet-pellet interfaces without gaps. The pellets carry a large portion of the bending moment resistance via pinching pellet corners and reduce the stress intensity of bottom (compression) portion of the clad. The major difference compared to the results of Fig. 17 is the extensive plastic deformation observed at the top region of the SS tube throughout the entire gauge section, instead of the localized yielding observed at interface region of Fig. 17. Due to the lack of a direct load transferring mechanism from pellet to clad or vice versa due to de-bonded pellet-clad interfaces, the clad takes over the majority of the bending moment resistance. 

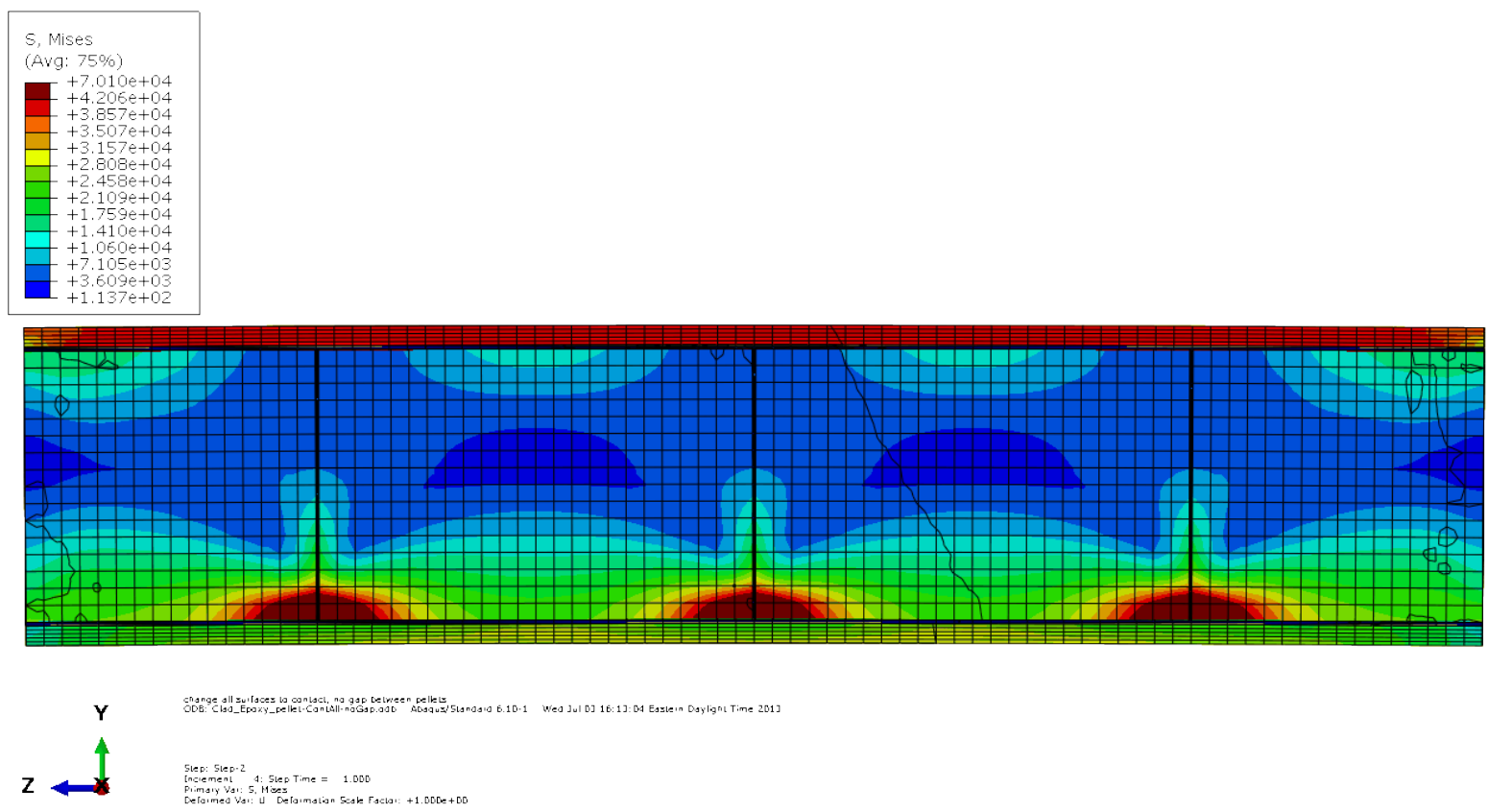

(a) Longitudinal cut view of resultant curvature and von Mises stress

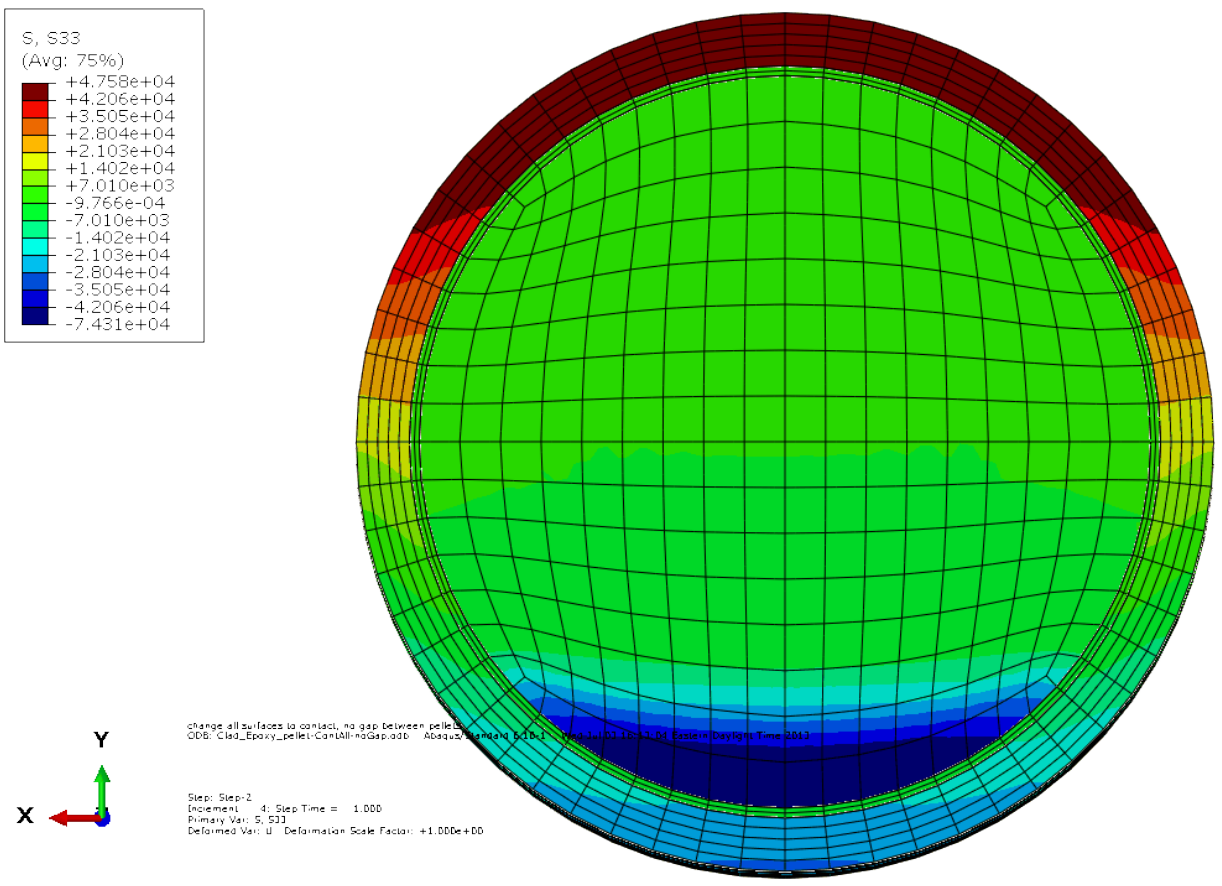

(b) Cross-sectional view of the resultant normal stress, $\sigma z z$, at a pellet-pellet interface.

Fig. 21. The resultant stress distribution and curvature of Clad-Epoxy-Pellet section model with four pellets with no gaps at de-bonded pellet-pellet interfaces and with an epoxy layer at de-bonded pellet-clad interfaces. 
The results of the evaluated curvature and flexural rigidity for the cases of de-bonding at pellet-clad and pellet-pellet interfaces are listed in Table 4. Compared to the results of the de-bonded pellet-pellet interface case listed in Table 3, the flexural rigidities are further decreased by $8 \%$ from $37 \mathrm{~N}^{*} \mathrm{~m}^{2}$ to $34 \mathrm{~N}^{*} \mathrm{~m}^{2}$ for pellets with gap cases and $19 \%$ from $104 \mathrm{~N}^{*} \mathrm{~m}^{2}$ to $84 \mathrm{~N}^{*} \mathrm{~m}^{2}$ for pellets with no gap cases. This result further validates the earlier hypothesis that interface bonding efficiency can significantly affect the flexural rigidity of the surrogate composite rod.

Table 4. The curvature and flexural rigidity for de-bonded pellet-clad and pellet-pellet interfaces

\begin{tabular}{lccc}
\hline & $\begin{array}{c}\text { Curvature, } \mathbf{~} \\
\mathbf{( 1 / \mathbf { m } )}\end{array}$ & $\begin{array}{c}\text { Bending moment, } \boldsymbol{M} \\
\mathbf{( \mathbf { N } ^ { * } \mathbf { m } )}\end{array}$ & $\begin{array}{c}\text { Flexural rigidity, EI } \\
\mathbf{( N *}^{\mathbf{2}} \mathbf{)}\end{array}$ \\
\hline $\begin{array}{l}\text { Clad-Epox-Pellet4-Contact- } \\
\text { Pellet-Contact-Gap }\end{array}$ & 0.727 & 25 & 34 \\
$\begin{array}{l}\text { Clad-Epoxy-Pellet4-Contact- } \\
\text { Pellet-Contact-noGap }\end{array}$ & 0.298 & 25 & 84 \\
\hline
\end{tabular}

In Table 4, the flexural rigidity of the case with no gaps at pellet-pellet interfaces is 2.5 times of that of the case with gaps. In Table 3, the ratio of the flexural rigidity is 2.8 times greater for the same comparison. The reason for the large increase in the flexural rigidity is the direct contact of the pellets at the pellet-pellet interfaces at the compression side. The direct pellet-pellet contact interaction also provides a significant increase in bending moment resistance; the above results in much less curvature deformation, as shown in Table 4.

\subsection{DE-BONDED PELLET-CLAD INTERFACE AND PELLET-PELLET INTERFACE WITH GAP}

In one out-of-cell surrogate rod test, bending deformation measurements were performed on a SSAP specimen with no epoxy bonding. Ten alumina pellets were inserted into a 6-in.-long SS tube with no gaps at the pellet-pellet interfaces.

A Clad-Pellet section model with four pellets is shown in Fig. 22. The surrogate rod is simulated with the same materials and dimensions as those of the previous Clad-Epoxy-Pellet section model. The difference is that no epoxy is used in the surrogate rod to provide cohesion bonding in the model, especially at pellet-clad interfaces. The first simulation case of the non-filled gaps at interfaces is shown in Fig. 23. The sizes of the gaps at pellet-clad and pellet-pellet interfaces are 0.0014 and 0.005 in., respectively. The boundary condition is the same as that of the previous cases, except the bending moment was set at $20 \mathrm{~N}^{*} \mathrm{~m}$, as was used in the testing. 


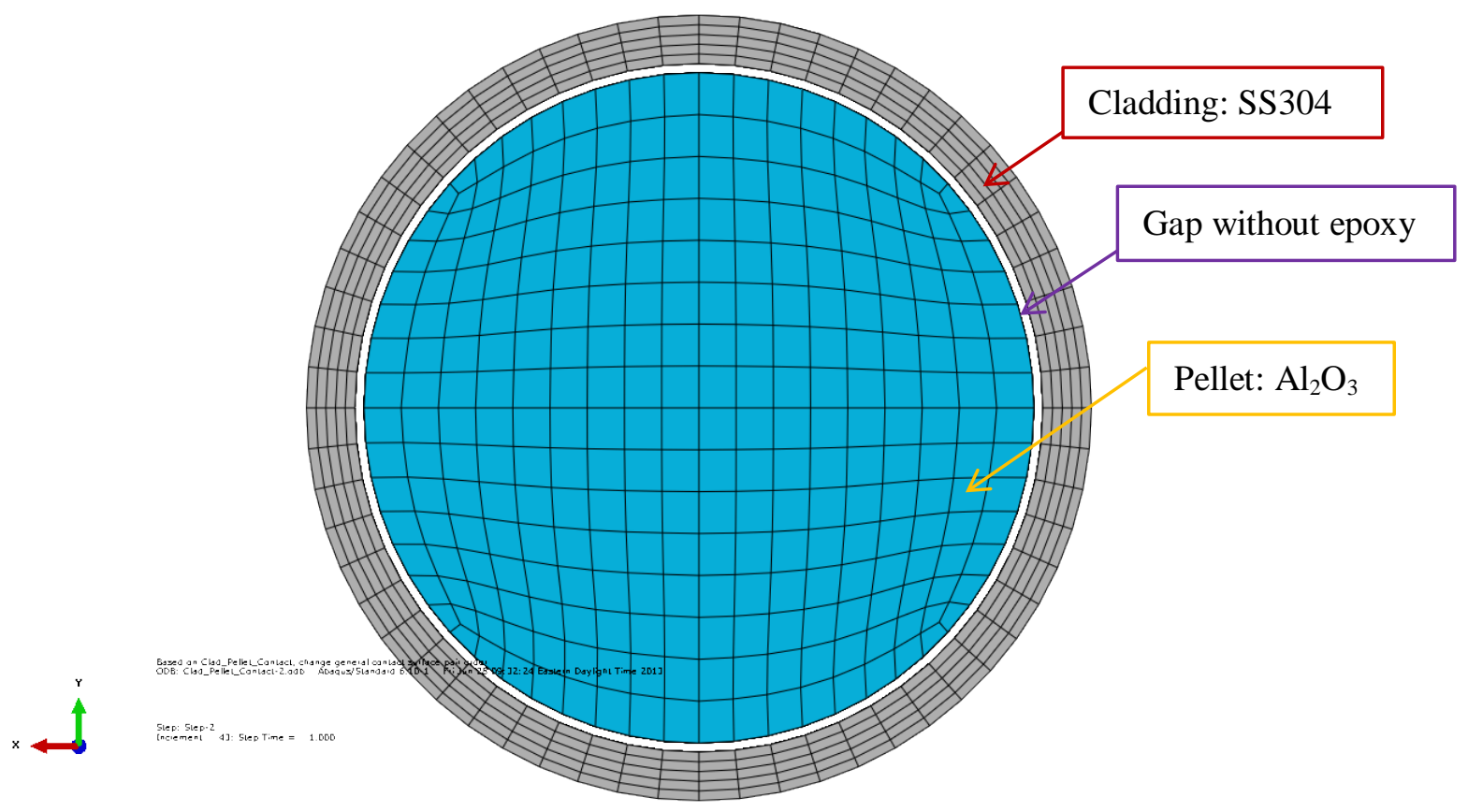

Fig. 22. Geometry of Clad-Pellet section model with four pellets.

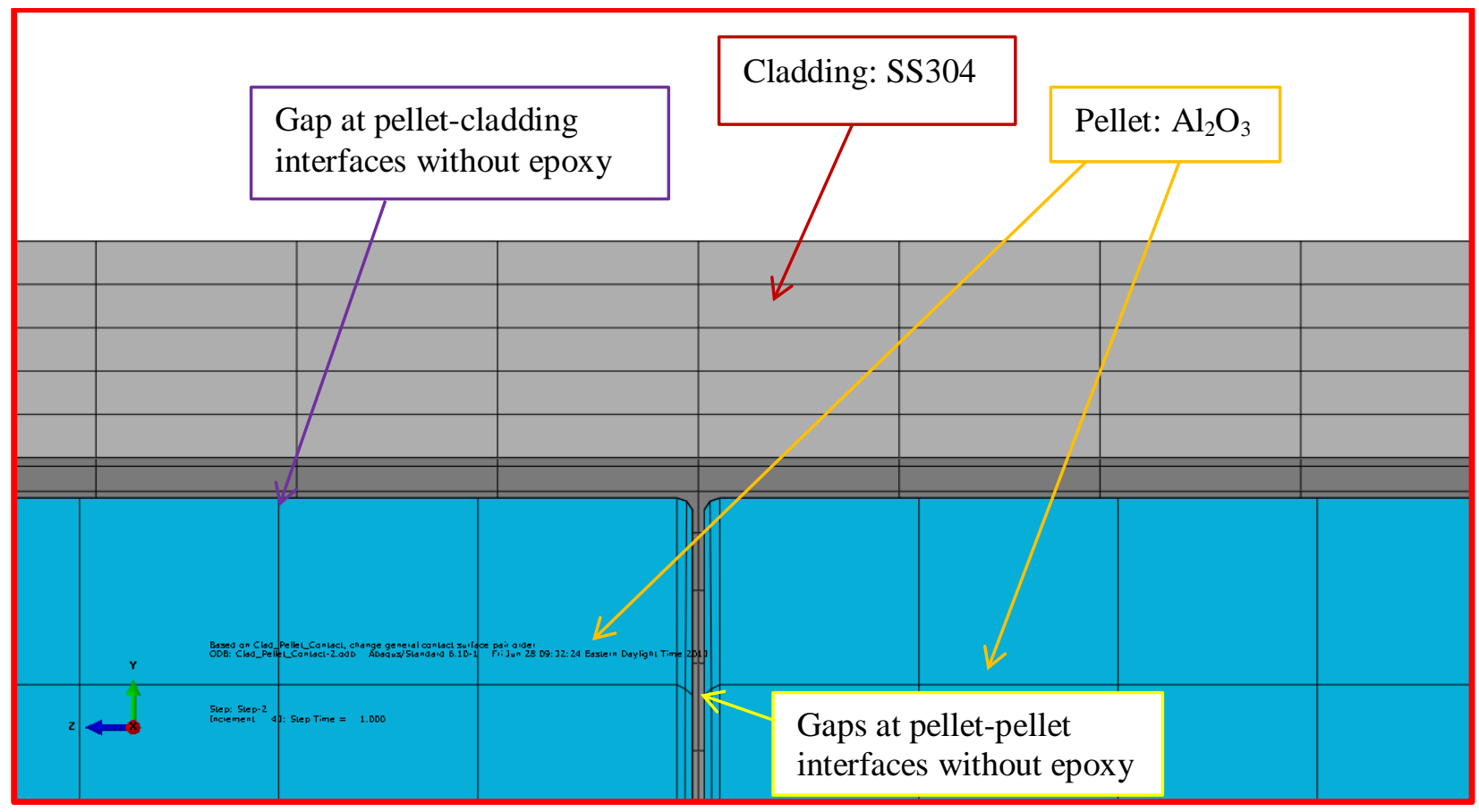

Fig. 23. Zoom-in area of Fig. 4 for the case of gaps at pellet-clad and pellet-pellet interfaces with no epoxy bonding.

The stress distribution of the non-epoxy-filled gaps scenario is shown in Fig. 24, which is similar to that of the interfacial de-bonding case illustrated in Fig. 19. The SS clad yields over the entire gauge section, and the maximum stress resides at the SS clad region. No stress concentration or typical dog-bone shape stress distribution was observed in the pellets. The results indicate that the SS clad bears almost all of the 
load capacity. The pellets move around in the gaps to get balance under the bending deformation, especially the center two pieces. The pellets only provide very limited support to the clad via contact; therefore, they carry only marginal bending moment resistance, as indicated in the resultant $\sigma_{\mathrm{zz}}$ of Fig. 24. The associated curvature is about $0.467 \mathrm{~m}^{-1}$.
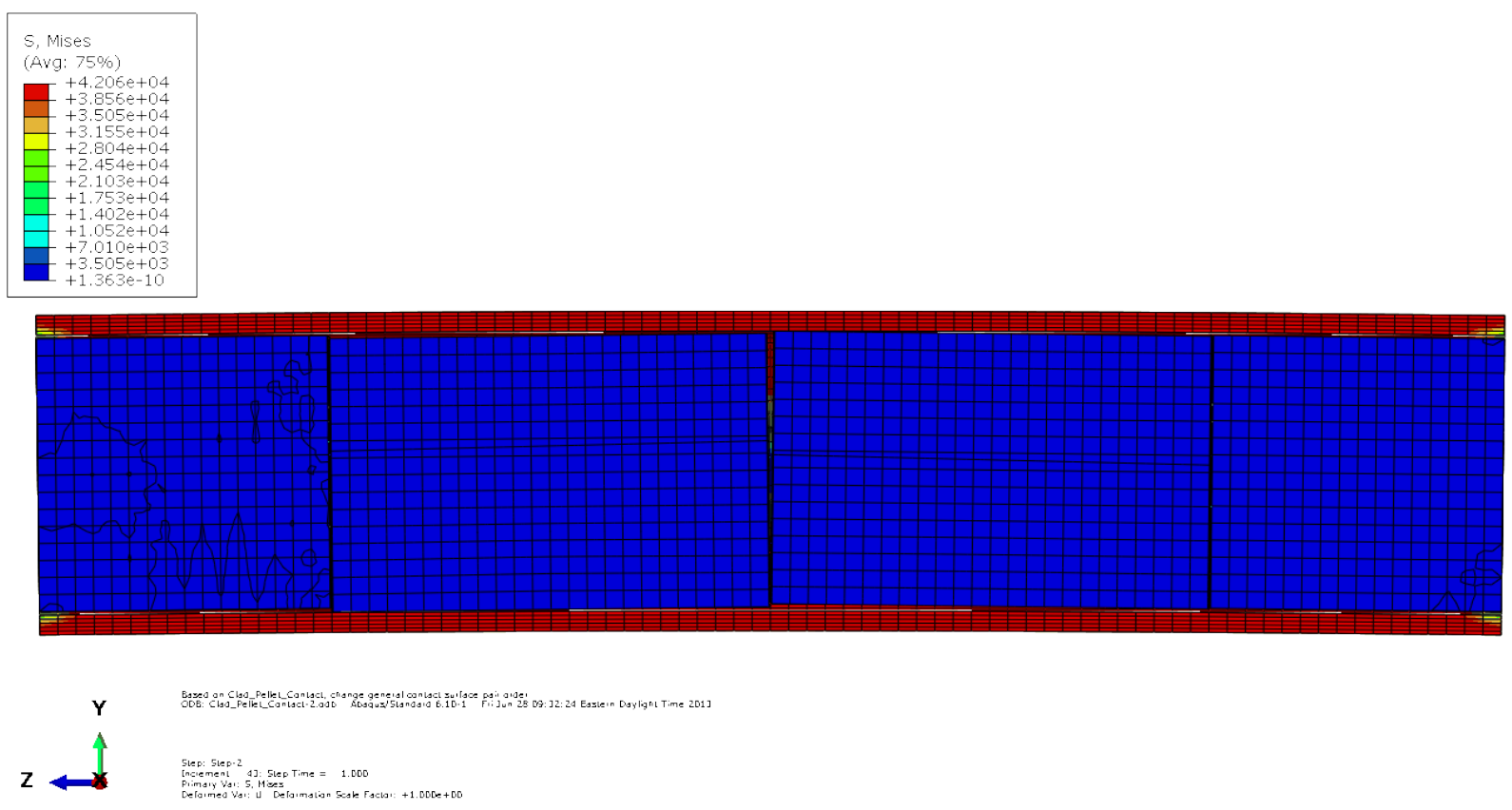

(a) Longitudinal cut view of resultant curvature and von Mises stress

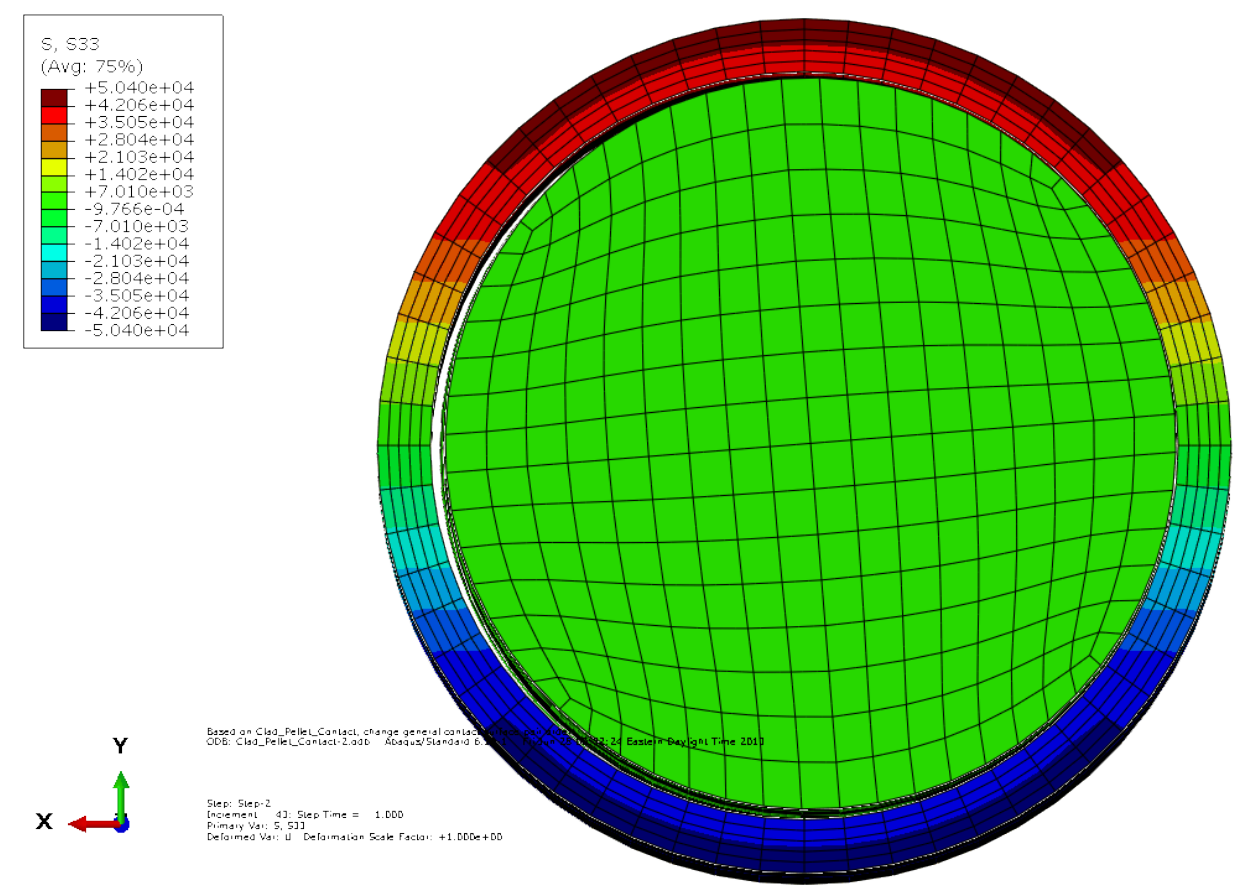

(b) Cross-sectional view of resultant $\sigma \mathrm{zz}$ at a pellet-pellet interface

Fig. 24. Resultant stress distribution and curvature of Clad-Pellet section model with four pellets and gaps at pellet-clad and pellet-pellet interfaces without epoxy bonding. 
As in the previous section, the second simulation case eliminated the gaps at pellet-pellet interfaces that were assigned in the first case, as shown in Fig. 25. The "general contact" algorithm was used for those interfaces in FEA. The bending moment was set at $20 \mathrm{N*m}$ to match that used in surrogate rod testing.

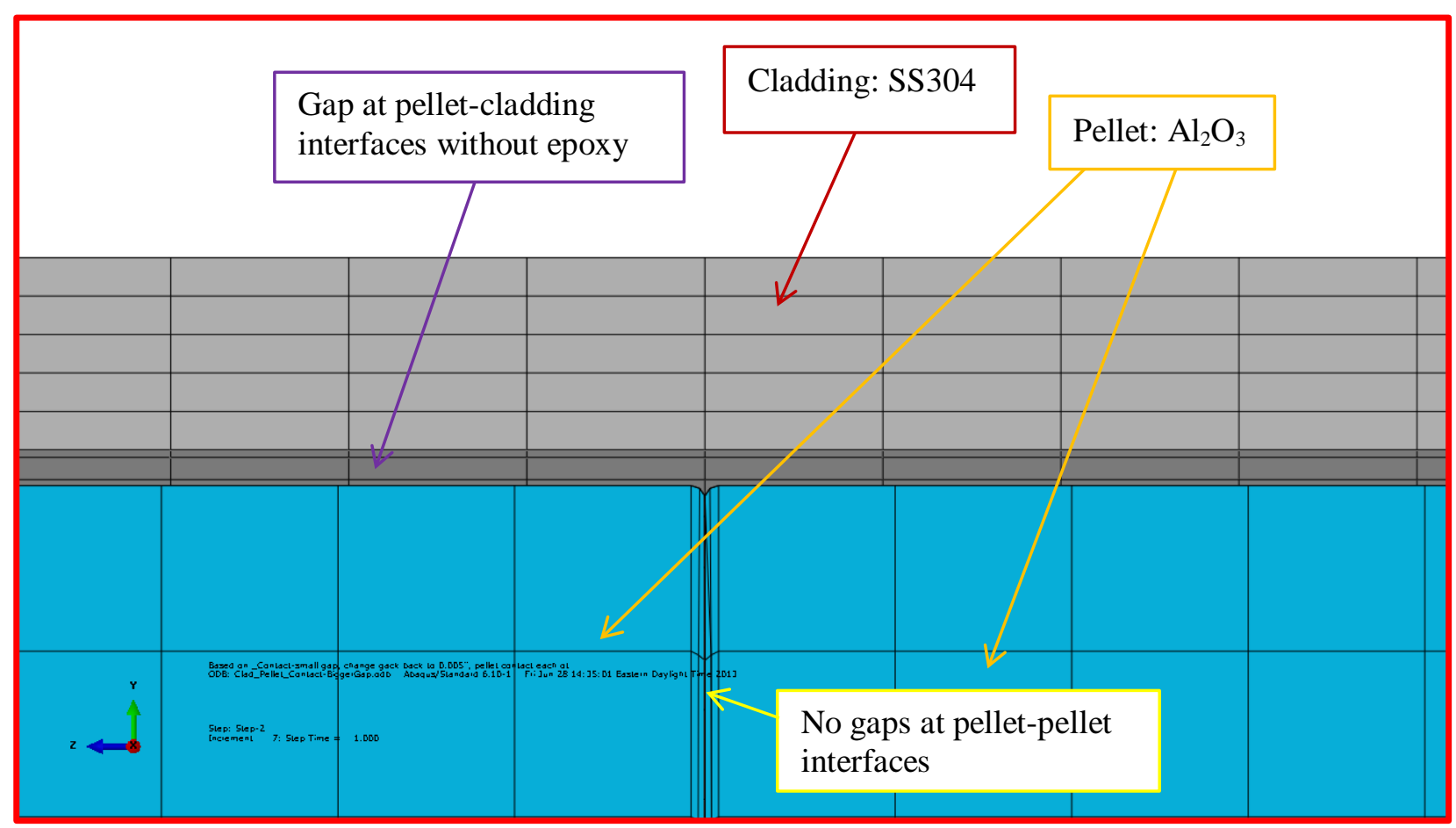

Fig. 25. Zoom-in area of Fig. 4 for the case of no gaps at pellet-pellet interfaces and gaps at pellet-clad interfaces with no epoxy bonding.

The FEA results for interfaces with no epoxy bonding and no gaps at pellet-pellet interfaces, as illustrated in Fig. 26, are similar to those shown in Fig. 21 for the de-bonded interfaces with no gaps at pellet-pellet interfaces. The SS clad yields at the top (tension) region throughout the entire gage section. Due to direct pellet contact without gaps, the pinned pellets, at the bottom (compression) portion of the pellet-pellet interface region, can take over a large portion of the bending load. This can significantly reduce the compressive stress in the clad region; the maximum stress of the surrogate rod resides at the pellets pinning regions. The resultant $\sigma_{\mathrm{zz}}$ shows that only the compression side of pinned pellets is responsible for the bending moment resistance, while very small resultant $\sigma_{\mathrm{zz}}$ appears at the tension side of pellet regions. The induced curvature is relatively small, $0.211 \mathrm{~m}^{-1}$, due to increased stiffness provided by the directly pinned pellets; that is, the pellets carry a significant portion of bending moment resistance. 

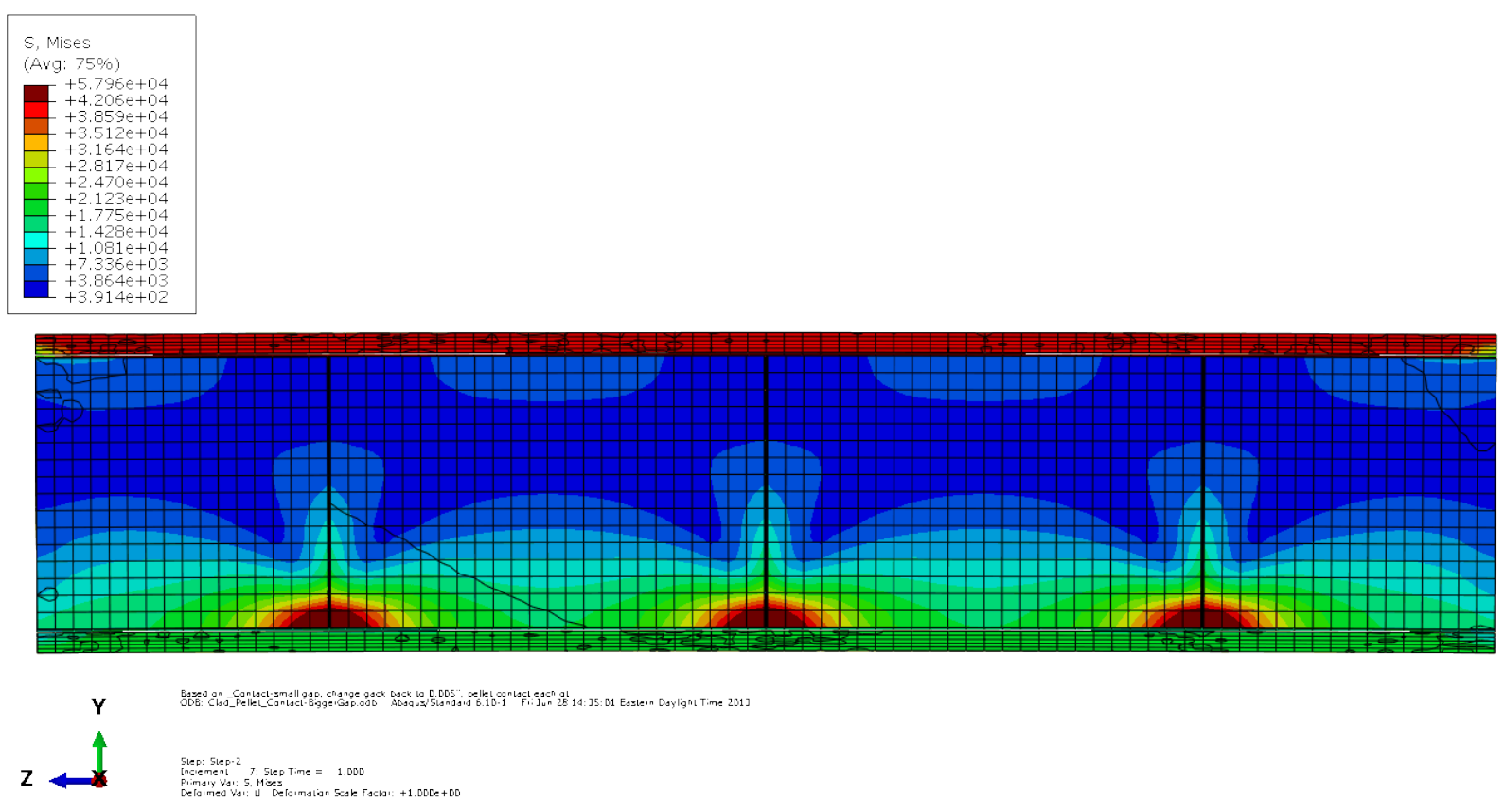

(a) Longitudinal cut view of resultant curvature and von Mises stress

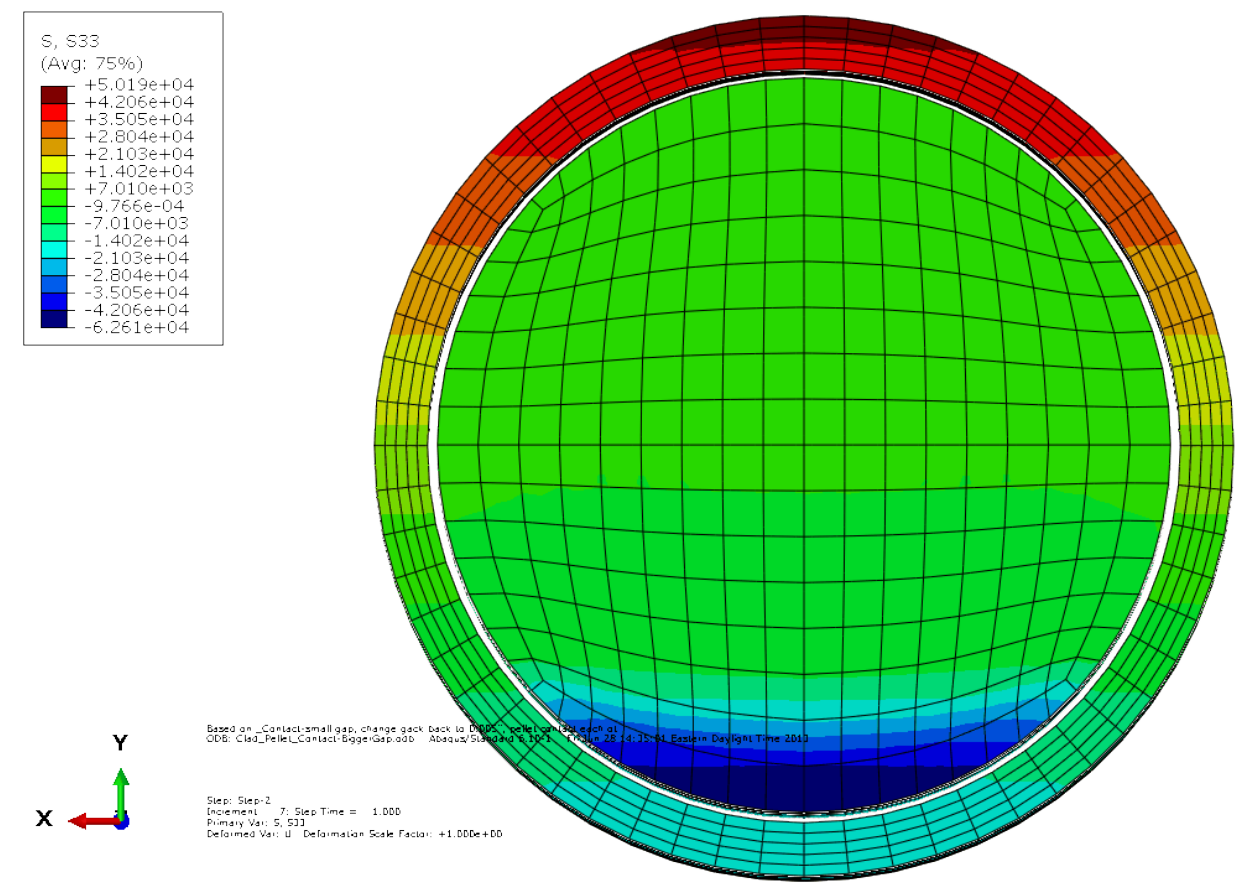

(b) Cross section view of resultant $\sigma \mathrm{zz}$ at a pellet-pellet interface

Fig. 26. Resultant stress distribution and curvature of Clad-Pellet section model with four pellets and gaps at pellet-clad interfaces with no epoxy bonding and no gaps at pellet-pellet interfaces.

Table 5 summarizes the curvature and flexural rigidity for the two simulation cases with no epoxy bonding at pellet-clad and pellet-pellet interfaces. Compared to the results of Table 4 for all interface de- 
bonding cases, the estimated flexural rigidities are increased by $10 \mathrm{~N}^{*} \mathrm{~m}^{2}$. This is due to direct (hard) contact with no epoxy at interfaces. The ratio of flexural rigidity between the cases of no gaps and gaps at pellet-pellet interfaces is 2.2, which is similar to that provided in Table 4.

Table 5. The curvature and flexural rigidity for pellet-clad and pellet-pellet interfaces with no epoxy bonding simulation

\begin{tabular}{|c|c|c|c|}
\hline & $\begin{array}{c}\text { Curvature, } \kappa \\
(1 / \mathrm{m})\end{array}$ & $\begin{array}{c}\text { Bending moment, } M \\
\left(\mathrm{~N}^{*} \mathrm{~m}\right)\end{array}$ & $\begin{array}{l}\text { Flexural rigidity, } E I \\
\left(\mathrm{~N}^{*} \mathrm{~m}^{2}\right)\end{array}$ \\
\hline $\begin{array}{l}\text { Clad-Pellet4-Contact-Pellet- } \\
\text { Contact-Gap }\end{array}$ & 0.467 & 20 & 43 \\
\hline $\begin{array}{l}\text { Clad-Pellet4-Contact-Pellet- } \\
\text { Contact-noGap }\end{array}$ & 0.211 & 20 & 95 \\
\hline
\end{tabular}

Testing data of the SSAP02 specimen, without epoxy bond, are shown in Fig. 27. The results from bend testing are very similar to those of the first FEA simulation case, with gaps at interfaces and with no epoxy bonding, from the perspective of both curvature and flexural rigidity. This may indicate that there are gaps at the interfaces of the SSAP02 specimen.

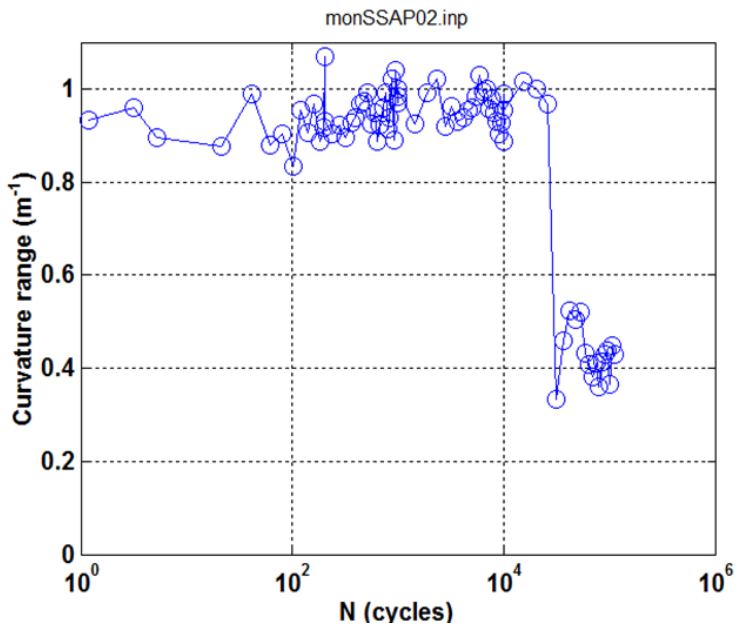

(a)

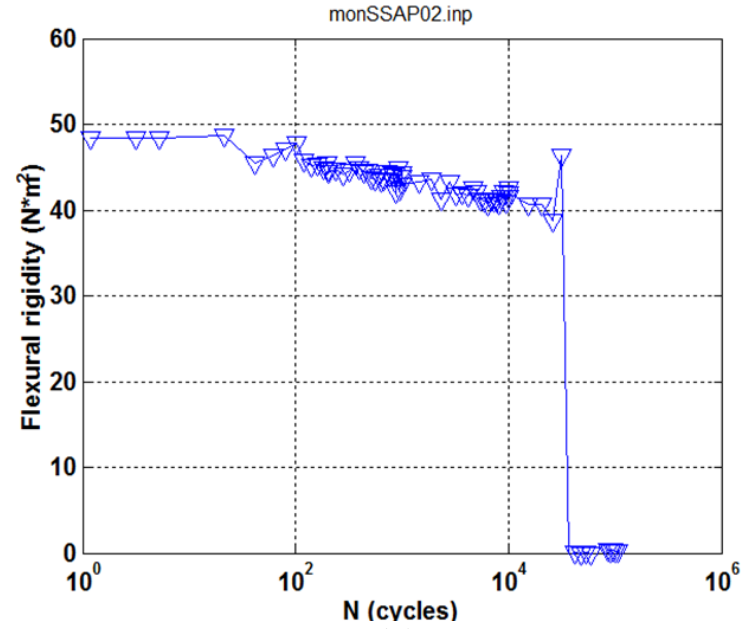

(b)

Fig. 27. Bending fatigue test results of SSAP02 specimen (with no epoxy bonding) under displacement control: (a) the curvature, (b) the flexural rigidity [4].

\subsection{VARIATIONS IN PELLETS LOCATIONS WITHIN GAGE SECTION}

In this section, the effect of pellet location variation within the gauge section on the flexural response under bending load was studied. As illustrated in Fig. 28, three pellets are contained in Clad-Epoxy-Pellet section model and the middle pellet is located at the center of the gauge section. The surrogate rod consists of the SS clad and alumina pellets with epoxy bonding. The materials of the components are the same as that listed in Table 1. Loading and boundary conditions are the same as the Clad-Epoxy-Pellet section model with four pellets.

In this section two cases were studied for the Clad-Epoxy-Pellet section model with three pellets, as shown in Figs. 29 and 30. In Fig. 29, there are no gaps at the pellet-pellet interfaces, while at the pellet- 
clad interfaces, the surfaces are tie to a thin epoxy layer to simulate full cohesion bonding. This case is similar to that shown in Fig. 16 of the model with four pellets.

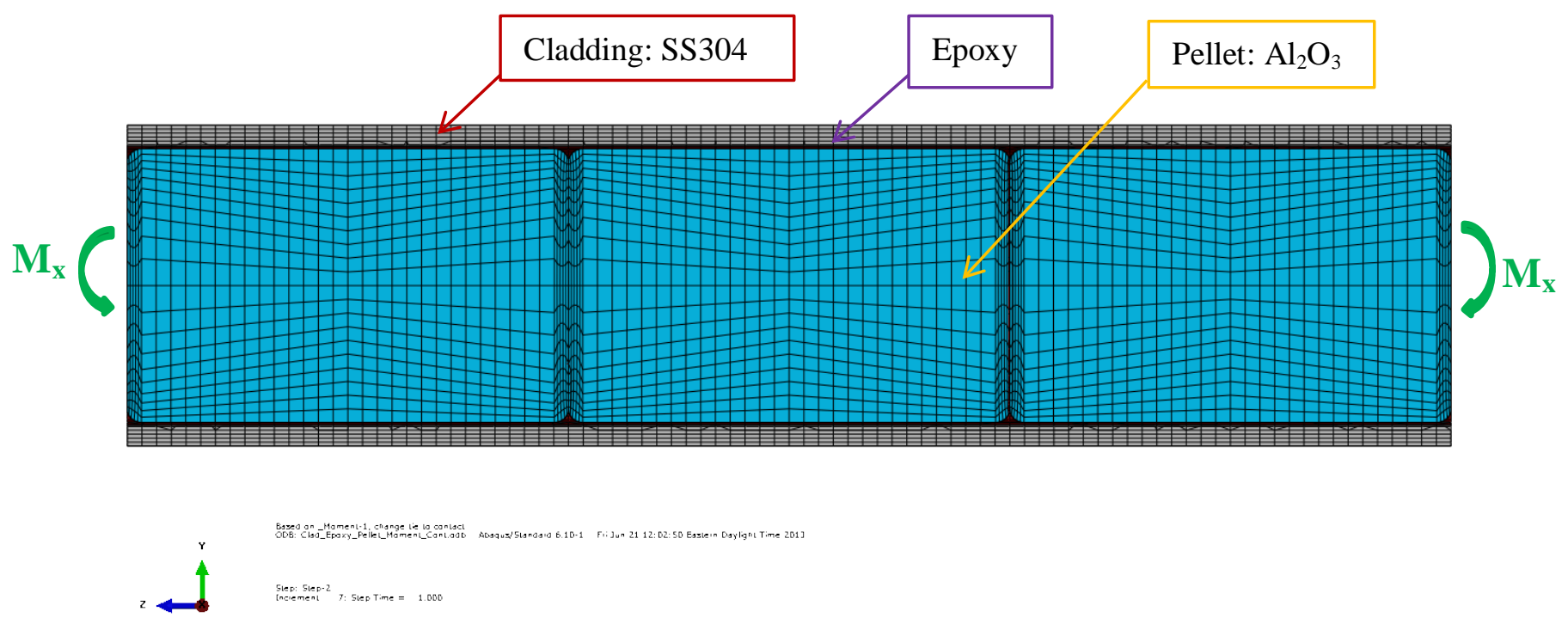

Fig. 28. Geometry of Clad-Epoxy-Pellet section model with three pellets.

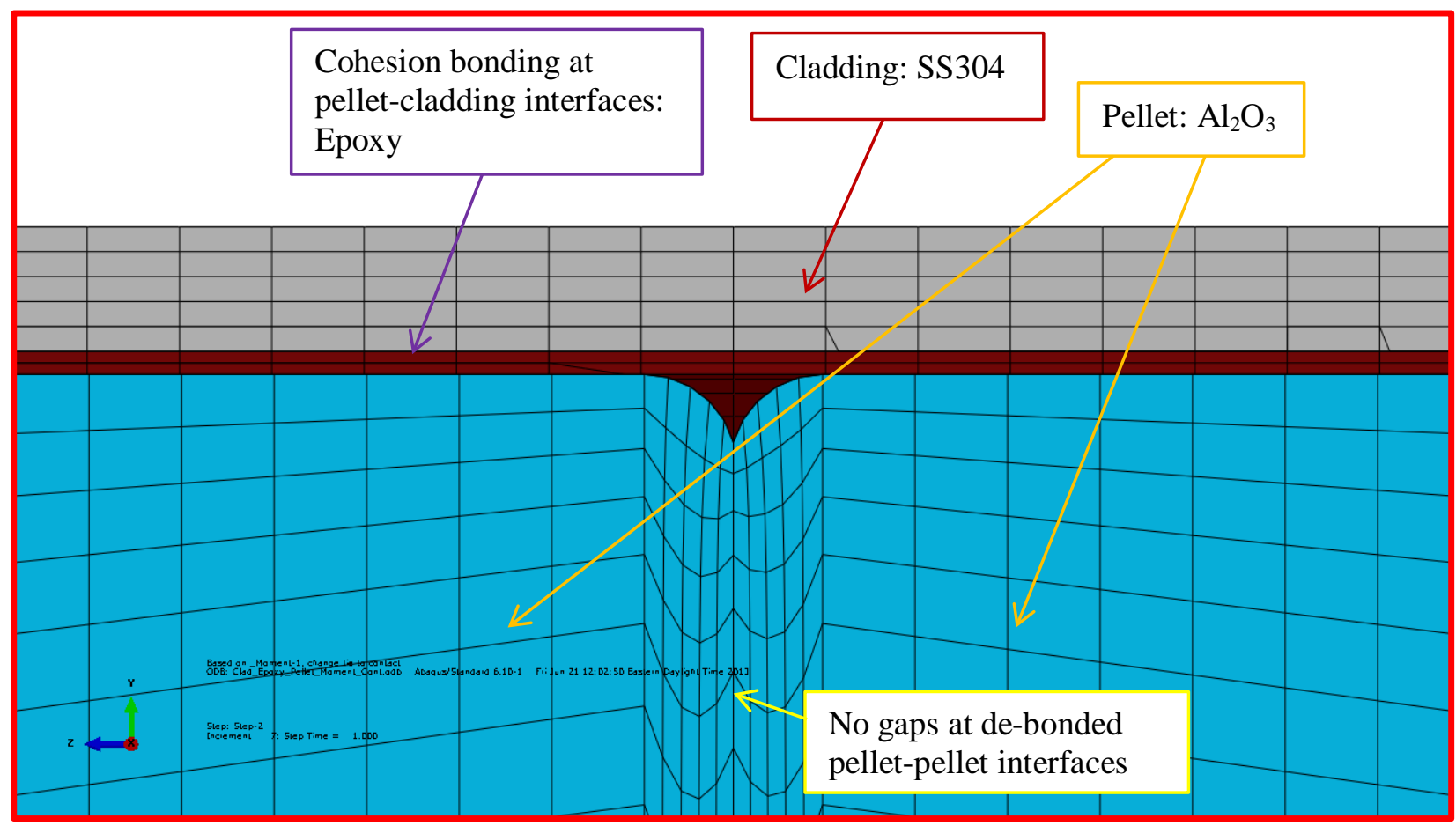

Fig. 29. Zoom-in area of Fig. 4 for the case of no gaps at de-bonded pellet-pellet interfaces and epoxy bonding at pellet-clad interfaces in the section model with three pellets. 

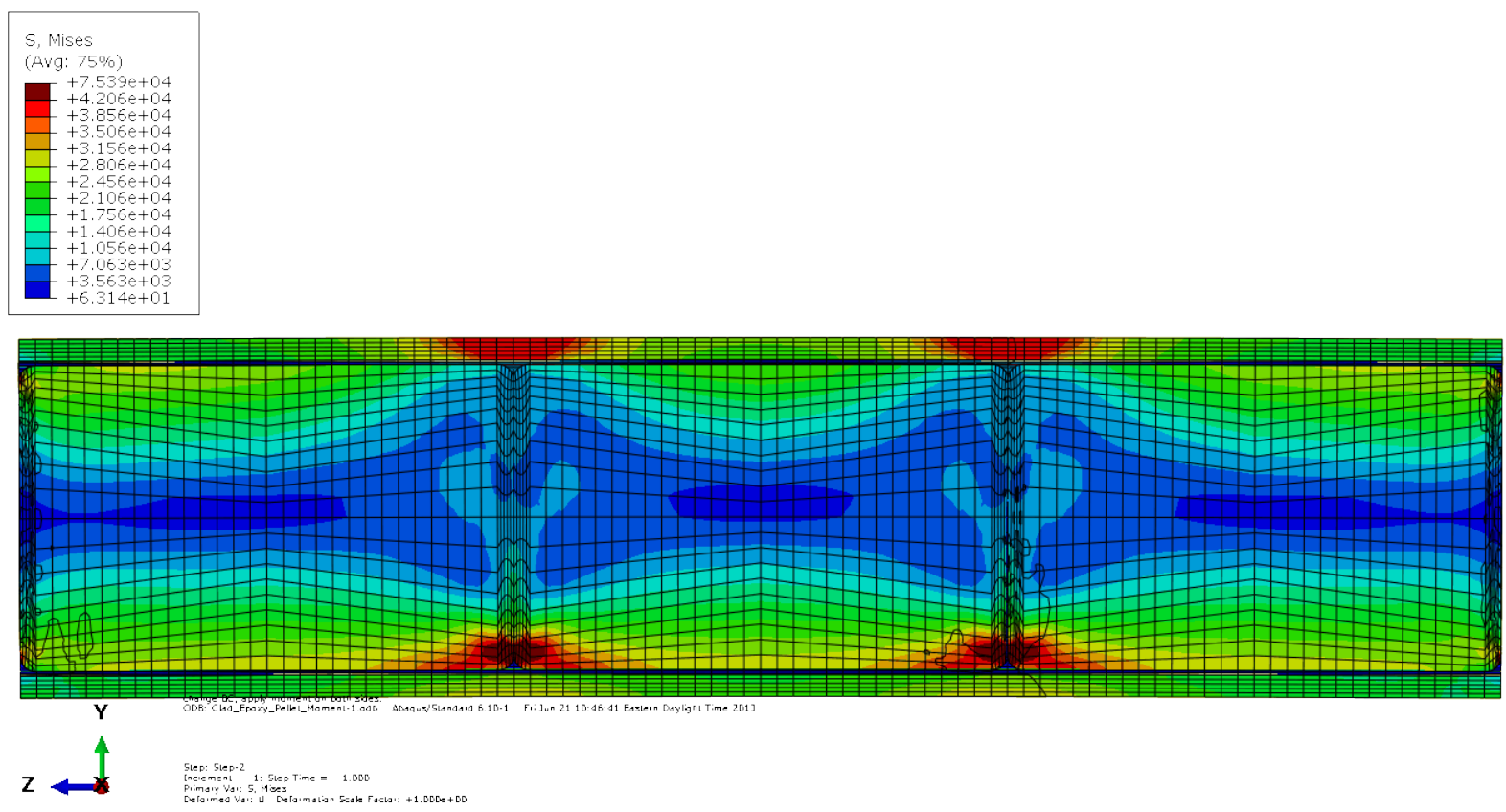

(a) Longitudinal cut view of resultant curvature and von Mises stress

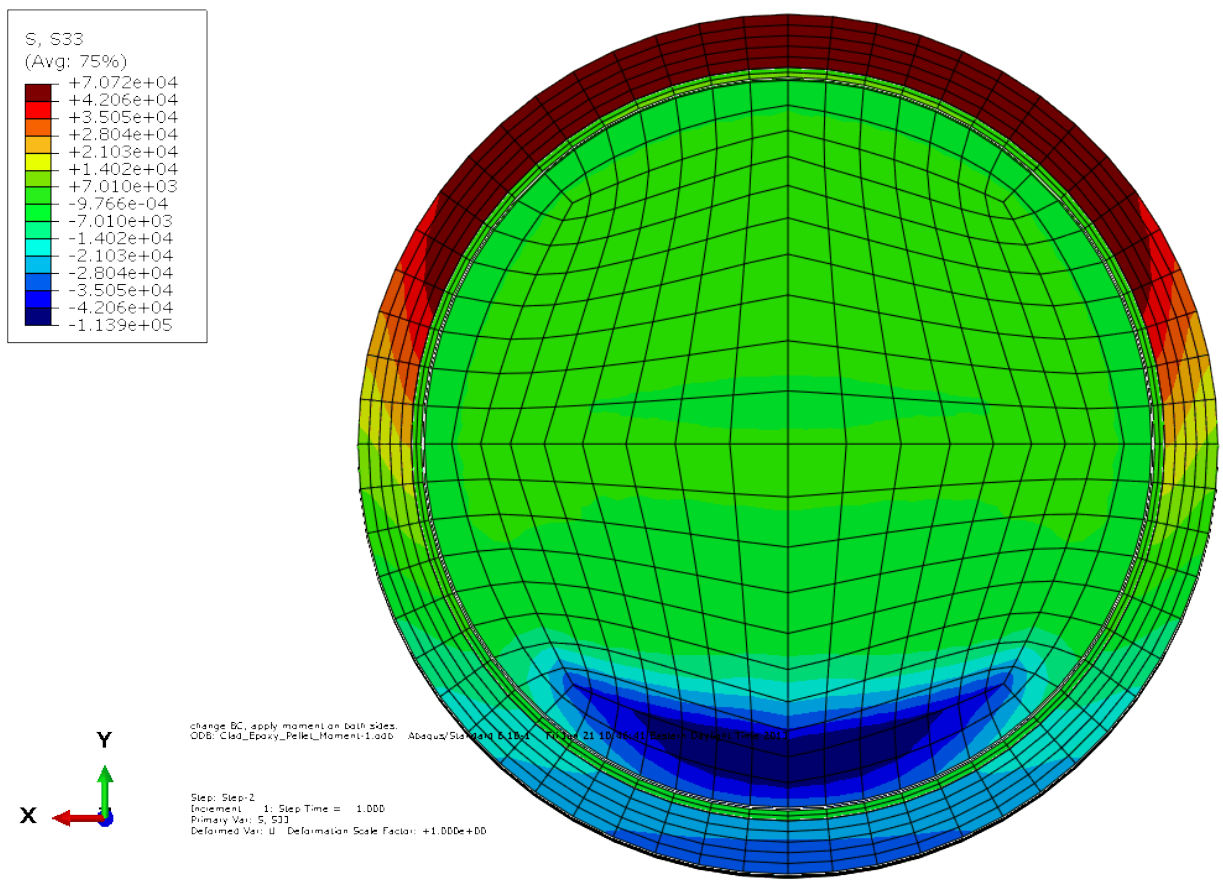

(b) Cross-sectional view of resultant $\sigma \mathrm{zz}$ at a pellet-pellet interface

Fig. 30. Resultant stress distribution and curvature of Clad-Pellet section model with three pellets and epoxy bonding at pellet-clad interfaces with no gaps at pellet-pellet interfaces.

Compared to the results of Figs. 17 and 31, both have similar boundary conditions and reveal similar stress distributions. For instance, the SS clad yields locally at the top (tension) portion of the pellet-pellet interface region and the maximum stress is located at the pinned pellet corners. The pellet stress contours 
show a typical dog-bone shape due to the pellet-pellet contact pressure. The induced curvature of 0.229 $\mathrm{m}^{-1}$ is slightly lower than the curvature of $0.241 \mathrm{~m}^{-1}$ shown in Fig. 17.

The second case of the section model with three pellets is the same as that of the first case, but the pelletclad interfaces were de-bonded, as shown in Fig. 31.This case is similar to the case of Fig. 20 for the model with four pellets.

Despite the difference in pellet positions at the gauge section, both Figs. 32 and 21 show very similar resultant stress profiles and curvature for the de-bonded pellet-clad interfaces case. The SS tube yields throughout the top (tension) region, and the maximum stress resides at the pellet pinching corner. The induced curvature is $0.307 \mathrm{~m}^{-1}$, which is similar to a curvature of $0.298 \mathrm{~m}^{-1}$ obtained from Fig. 21.

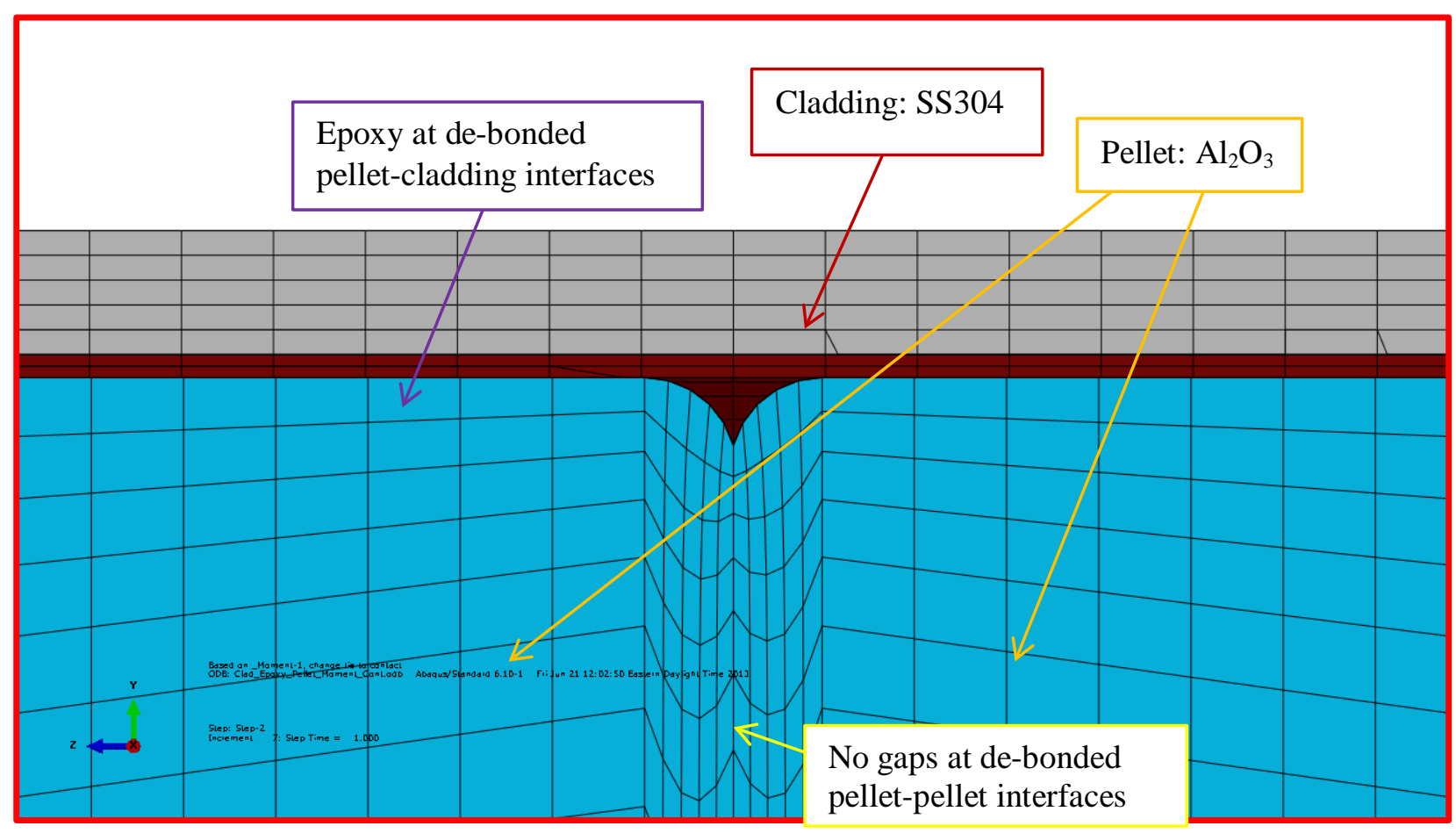

Fig. 31. Zoom-in area of Fig. 4 for the case of no gaps at de-bonded pellet-pellet interfaces and epoxy contact at de-bonded pellet-clad interfaces in the section model with three pellets. 

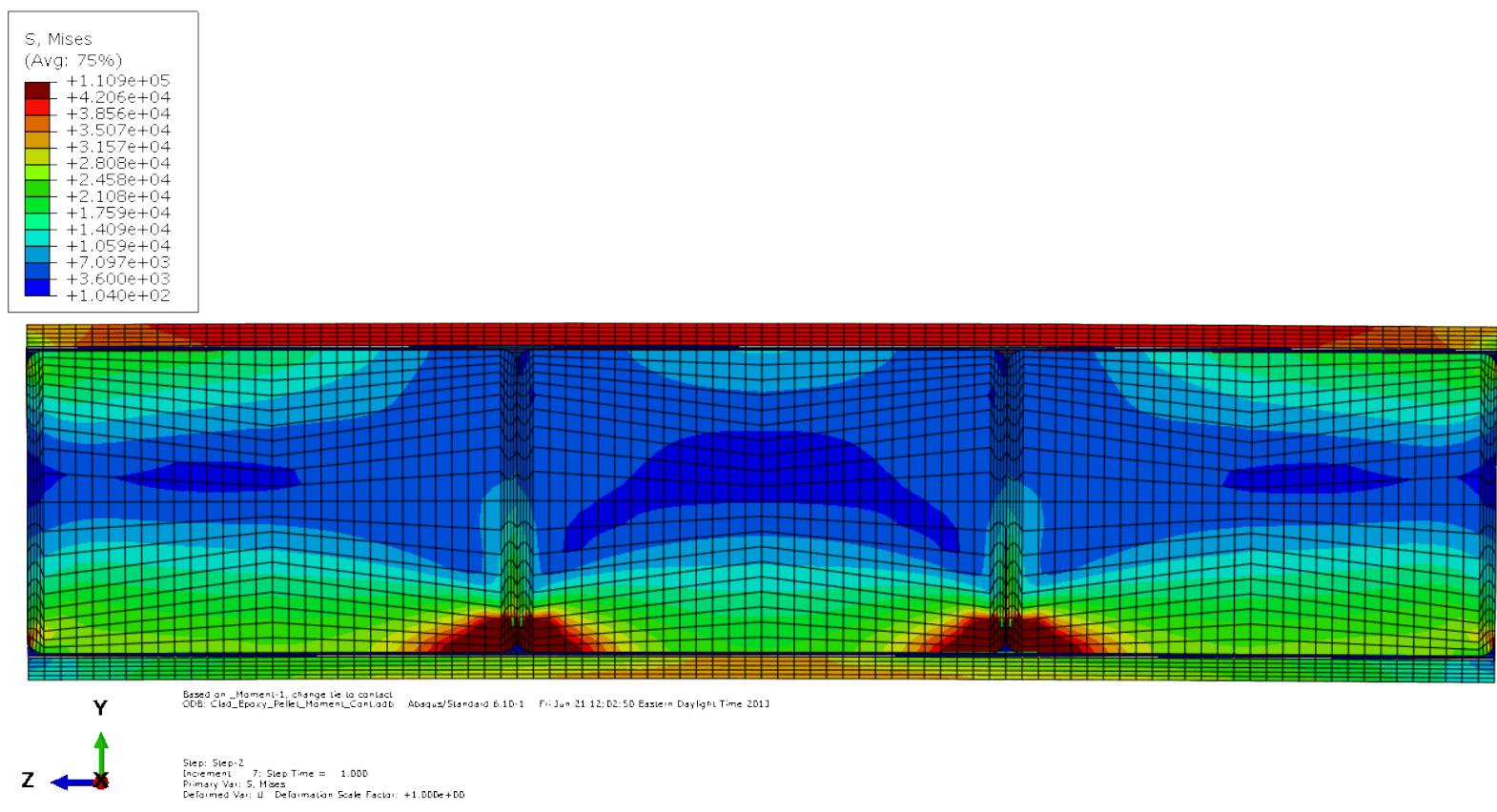

(a) Longitudinal cut view of resultant curvature and von Mises stress

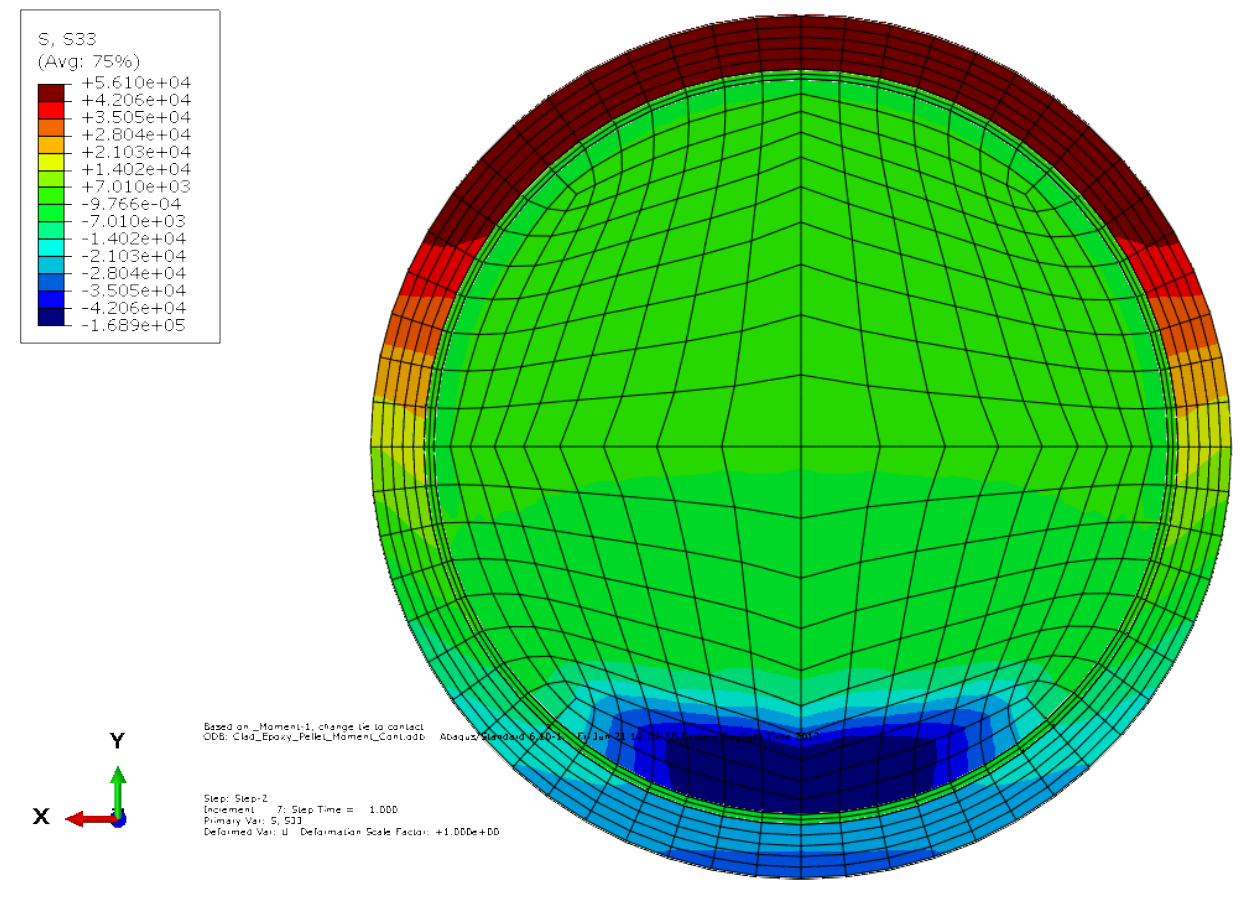

(b) Cross-sectional view of resultant $\sigma \mathrm{zz}$ at a pellet-pellet interface

Fig. 32. Resultant stress distribution and curvature of Clad-Pellet section model with three pellets, with filled epoxy at de-bonded pellet-clad interfaces and no gaps at de-bonded pellet-pellet interfaces.

The curvature and flexural rigidity for Clad-Epoxy-Pellet section model with three pellet simulation cases are summarized in Table 6 . The estimated flexural rigidity of epoxy bonding at pellet-clad interfaces is 
$109 \mathrm{~N}^{*} \mathrm{~m}^{2}$, about a 5\% difference compared to that of the similar case with four pellets $\left(104 \mathrm{~N}^{*} \mathrm{~m}^{2}\right)$. The flexural rigidity of the de-bonded pellet-clad case is $81 \mathrm{~N}^{*} \mathrm{~m}^{2}$, an $\sim 2 \%$ difference compared to that of the similar case with four pellets $\left(83 \mathrm{~N}^{*} \mathrm{~m}^{2}\right)$. Therefore, the pellet position variation will have a very limited impact on the surrogate rod system response under bending deformation.

Table 6. The curvature and flexural rigidity for Clad-Epoxy-Pellet section model with three pellet cases

\begin{tabular}{|c|c|c|c|}
\hline & $\begin{array}{c}\text { Curvature, } \kappa \\
(1 / \mathrm{m})\end{array}$ & $\begin{array}{l}\text { Bending moment, } M \\
\left(\mathrm{~N}^{*} \mathrm{~m}\right)\end{array}$ & $\begin{array}{c}\text { Flexural rigidity, } E I \\
\left(\mathrm{~N}^{*} \mathbf{m}^{2}\right)\end{array}$ \\
\hline $\begin{array}{l}\text { Clad-Epoxy-Pellet3-Tie-Pellet- } \\
\text { Contact-noGap }\end{array}$ & 0.229 & 25 & 109 \\
\hline $\begin{array}{l}\text { Clad- Epoxy-Pellet3-Contact- } \\
\text { Pellet-Contact-noGap }\end{array}$ & 0.307 & 25 & 81 \\
\hline
\end{tabular}

All the above FEA simulations were based on load/moment control mode. In the Clad-Epoxy-Pellet section model with three pellets, the FEA was also carried out with a displacement-controlled procedure, in which rotations were applied to the surrogate rod to induce flexural deformation.

The FEA simulation cases in Figs. 29 and 32 are repeated with a rotation angle of 0.005 rad applied at the both ends of the surrogate rod, and the induced curvature is about $0.219 \mathrm{~m}^{-1}$.

The system responses under the displacement control are shown in Figs. 33 and 34 for the pellet-clad interface bonding and de-bonding cases, respectively. The FEA results are similar to those using a load control procedure under the same conditions shown in Figs. 30 and 32, except for the case of epoxy bonding at the pellet-clad interfaces (Fig. 33), where the SS clad locally yields both at the top and bottom portions of pellet-pellet interfaces. The maximum stresses for both cases occur at the pellet-pellet pinching corners.

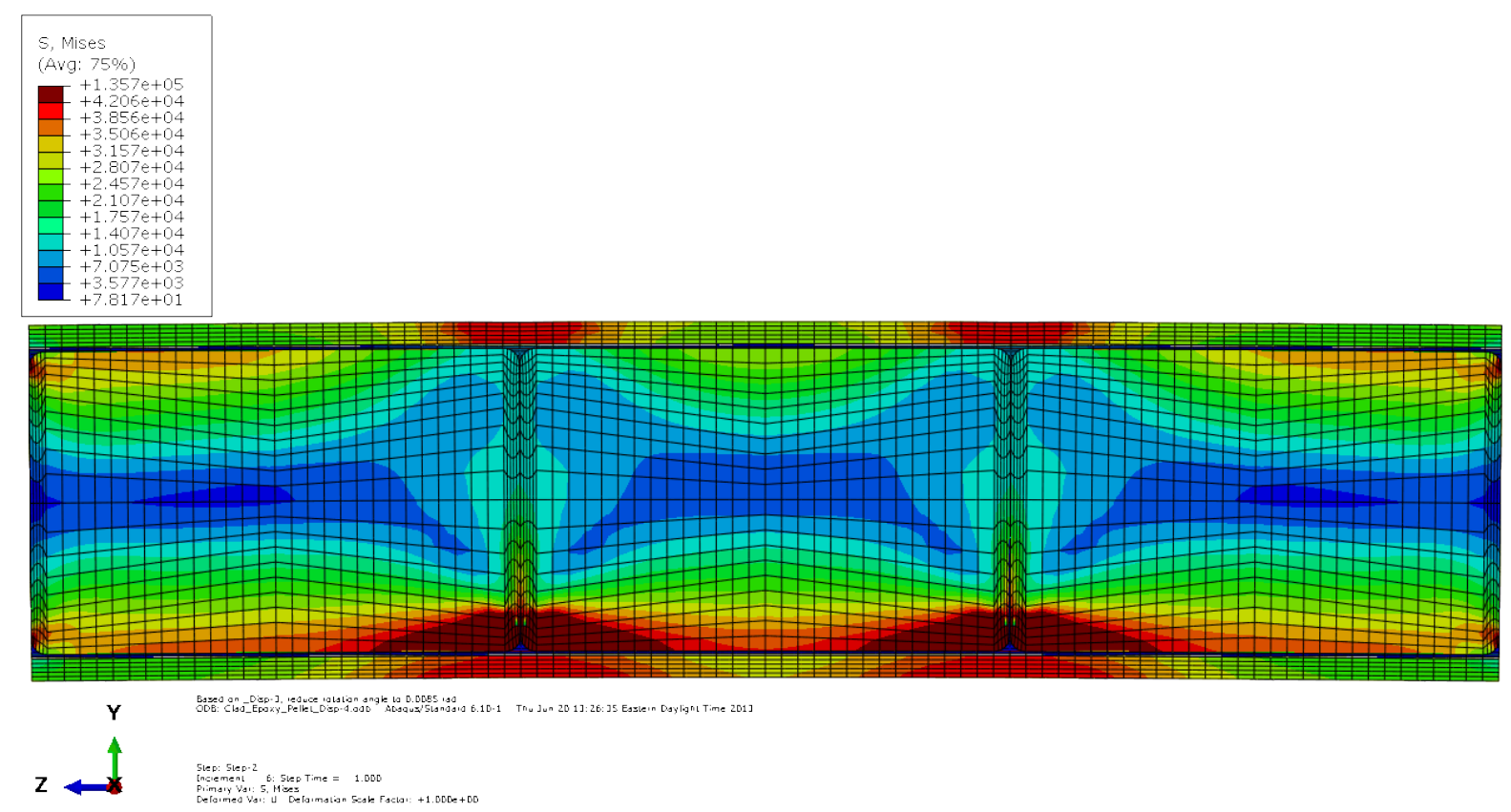

(a) Longitudinal cut view of resultant curvature and von Mises stress 

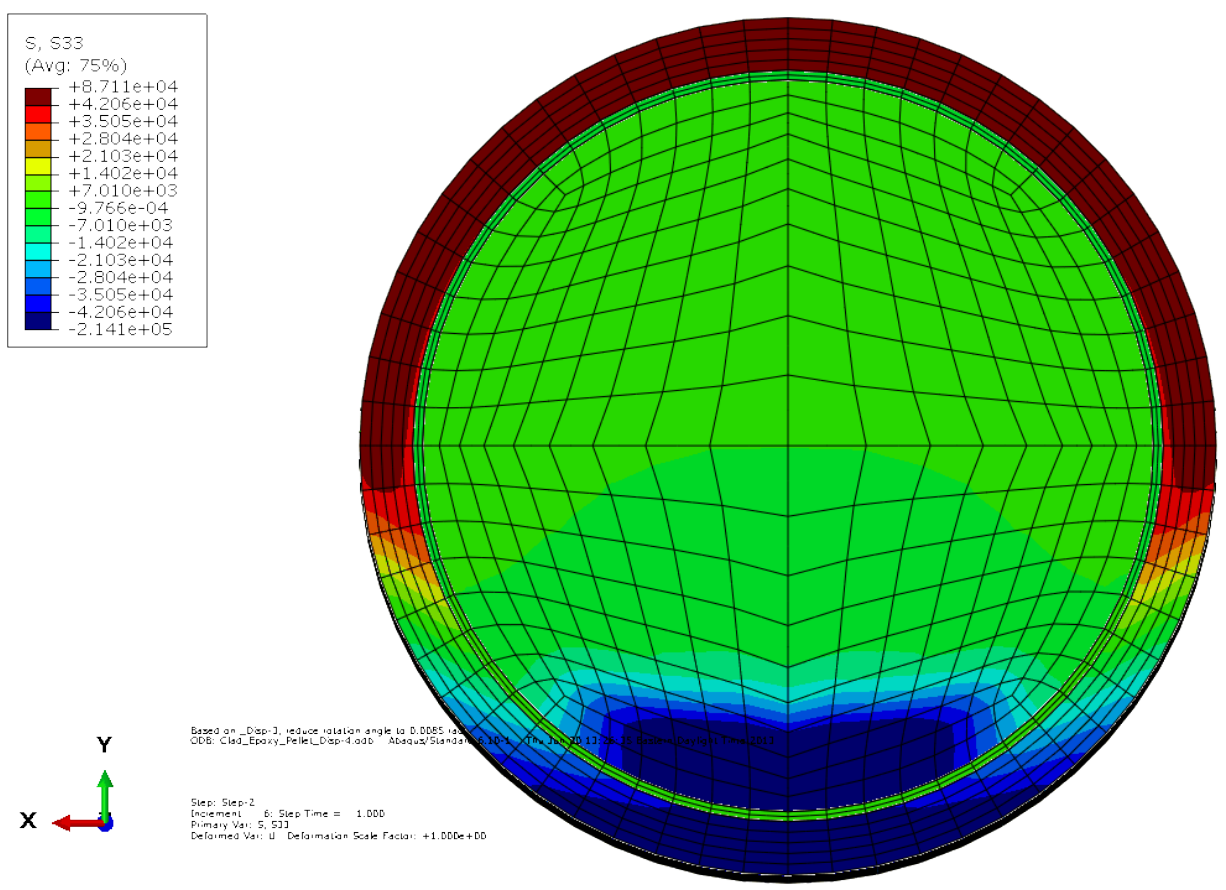

(b) Cross-sectional view of resultant $\sigma \mathrm{zz}$ at a pellet-pellet interface

Fig. 33. Resultant stress distribution and curvature of Clad-Pellet section model with three pellets and epoxy bonding at pellet-clad interfaces with no gaps at pellet-pellet interfaces under displacement control.
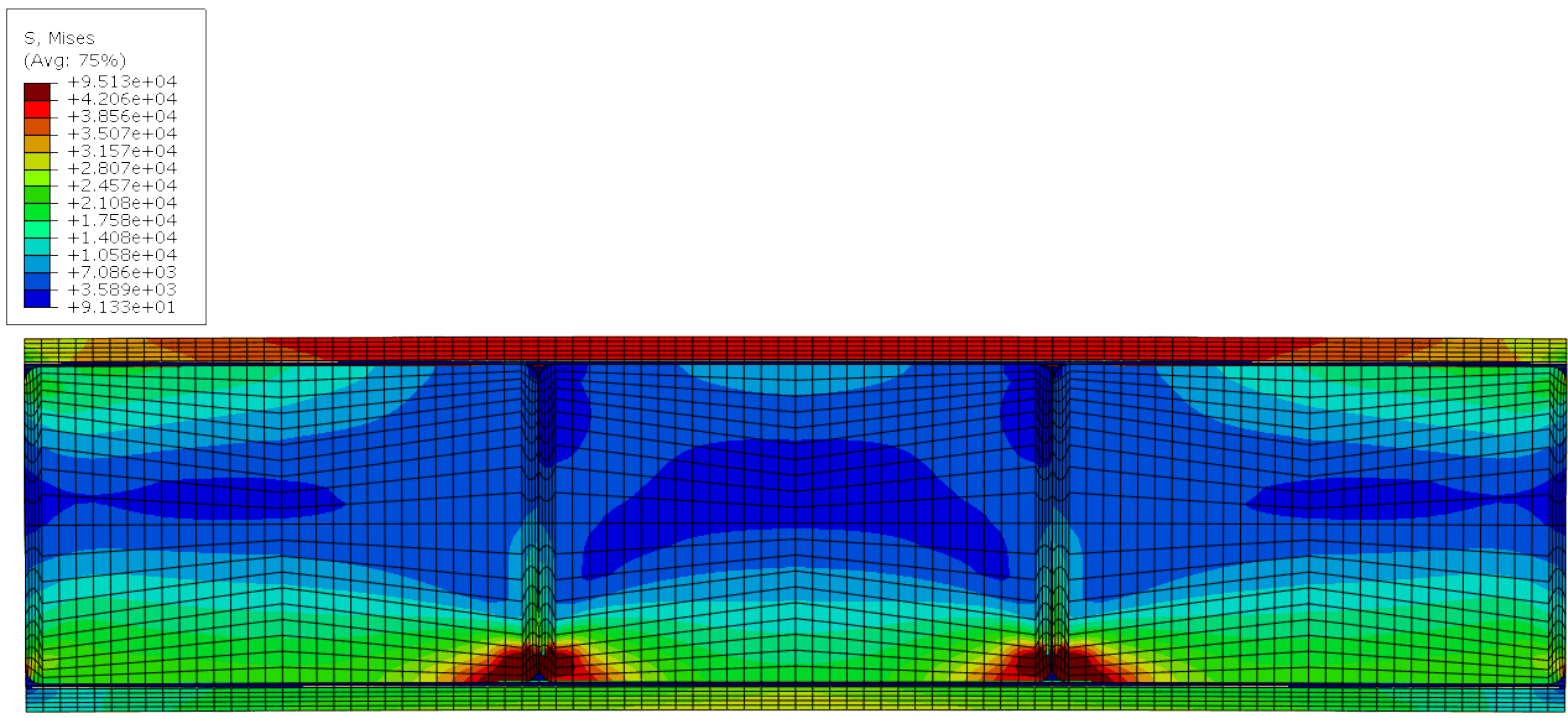

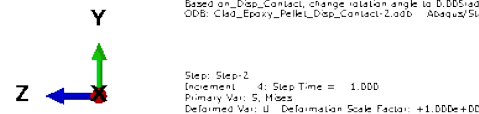

(a) Longitudinal cut view of resultant curvature and von Mises stress 


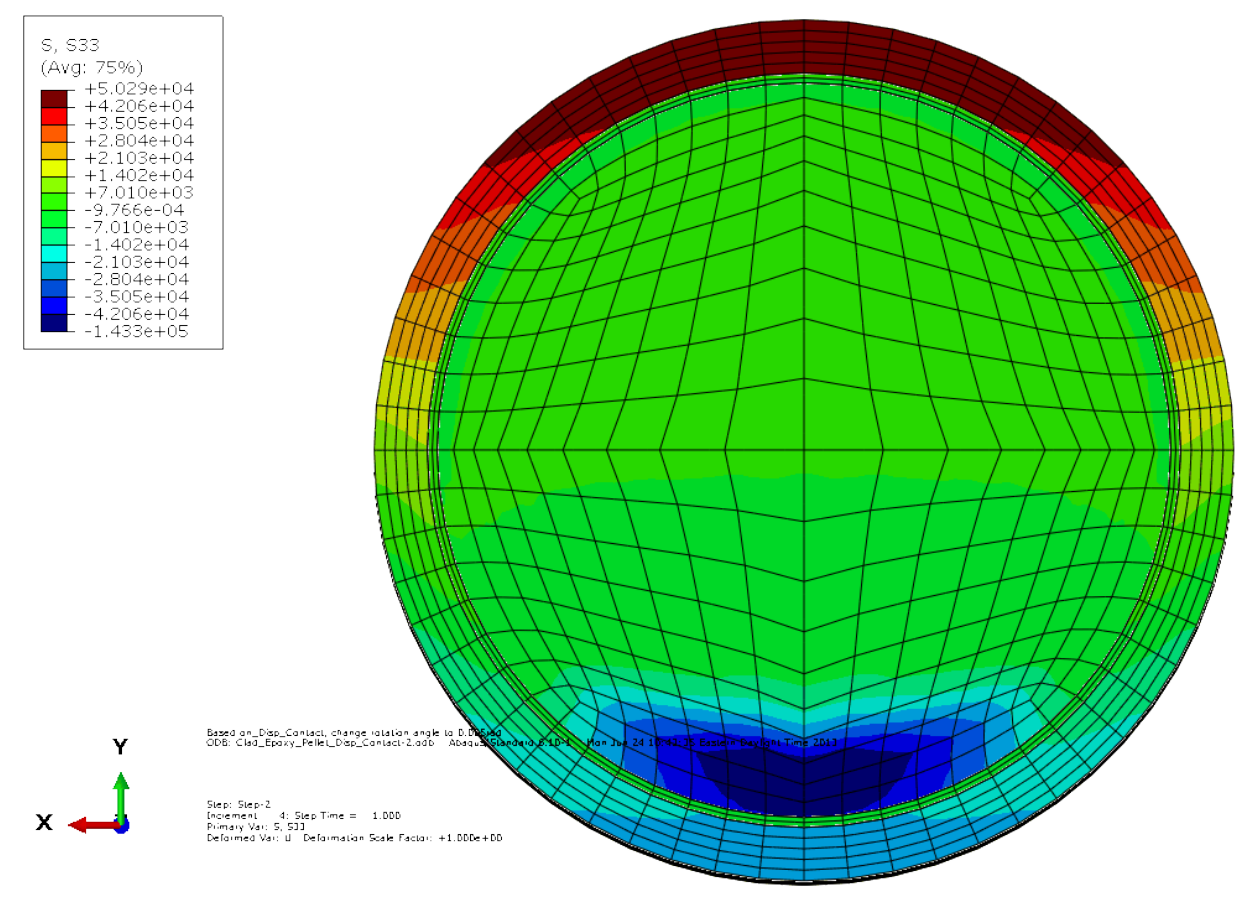

(b) Cross-sectional view of resultant $\sigma \mathrm{zz}$ at a pellet-pellet interface

Fig. 34. Resultant stress distribution and curvature of Clad-Pellet section model with three pellets, with filled epoxy at de-bonded pellet-clad interfaces and no gaps at de-bonded pellet-pellet interfaces under displacement control.

The curvature, the resultant bending moment, and the estimated flexural rigidity are listed in Table 7. In displacement-control mode, the induced curvatures are the same for both cases, and the resultant bending moments can used as a direct indication of the bending load resistance capacity of the surrogate rod system for the specific case. Table 7 shows the bending resistance capacity of the surrogate rod was reduced by $17 \%$ upon the de-bonding at the pellet-clad interfaces; this also results in a $17 \%$ reduction in the flexural rigidity. The trends of FEA results from displacement control and load control are very similar; thus, FEA results from both procedures are comparable.

Table 7. The curvature and flexural rigidity for Clad-Epoxy-Pellet section model with three pellets under displacement control simulation cases

\begin{tabular}{|c|c|c|c|}
\hline & $\begin{array}{c}\text { Curvature, } \kappa \\
(1 / \mathrm{m})\end{array}$ & $\begin{array}{c}\text { Bending moment, } M \\
\left(\mathrm{~N}^{*} \mathrm{~m}\right)\end{array}$ & $\begin{array}{c}\text { Flexural rigidity } E I \\
\left(\mathrm{~N}^{*} \mathbf{m}^{2}\right)\end{array}$ \\
\hline $\begin{array}{l}\text { Clad-Epoxy-Pellet3-Tie-Pellet- } \\
\text { Contact-noGap-Dispacement- } \\
\text { Control }\end{array}$ & 0.219 & 26 & 120 \\
\hline $\begin{array}{l}\text { Clad- Epoxy-Pellet3-Contact- } \\
\text { Pellet-Contact-noGap- } \\
\text { Displacement-Control }\end{array}$ & 0.219 & 23 & 103 \\
\hline
\end{tabular}




\section{FUTURE WORK}

These research activities are designed to provide effective benchmark/calibration data to support DOE UFD campaign modeling efforts, and eventually migrate into developing prediction protocols for SNF system effective lifetime evaluations under normal transportation considerations.

Currently we are developing computational models using surrogate rods tested in the out-of-cell environment. The next phase of the FEA simulation effort will be focused on the in-cell SNF test results, with more refined boundary conditions to provide a more realistic evaluation and system calibration. Therefore, performing controlled experiments with suitable boundary conditions is recommended to support the generation of more accurate calibration data to effectively describe the interfacial material properties at material interfaces as input to more realistic FEA material modeling.

Proposed future work also includes an investigation of the pellet-clad pinning fatigue mechanisms at the pellet-pellet-clad interface regions, and a parameter study on the effect of pellet-clad interaction, as well as the impact of the pellet and/or clad fracture on the fatigue strength of the composite SNF system.

Fracture toughness, $\mathrm{K}_{\mathrm{IC}}$, and dynamic (high-rate) fracture toughness data for fuel, clad, and SNF rod systems should be evaluated. Oxide fracture toughness can degrade significantly under high-rate loading. If during transportation the fuel pellet fracture threshold has been reached under normal handling drops or transient shock loading, the majority of the bending moment resistance capacity will be shifted to the clad tubing structure. This will result in an accelerated aging of the fuel clad under continuous vibration loading. Thus, in order to have a more realistic and accurate SNF vibration reliability evaluation, an investigation of the impact of high rate loading, such as transient shocks or handling loading drops, on the accumulated damage to the SNF system under normal transportation conditions will be essential. 


\section{SUMMARY}

Based on the FEA simulation results and further verification from ORNL surrogate rod bending test results, the impacts of interfacial bonding efficiency at pellet-pellet and pellet-clad interfaces on surrogate rod system performance can be summarized as follows.

First, with good interface bonding and without fuel pellet and clad fracture, the pellets in the surrogate rod will carry more bending moment resistance than the clad under normal transportation vibration. The maximum stress resides at the pellets and the stresses at the clad and pellet are both below the yield condition; therefore, the system is in a linear elastic state under the target bending loads.

Upon fuel pellet failure including de-bonding at the pellet-pellet interfaces, the load carrying capacity shifts from fuel pellets to the clad, and the clad starts to carry the majority of the bending moment at the pellet-pellet interface region, which results in localized plastic deformation of the clad. With good cohesion bonding at the pellet-clad interfaces, the pellets can still provide support to the clad and carry a sufficient portion of the bending moment resistance, so that a major portion of the clad at the gauge section remains in the linear elastic range.

Upon further de-bonding at the pellet-clad interfaces, the embedded pellets can no longer provide effective structural support to the clad as well as assist the load transfer within the surrogate rod system. Thus, the majority of the load carrying capacity shifts to the clad throughout the entire gauge section. That leads to the clad yielding in the entire gauge section instead of at localized pellet-pellet interface regions. When the pellets contact and pinch each other, the pellets seem to take over a significant portion of the bending load resistance, especially for cases where there are no gaps at the pellet-pellet interfaces. This pellet pinning action certainly mitigates and avoids the clad yielding, and the maximum stress resides at the pellet region and below the yield.

The immediate consequence of interface de-bonding is the load carrying capacity shift from fuel to clad, as well as the reduction of flexural rigidity, as shown in Table 8. Compared to the flexural rigidity of $153 \mathrm{~N}^{*} \mathrm{~m}^{2}$ for a perfect bond, the flexural rigidity for the de-bonding at pellet-pellet interfaces alone is reduced by $76 \%$ to $37 \mathrm{~N}^{*} \mathrm{~m}^{2}$ in the case with gaps at the pellet-pellet interfaces and by $32 \%$ to $104 \mathrm{~N}^{*} \mathrm{~m}^{2}$ for the case with no gaps. Upon further de-bonding at the pellet-clad interfaces, the flexural rigidity further reduces by $8 \%$ and $19 \%$ for the cases with gaps and without gaps, respectively. The overall reductions from the perfect bonded case to the de-bonded case at all interfaces are about $78 \%$ and $45 \%$, respectively, for the cases with gaps and without gaps.

There are more reductions in the flexural rigidities due to de-bonding at pellet-pellet interfaces than due to de-bonding at pellet-clad interfaces. Table 8 shows about a $60 \%$ increase in the flexural rigidity from the case with gaps to the case without gaps, which indicates a significant increase in system stiffness for the surrogate rod without gaps. Therefore, gaps at the interfaces of the surrogate rod system can have a significant impact on system reliability, especially at pellet-pellet interfaces.

The flexural rigidity and bending moment resistance capacity of the surrogate rod system (which is designed to resemble the SNF system) are strongly dependent on interface bonding efficiency at pelletclad and pellet-pellet interfaces. This discovery was also validated by ORNL reversal bending fatigue test results performed on the surrogate SS rod with alumina pellets inserts. 
Table 8. The flexural rigidity comparison between the different bonding and de-bonding cases

\begin{tabular}{|c|c|c|c|c|}
\hline & $\begin{array}{c}\text { Flexural rigidity, } \\
E I\left(\mathrm{~N}^{*} \mathrm{~m}^{2}\right)\end{array}$ & $\begin{array}{l}\text { Reduction from } \\
\text { perfect bond (\%) }\end{array}$ & $\begin{array}{c}\text { Reduction from } \\
\text { only pellet-pellet } \\
\text { de-bond to further } \\
\text { pellet-clad de-bond } \\
(\%)\end{array}$ & $\begin{array}{l}\text { Increase from with } \\
\text { gaps to without } \\
\text { gaps (\%) }\end{array}$ \\
\hline Perfect bond & 153 & & & \\
\hline $\begin{array}{l}\text { De-bond Pellet-Pellet } \\
\text { Interfaces with Gaps }\end{array}$ & 37 & 76 & & \\
\hline $\begin{array}{l}\text { De-bond Pellet-Pellet and } \\
\text { Pellet-Clad Interfaces with } \\
\text { Gaps }\end{array}$ & 34 & 78 & 8 & \\
\hline $\begin{array}{l}\text { De-bond Pellet-Pellet } \\
\text { interfaces without Gaps }\end{array}$ & 104 & 32 & & 64 \\
\hline $\begin{array}{l}\text { De-bond Pellet-Pellet and } \\
\text { Pellet-Clad Interfaces } \\
\text { without Gaps }\end{array}$ & 84 & 45 & 19 & 60 \\
\hline
\end{tabular}

The FEA results of the surrogate rod system with gaps at interfaces reveal very similar results for the case of full system de-bonding and for the case of de-bonded pellet-pellet interfaces only. The variation in pellet position at the gauge section has little impact on the surrogate rod system response under bending loading. The FEA results using displacement-control procedure is consistent with that using a load control approach. 


\section{REFERENCES}

1 US Department of Energy, Used Fuel Disposition Campaign, Used Nuclear Fuel Loading and Structural Performance under Normal Conditions of Transport - Modeling, Simulation and Experimental Integration RD\&D Plan, FCRD-UFD-2013-000135, April 1, 2013.

2 J.-A.J. Wang, H. Wang, Y. Yan, R. Howard, B. Bevard, High Burn-up Spent Fuel Vibration Integrity Study Progress Letter Report (Out-of-Cell Fatigue Testing Development - Task 2.1), ORNL/TM2010/288, Oak Ridge National Laboratory, Oak Ridge, TN, 2011.

3 J.-A.J. Wang, H. Wang, T. Tan, H. Jiang, T. Cox, Y. Yan, Progress Letter Report on U-frame Test Setup and Bending Fatigue Test for Vibration Integrity Study (Out-of-Cell Fatigue Testing Development - Task 2.2), ORNL/TM-2011/531, Oak Ridge National Laboratory, Oak Ridge, TN, 2012

4 H. Wang, J.-A.J. Wang, T. Tan, H. Jiang, T. Cox, R. Howard, B. Bevard, M. Flanagan, "Development of U-Frame Bending System for Studying the Vibration Integrity of Spent Nuclear Fuel,” Journal of Nuclear Material, 440, 201-213, 2013. 
